VIVIANE VERDU RICO

Variáveis relevantes para a emergência de simetria em pombos em procedimento de matching-to-sample sucessivo

São Paulo

2010 


\section{Variáveis relevantes para a emergência de simetria em pombos em procedimento de matching-to-sample sucessivo}

Tese apresentada ao Instituto de Psicologia da Universidade de São Paulo, como parte dos requisitos para a obtenção do título de Doutor em Psicologia.

Área de Concentração: Psicologia Experimental

Orientador: Prof. Dr. Gerson Yukio Tomanari

São Paulo 
AUTORIZO A REPRODUÇÃO E DIVULGAÇÃO TOTAL OU PARCIAL DESTE TRABALHO, POR QUALQUER MEIO CONVENCIONAL OU ELETRÔNICO, PARA FINS DE ESTUDO E PESQUISA, DESDE QUE CITADA A FONTE.

Catalogação na publicação Biblioteca Dante Moreira Leite Instituto de Psicologia da Universidade de São Paulo

Rico, Viviane Verdu.

Variáveis relevantes para a emergência de simetria em pombos em procedimento de matching-to-sample sucessivo / Viviane Verdu Rico; orientador Gerson Yukio Tomanari. -- São Paulo, 2010.

$86 \mathrm{f}$.

Tese (Doutorado - Programa de Pós-Graduação em Psicologia. Área de Concentração: Psicologia Experimental) - Instituto de Psicologia da Universidade de São Paulo.

1. Equivalência de estímulo 2. Simetria 3. Matching-to-sample 4. Pombos I. Título.

BF319 
Nome: Rico, Viviane Verdu

Título: Variáveis relevantes para a emergência de simetria em pombos

Tese apresentada ao Instituto de Psicologia da Universidade de São Paulo, como parte dos requisitos para obtenção do título de Doutor em Psicologia.

Aprovado em:

Banca Examinadora

Prof. Dr.

Instituição:

Assinatura:

Prof. Dr.

Instituição:

Assinatura:

Prof. Dr.

Instituição:

Assinatura:

Prof. Dr.

Instituição:

Assinatura:

Prof. Dr.

Instituição:

Assinatura: 
Para a pequena Mariana, meu pedaço de paraíso. 


\section{AGRADECIMENTOS}

Ao Prof. Gerson Tomanari, pela orientação competente e sempre presente. Obrigada pela confiança em mim depositada e por todo o apoio profissional e pessoal.

Ao Prof. Romariz Barros, pelas discussões que originaram este trabalho e por todas as contribuições dadas posteriormente. Obrigada pelo carinho e apoio.

Às Professoras Deisy de Souza e Paula Debert e ao Prof. Armando Machado, pelas contribuições valiosas a este trabalho.

Ao colega Marcio Bandeira, pela ajuda na construção do protótipo do equipamento usado nessa pesquisa.

Ao Noel, que trabalhou arduamente para consertar e melhorar todo o equipamento. Sou muito grata pela sua competência, disponibilidade, paciência e bom humor.

À Heloísa, pela ajuda na construção do equipamento, cuidado com os pombos e coleta de dados, e pela disposição em coletar às sete horas da manhã para facilitar a minha vida de mãepesquisadora.

Ao Vinícius Stefa, o Vini, responsável pela programação dos experimentos. Obrigada pela ajuda, paciência e risadas.

Ao Marcelo, meu braço direito (e às vezes o esquerdo) na melhoria do equipamento e do biotério, no cuidado com os pombos e na coleta de dados. Obrigada por toda ajuda, pelos debates instigantes e pela amizade tão essencial!

À minha querida Édila, pelos cuidados com os animais, por ajudar sempre que necessário e por sua alegria contagiante. 
Às minhas queridas amigas Eliana, Ilara, Lúcia e Miriam, por todos os momentos alegres e, especialmente, por todo o apoio e incentivo. Eu tenho muita sorte de ter vocês comigo! É por isso que, Eliana, eu te desculpo!

Aos demais colegas do Laboratório F. S. Keller de Estudos do Comportamento Operante, pela convivência agradável, pelos debates, pelas risadas e por todas as dicas valiosas: Arturo, Candido, Cássia, Daniela, Edson, Lígia, Luiza, Nathalí, Peter, Priscila, Rafael, Saulo e William.

Aos colegas da pós-graduação, pelas conversas, pelas risadas, pelo apoio, e pelas amizades construídas ao longo desses anos: Ana, Angélica Capelari, Angélica Yochiy, Ariene, Desirée, Emileane, Fernanda, Ingrid, Márcia, Marcos, Mariana, Tauane, Thrissy, Raimundo e Raquel.

Aos meus pais, Antonio Carlos e Cleia, pelo apoio essencial à minha formação, embora continuem sem entender porque a filha psicóloga não faz pesquisa com seres humanos.

À família Margionti, que tanto me ajudou nos momentos de dificuldade nos últimos anos sem nunca pedir nada em troca: Tiro, Roberto, Célia, Dani, Mayra, Marcelo e Maurício.

À minha amada filha Mariana, por todo o carinho, por compreender os momentos em que eu precisava trabalhar e por me lembrar que uma grande parte dos problemas da vida se dissipa com um abraço. Você é muito especial, meu anjo!

Aos meus sujeitos experimentais, que tanto trabalharam para que essa Tese pudesse ser feita.

À Sonia, por estar sempre pronta a ajudar os pós-graduandos do Instituto de Psicologia.

Ao Conselho Nacional de Desenvolvimento Científico e Tecnológico (CNPq), pelo fundamental auxilio financeiro. 


\section{RESUMO}

RICO, V. V. (2010). Variáveis relevantes para a emergência de simetria em pombos em procedimento de matching-to-sample sucessivo. Tese de Doutorado, Instituto de Psicologia, Universidade de São Paulo, São Paulo. 86p.

Treinos discriminativos específicos podem favorecer que um organismo responda consistentemente sob controle de relações entre estímulos que não foram diretamente ensinadas. Diz-se, então, que estas são relações emergentes. Caso tais relações estejam de acordo com as propriedades de reflexividade, simetria e transitividade, é constatada a formação de classes de estímulos equivalentes. Nas últimas décadas, diversos estudos vêm tentando demonstrar a formação de classes de estímulos equivalentes em animais não humanos, mas poucos têm tido sucesso. Dentre as propriedades definidoras da equivalência, a simetria tem sido a mais difícil de ser observada. Ao identificarem variáveis relacionadas aos resultados inconsistentes de estudos envolvendo testes de simetria, Frank e Wasserman (2005) planejaram um experimento com pombos, no qual tentativas de relações de identidade e arbitrárias eram apresentadas em uma mesma sessão, que resultou em desempenho positivo nos testes. O objetivo do presente trabalho foi identificar algumas das variáveis que possivelmente contribuíram para os resultados obtidos no referido estudo. Para tanto, foram realizados dois experimentos, com três pombos cada, para verificar: 1) a replicabilidade dos dados obtidos por Frank e Wasserman (2005); 2) se o treino de reversibilidade de combinações negativas é um fator importante na obtenção de simetria emergente com este procedimento. Os sujeitos foram ensinados a bicar estímulos apresentados isoladamente na tela de um computador em uma tarefa de matching sucessivo. O Experimento I consistiu no treino misto das relações $\mathrm{AA}, \mathrm{BB}$ e $\mathrm{AB}$ e no teste de simetria $\mathrm{BA}$. O Experimento II era semelhante ao anterior, exceto que, para que não ocorresse o treino de reversibilidade das combinações negativas, foram acrescentadas as relações $\mathrm{CC}$ no treino. Apenas dois pombos, um de cada experimento, apresentaram responder discriminado no treino. Ambos apresentaram desempenho semelhante ao do estudo de Frank e Wasserman (2005), o que indicaria emergência de simetria. Entretanto, uma análise mais detalhada do desempenho destes dois pombos revelou um responder instável entre as sessões de teste. Os outros quatro sujeitos não apresentaram responder discriminado apesar do elevado número de sessões (entre 65 e 220). A análise da distribuição das respostas ao longo do tempo de apresentação dos estímulos indicou diferenças entre o responder dos pombos que concluíram e que não concluíram o treino. Estes últimos apresentaram um responder marcado por longas pausas entre respostas, com menor freqüência de respostas para o estímulo modelo. Os pombos que concluíram a fase de treino apresentaram um responder constante, com poucas e curtas pausas, com maior freqüência de respostas diante do modelo do que diante dos estímulos de comparação. Os resultados dos testes de simetria indicam que o treino de reversão das combinações negativas não foi um fator relacionado à emergência de simetria com este procedimento. $\mathrm{O}$ fato de que a maioria dos sujeitos não aprendeu as relações treinadas, bem como os diferentes padrões de responder apresentados pelos sujeitos ao longo do treino e o desempenho instável nas sessões de teste, indicam a necessidade de refinamento do procedimento, buscando favorecer a aprendizagem e produzir estabilidade nos testes.

Palavras-chave: Equivalência de estímulo. Simetria. Matching-to-sample. Pombos. 


\begin{abstract}
RICO, V. V. (2010). Relevant variables for emergence of symmetry in pigeons in successive matching-to-sample procedure. Doctoral Thesis, Instituto de Psicologia, Universidade de São Paulo, São Paulo. 86p.

Specific conditions in the discriminative training should set conditions for an organism to respond controlled by stimuli relations, not directly trained. These stimuli relations are said to be emergent. If these relations are reflexive, symmetric and transitive, than classes of equivalent stimuli were established. In the last decades, several studies tried to demonstrate the formation of equivalence classes in non-humans animals, but a few succeed. From among those properties that define equivalence relations, symmetry is the most hardly observed. Once identified some variables involved with the discrepant results in the symmetry tests, Frank and Wasserman (2005) designed an experiment with pigeons, where identity and arbitrary trials were presented altogether in the training sessions. This procedure resulted in positive outcomes in symmetry tests. The purpose in this study was to assess some of the variables that possibly contributed to Frank and Wasserman's (2005) positive results. Two experiments were conducted in order to verify 1) Frank and Wasserman' (2005) data replicability; 2) if training the negative combinations reversals is relevant in producing emergent symmetry by this procedure. Tree pigeons participated in each one of them. The pigeons were trained to peak stimuli presented alone in a computer screen in a successive matching task. Experiment I consisted in mixed training of $\mathrm{AA}, \mathrm{BB}$ and $\mathrm{AB}$ relations followed by symmetry tests for BA relation. Experiment II was identical to the previous one, except that $\mathrm{CC}$ relations were added in order to avoid the negative relations reversal training. Only two pigeons, one of each experiment, reach training criterion. Their performances in symmetry tests were quite similar to those presented by Frank and Wasserman (2005) indicating that training resulted in symmetry relations. Meanwhile, a careful analysis of these symmetric performances in the testes revealed to be unstable from session to session. The four remaining pigeons did not reached training criterion despite of been exposed to high number of training sessions (about 65 to 220 sessions). Differences in distribution of responses over stimuli presentation interval were observed comparing data of the two pigeons that reached training criterion and pigeons that did not reach training criterion. Low frequency of response and long inter-response interval to the sample stimulus characterized the performances of the four pigeons whose training criterion has never been reached. For the pigeons whose training criterion was reached the responses occurred constantly, with few and short inter-responses intervals and high frequency of responding to the sample stimulus when compared to the comparison stimulus. The symmetry tests results suggests that training the negative combinations reversals did not affected the emergence of symmetric relations in this procedure. The fact that most of the pigeons did not reached training criterion, along with the different response patterns shown by each pigeon in the training task and the unstable performance observed in the tests indicates that procedure refining is needed in order to improve learning to criterion and produce stability during tests.
\end{abstract}

Keywords: Stimulus equivalence. Symmetry. Matching-to-sample. Pigeons. 


\begin{tabular}{|c|c|}
\hline NTRODUÇÃO ........ & 10 \\
\hline EXPERIMENTO I . & 32 \\
\hline Método & 2 \\
\hline Sujeitos .......... & 30 \\
\hline Ambiente Experimental e Equipamentos ......................... & 32 \\
\hline Estímulos ........... & 34 \\
\hline Procedimento ....... & 35 \\
\hline Resultados e Discussão ... & 40 \\
\hline EXPERIMENTO II & 61 \\
\hline Método & 61 \\
\hline Sujeitos ............ & 61 \\
\hline Ambiente Experimental e Equipamentos ........................ & 61 \\
\hline Estímulos ......... & 61 \\
\hline Procedimento ....... & 62 \\
\hline Resultados e Discussão .. & 65 \\
\hline DISCUSSÃO GERAL .... & 78 \\
\hline REFERÊNCIAS . & \\
\hline
\end{tabular}


Os símbolos fazem parte do mundo com o qual o ser humano desde cedo aprende a se relacionar. Uma criança de desenvolvimento típico rapidamente aprende a nomear objetos e ações. Estes "nomes" são símbolos, convencionados arbitrariamente, dos eventos concretos representados por eles. É possível que aprender a relacionar estímulos arbitrários de modo que eles compartilhem um mesmo significado seja a base para o desenvolvimento da linguagem. Porém, esta é uma aprendizagem complexa, que ocorre de tal forma em ambiente natural que se torna difícil identificar todas as variáveis nela envolvidas. Tal conhecimento, entretanto, é essencial para que se desenvolvam procedimentos que sejam efetivos no ensino de pessoas com atraso no desenvolvimento cognitivo ou com dificuldades de aprendizagem.

Dentre as maneiras de abordar este tema encontra-se o modelo de equivalência de estímulos proposto por Sidman e colaboradores (e.g. Sidman, 1994 e 2000; Sidman \& Tailby, 1982), considerado adequado para elucidação das variáveis envolvidas nas relações de significado (relações entre estímulos estabelecidas de forma arbitrária).

Nos estudos na área de equivalência de estímulos, geralmente, são treinadas discriminações condicionais por meio do procedimento de matching-to-sample - MTS (Cumming \& Berryman, 1965). Neste procedimento, um estímulo (denominado estímulo modelo) controla a função discriminativa positiva (S+) ou negativa (S-) de outros estímulos (chamados estímulos de comparação). Geralmente, o estímulo modelo é apresentado para o sujeito, que deve emitir uma resposta específica (chamada resposta de observação) que produz os estímulos de comparação. Respostas ao estímulo de comparação determinado pelo experimentador como S+ para aquele modelo são seguidas de reforço e de um intervalo (intervalo entre tentativas - IET). Respostas ao estímulo de comparação determinado pelo experimentador como S- para aquele modelo são seguidas apenas pelo IET.

A escolha do estímulo de comparação pode ter como base diferentes tipos de relações: igualdade, singularidade ou arbitrária. Se a escolha se basear na relação de igualdade, o procedimento é chamado de MTS de identidade e o S+ será sempre o estímulo de comparação idêntico ao estímulo modelo (Cumming \& Berryman 1965; Iversen 1993, 1997). Se a escolha do estímulo de comparação se basear na relação de singularidade, o procedimento é chamado de MTS de singularidade (oddity-from-sample - OFS) e o S+ será o estímulo de comparação diferente do modelo, enquanto o S- será o estímulo idêntico ao modelo (Berryman, Cumming, Cohen, \& Johnson, 1965). Se a escolha do estímulo de comparação se basear em relações arbitrárias entre estímulos, o procedimento é denominado de MTS arbitrário (ou simbólico) e o $\mathrm{S}+$ será um estímulo determinado pelo experimentador como sendo o correto, a despeito de 
compartilhar ou não alguma propriedade física com o estímulo modelo (Carter \& Eckerman, 1975).

O procedimento de MTS pode variar quanto à forma de apresentação dos estímulos. Quando os estímulos modelo e de comparação são apresentados simultaneamente, o procedimento é denominado MTS simultâneo. Quando modelo e comparações apresentados alternadamente, de modo que, após uma resposta de observação, o modelo desaparece e os estímulos de comparação são apresentados, o procedimento é denominado de MTS sucessivo. No MTS sucessivo é possível manipular o intervalo entre a retirada do estímulo modelo e a apresentação dos estímulos de comparação. Quando os estímulos de comparação são apresentados imediatamente após a retirada do modelo, o procedimento é denominado MTS sucessivo sem atraso ou com atraso zero. Quando há um intervalo entre a retirada do modelo e a apresentação dos estímulos de comparação, o procedimento é chamado de MTS sucessivo com atraso (Cumming \& Berryman, 1965).

Os estudos na área de equivalência de estímulos, geralmente, utilizam o procedimento de MTS simultâneo ou sucessivo com atraso zero ${ }^{1}$. O paradigma de equivalência de estímulos teve origem na observação de que relações arbitrárias entre estímulos emergiam sem treino direto, a partir do ensino de discriminações condicionais relacionadas ${ }^{2}$, de modo que os estímulos se tornavam substituíveis uns pelos outros em contextos específicos (Sidman, 1971, 1994; 2000; Sidman \& Cresson, 1973; Sidman \& Tailby, 1982). Quando isto ocorre, diz-se que houve a formação de classes de estímulos equivalentes.

A formação de classes de equivalência é atestada pela demonstração de suas três propriedades definidoras (Sidman \& Tailby, 1982): reflexividade (relação do estímulo com ele mesmo); simetria (reversibilidade de função dos estímulos modelo e comparação); transitividade (relação entre estímulos indiretamente relacionados); e equivalência (reversão de função dos estímulos da relação transitiva, ou seja, simetria da transitividade). Desta forma, após um treino das relações arbitrárias $\mathrm{AB}$ e $\mathrm{BC}$, por exemplo, são feitos testes da emergência das seguintes relações: AA, BB e CC (reflexividade); BA e CB (simetria); $\mathrm{AC}$ (transitividade); e CA (equivalência).

A equivalência de estímulos vem sendo amplamente demonstrada com humanos de diversas idades, com desenvolvimento cognitivo típico e atípico. Entretanto, relações de

\footnotetext{
${ }^{1}$ Por estes procedimentos serem majoritariamente utilizados nas pesquisas sobre equivalência de estímulos, ocasionalmente este texto se referirá a eles pelo termo "MTS padrão".

${ }^{2}$ São denominadas discriminações condicionais relacionadas aquelas que apresentam estímulos em comum. Por exemplo, as discriminações condicionais $\mathrm{AB}$ e $\mathrm{BC}$ são relacionadas, dada a presença dos estímulos $\mathrm{B}$ em ambas.
} 
equivalência não emergem tão facilmente em organismos não humanos ou em pessoas com pouco repertório lingüístico. Duas hipóteses explicativas desta dificuldade ganharam maior peso no debate sobre a emergência de relações de equivalência. Para alguns autores (e.g. Hayes, 1991; Horne \& Lowe, 1996) a linguagem seria condição necessária para a formação de classes de equivalência. Ao aprender a falar, uma pessoa aprende a nomear da mesma maneira diferentes estímulos (por exemplo, chamar de "bola" um desenho de uma bola e o objeto bola) e essa habilidade (dar um mesmo nome a estímulos diferentes) seria a responsável pelo desempenho positivo em testes de equivalência. Por essa lógica, sujeitos não humanos, ou humanos com pouco ou nenhum repertório verbal, não seriam capazes de formar classes de equivalência. Outros autores (cf. Sidman, 1994 e 2000), porém, consideram que a equivalência de estímulos seria um processo comportamental básico, gerado diretamente por contingências de reforçamento, não dependendo, portanto, da linguagem; ao contrario, seria ela própria parcialmente responsável pela aprendizagem lingüística. Neste caso, sujeitos não humanos ou humanos com pouco repertório lingüístico deveriam apresentar emergência de relações de equivalência com um procedimento adequado de treino.

Estudos realizados em laboratório podem contribuir muito para a elucidação do fenômeno da equivalência de estímulos. Tais estudos permitem a observação e mensuração de algumas variáveis necessárias ou suficientes envolvidas na aquisição das habilidades envolvidas na formação de classes, o que, em ambiente natural, é praticamente impossível dada a rapidez do processo de aquisição em pessoas normais e a multiplicidade de variáveis envolvidas (Galvão, Barros, Rocha, Mendonça, \& Goulart, 2002; McIlvane \& Cataldo, 1996).

Alguns estudos têm demonstrado resultados positivos em testes de equivalência com organismos não humanos (Kastak, Schusterman, \& Kastak, 2001; Schusterman \& Kastak, 1993) ou humanos com mínimo repertório verbal (e.g. Carr, Wilkinson, Blackman, \& McIlvane, 2000; Sidman \& Cresson, 1973), justificando a continuidade de pesquisas com estes sujeitos. Embora em minoria na vasta literatura de equivalência com não humanos, a existência de dados positivos com relação à formação de classes de equivalência com essas populações indica que possivelmente a não obtenção deste repertório em grande parte seja uma questão de insuficiência de procedimento, sendo precipitada a atribuição da sua ausência à falta de capacidade do sujeito ou espécie estudados (Dube, McIlvane, Callahan, \& Stoddard, 1993; Galvão et al., 2002). Pode ocorrer, por exemplo, que sujeitos não humanos, ou humanos com atraso severo no desenvolvimento, precisem aprender uma série de pré-requisitos para a formação de classes que os humanos com desenvolvimento normal adquiriram ao longo de sua história pré-experimental. 
Dentre as propriedades definidoras da equivalência de estímulos, a simetria tem sido a mais difícil de ser demonstrada com animais não humanos (Lionello-DeNolf, 2009). Alguns estudos apresentaram dados positivos em testes de simetria com estes sujeitos, mas estes dados geralmente eram inconsistentes (alguns sujeitos apresentavam simetria e outros não, ou, ainda, os dados obtidos nos testes eram instáveis) ou podiam ser explicados por outros processos comportamentais.

Schusterman e Kastak (1993) apresentaram uma das demonstrações mais convincentes de equivalência com animais não humanos. Utilizando um leão marinho fêmea como sujeito, foi realizado um extensivo treino de relações $\mathrm{AB}$, com trinta conjuntos de três estímulos cada, por meio do procedimento de MTS simultâneo com duas escolhas. Como estímulos foram usados objetos tridimensionais e figuras.

Inicialmente, foram treinadas duas relações $\mathrm{AB}$. Quando estas relações foram adquiridas, outras seis relações foram ensinadas com o uso de um procedimento de exclusão. Neste procedimento, uma tentativa é composta por um modelo e um estímulo de comparação novo como S+ e um estímulo já treinado como S-. Desta forma, o sujeito pode aprender a relação nova com um menor número de erros. Da nona à décima segunda relação foi feito um treino semelhante àquele utilizado para ensinar as duas primeiras relações (apenas com pares de estímulos novos). Cada relação aprendida era incorporada a uma linha de base.

Após o treino, foi feito um teste de simetria (BA) com doze das trinta relações, no qual eram apresentadas quatro tentativas de cada de relação de teste. Havia reforçamento diferencial programado para todas as tentativas de teste. O resultado de um teste era considerado positivo caso o sujeito escolhesse o $\mathrm{S}+$ na primeira das quatro tentativas e em pelo menos duas das três tentativas seguintes. Não foram observados resultados positivos nestes testes.

As relações BA testadas foram submetidas a um procedimento de treino. Em seguida foi feito um treino das doze relações BC com os mesmos conjuntos de estímulos e conduzidos os testes de simetria $\mathrm{CB}$, transitividade $\mathrm{AC}$ e simetria $\mathrm{CA}^{3}$. O leão marinho apresentou elevado número de acertos nestes testes. Foram então realizados os treinos das outras dezoito relações $\mathrm{AB}$ e $\mathrm{BC}$, seguidos dos testes $\mathrm{CA}$ (equivalência). $\mathrm{O}$ sujeito apresentou alto número de acertos também nesses testes.

Em um estudo posterior, Kastak, Schusterman e Kastak (2001) fizeram um estudo com dois leões marinhos (incluindo o que foi sujeito no estudo anterior). Neste estudo,

\footnotetext{
${ }^{3}$ Como o procedimento de teste envolvia reforçamento diferencial das tentativas, não se pode dizer que o teste CA foi um teste de equivalência, dado o reforçamento das tentativas no teste AC.
} 
primeiramente foram treinadas duas classes funcionais de estímulos por meio de procedimento de discriminação simples com reforçamento específico com múltiplas reversões (Vaughan, 1988). Em seguida os sujeitos foram submetidos a um procedimento de MTS simultâneo com os mesmos estímulos para verificar se eles responderiam de acordo com a classe funcional previamente estabelecida. Por fim, os sujeitos foram passaram por um treino, com procedimento de MTS, no qual novos estímulos eram relacionados a um dos estímulos de uma das classes funcionais. Em seguida foram feitos testes de equivalência entre os novos estímulos e os outros membros da classe funcional. Ambos os sujeitos apresentaram desempenho condizente com a formação de classes de estímulos equivalentes, demonstrando simetria e transitividade.

Os estudos de Schusterman e Kastak, (1993) e Kastak et al. (2001), obtiveram resultados positivos robustos nos testes de simetria, transitividade e equivalência. Entretanto, esses resultados só ocorreram após um extenso treino, incluindo o treino de simetria e transitividade. Para alguns autores (c.f. Hayes, 1989), resultados positivos nos testes de equivalência após esse tipo de treino não indicariam desempenho emergente. Isto porque, mesmo que os testes tenham sido feitos com estímulos novos, o sujeito teria aprendido com outros estímulos a responder diante de relações simétricas e transitivas. Desta forma, um desempenho positivo nos testes decorreria de um treino direto do comportamento de responder diante de relações inversas àquelas treinadas.

Outro estudo que demonstrou emergência de simetria foi realizado por Tomonaga, Matsuzawa, Fujita, \& Yamamoto (1991) com três chimpanzés como sujeitos. Buscando demonstrar simetria sem a necessidade de treino adicional, este estudo utilizou um procedimento de MTS arbitrário com atraso zero, no qual eram misturadas tentativas de identidade e de relações arbitrárias em cada sessão, utilizando cores e formas como estímulos. Para evitar um controle por posição dos estímulos, tanto o modelo como os estímulos de comparação eram apresentados em diferentes posições a cada tentativa. Como resultado, apenas um dos três sujeitos apresentou simetria emergente.

Posteriormente, Tomonaga (1993) realizou um estudo para investigar a possível razão para o desempenho emergente em apenas um dos sujeitos do estudo anterior. $\mathrm{O}$ autor pretendia averiguar se a emergência de simetria daquele chimpanzé teria se devido a um controle tanto por S+ quanto por S-. Submeteu, então, os mesmos três sujeitos a um treino de relações arbitrárias com semelhante ao usado no estudo de Tomonaga et al. (1991), seguido por testes de relações de controle. No teste de controle pelo $\mathrm{S}+$ as tentativas de MTS consistiam de um modelo e S+ conhecidos e um S- novo. No teste de controle pelo S- as 
tentativas apresentavam modelo e S- conhecidos e um S+ novo. O chimpanzé que apresentou simetria no estudo anterior apresentou altos índices de acertos nos dois testes, indicando controle misto (por S+ e por S-) do responder discriminado. Os outros sujeitos não apresentaram responder sob controle do S-.

Yamamoto e Asano (1995) também realizaram um estudo com um chimpanzé que demonstrou emergência de simetria. Utilizando o procedimento de MTS com muitos conjuntos de estímulos, os autores submeteram o sujeito a um treino de relações de identidade AA e BB seguido por um treino de relações arbitrárias AB. Após o treino, foi feita a redução da probabilidade de reforçamento das tentativas de linha de base. Então tentativas de teste de simetria, para as quais não havia conseqüência programada, foram introduzidas nessa linha de base. Era testada apenas uma relação por sessão. Caso o chimpanzé não apresentasse altos índices de acerto no teste a relação BA era treinada e uma nova sessão de teste era feita com outra relação. Este procedimento foi repetido com vários conjuntos de estímulos, até que o chimpanzé demonstrou simetria com um conjunto, apresentando $80 \%$ de acertos. Entretanto, este desempenho não se repetiu no teste de um novo conjunto de estímulos.

Santos (2003) realizou um experimento para verificar a emergência de simetria com macaco-prego. O sujeito, que já tinha apresentado identidade generalizada, passou por um treino de relações arbitrárias $\mathrm{AB}$ utilizando um procedimento de modelagem do estímulo modelo. Neste procedimento, o estímulo de comparação idêntico ao modelo vai sendo transformado gradualmente em um S+ diferente (Cruz et al., 2009). Adquiridas as relações arbitrárias, foi realizado um teste de simetria com linha de base cheia. Tanto tentativas de treino como de teste eram reforçadas com probabilidade reduzida $(0,75$ e 0,83 , respectivamente). O sujeito apresentou $100 \%$ de acertos na única sessão de teste realizada neste estudo.

O mesmo macaco do estudo de Santos (2003) passou, posteriormente, por um treino de novas relações arbitrárias (Santos, Barros, \& Galvão, 2003) e novo teste de simetria. Desta vez, o sujeito respondeu ao nível do acaso nas tentativas de teste. Os dados dois testes de simetria realizados por esse sujeito indicam uma simetria inconsistente.

Os procedimentos de treino utilizados por Tomonaga et al. (1991), Yamamoto e Asano (1995) e Santos (2003) têm em comum o treino de relações de identidade antes do treino arbitrário. É possível que este treino tenha favorecido o aprendizado dos sujeitos, já que garante uma experiência prévia com os estímulos funcionando tanto como modelo quanto como comparação. Os dados inconsistentes desses estudos, entretanto, sugerem a existência de outras variáveis relevantes para a obtenção de simetria. 
Velasco (2009) ensinou relações arbitrárias com procedimento de MTS com duas escolhas para quatro pombos posteriormente testados quanto à emergência de simetria. Foi realizado um teste com reforçamento diferencial de relações consistentes e inconsistentes com. Neste procedimento, a emergência de simetria é demonstrada por diferenças nas curvas de aquisição: caso os sujeitos adquiram as relações consistentes mais rapidamente que as inconsistentes, pode-se supor a emergência de simetria. Dois testes foram realizados. No primeiro teste, feito com metade das relações treinadas, não foi observada diferença entre as curvas de aquisição das relações consistentes e inconsistentes. No segundo teste, foi observada uma diferença significativa entre a porcentagem de respostas corretas nas relações consistentes e inconsistentes para dois pombos. Este resultado foi obtido a partir de um treino de poucas relações condicionais, o que tem sido raro nesta linha de investigação. É importante observar que, embora tenham sido testadas relações diferentes em cada teste, o resultado obtido no segundo teste pode ser atribuído ao treino da relação consistente no teste anterior (treino de simetria). Como os testes são realizados com reforçamento diferencial neste procedimento, todos os pombos tiveram tentativas simétricas reforçadas no primeiro teste. Dessa forma, a mesma crítica feita aos estudos de Schusterman e Kastak, (1993) e Kastak et al. (2001) podem ser aplicadas aos resultados obtidos por Velasco (2009).

Todos os estudos apresentados até o momento conseguiram obter simetria emergente utilizando o procedimento de MTS padrão. Entretanto, a maioria desses estudos não obteve resultados consistentes. Os estudos com resultados mais consistentes (Kastak et al., 2001; Schusterman \& Kastak, 1993) foram obtidos após um treino com múltiplos exemplares. Estudos que obtenham dados consistentes de simetria sem treino de múltiplos exemplares seriam essenciais no esclarecimento da questão sobre a possibilidade de animais não humanos formarem classes de equivalência.

Frank e Wasserman (2005) analisaram dois estudos com animais não humanos que utilizaram procedimentos semelhantes de treino, mas obtiveram resultados distintos nos testes. Um dos estudos analisados foi o de Tomonaga et al. (1991), que, após treino misto de relações de identidade e arbitrárias em procedimento de MTS sem atraso, obtiveram emergência de simetria para um dos três sujeitos (chimpanzés). O outro estudo foi o de Lionello-DeNolf e Urcuioli (2002), que também utilizaram o procedimento de MTS sem atraso, treinando identidade e relações arbitrárias em sessões separadas, mas que obtiveram resultados negativos nos testes de simetria com todos os pombos.

Frank e Wasserman (2005) concluíram que o treino misto de relações de identidade e arbitrárias foi o responsável pela emergência de simetria observada no estudo de Tomonaga et 
al. (1991). Isto porque este treino teria evitado um controle pela localização temporal dos estímulos, ou seja, teria possibilitado que o chimpanzé aprendesse a responder diante de um estímulo tanto como modelo quanto como comparação, ao mesmo tempo que aprendia a relacionar aquele mesmo estímulo a outro em um treino arbitrário. Assim, no teste de simetria, o sujeito não responderia sob controle da ordem de apresentação dos estímulos (o que antes era modelo virava comparação e vice-versa) e sim da relação arbitrária treinada. Frank e Wasserman (2005) identificaram também um problema em comum nos dois estudos analisados, que pode ter prejudicado o desempenho dos pombos (Lionello-DeNolf \& Urcuioli, 2002;) e dos outros dois chimpanzés (Tomonaga et al., 1991) nos testes: o controle pela localização espacial (controle pela posição) dos estímulos.

Com base nesta análise,Frank e Wasserman (2005) utilizaram um procedimento com pombos que pudesse controlar a localização espacial e temporal dos estímulos para, assim, produzir resultados positivos nos testes de simetria sem treino de múltiplos exemplares. Para lidar com a questão da localização espacial (posição dos estímulos na tela), foi utilizado um procedimento de matching-to-sample sucessivo com atraso, no qual aparecia apenas um estímulo de comparação por tentativa (podendo ser o S+ ou o S-), de modo que todos os estímulos (modelo ou comparação) apareciam em uma única posição. Para lidar com a questão da localização temporal (ordem de apresentação dos estímulos), as sessões de treino eram compostas por tentativas de MTS de identidade e arbitrário.

No procedimento utilizado por Frank e Wasserman (2005), o sujeito deveria bicar estímulos localizados na porção central da tela. Cada tentativa era iniciada pela apresentação de um estímulo de orientação (uma cruz preta no centro de um quadrado branco de 7 X $7 \mathrm{~cm}$ ). Quando o pombo bicava uma vez este estímulo, o mesmo era removido e imediatamente aparecia outro estímulo (S1) na tela (um desenho colorido no centro do quadrado branco), que só desaparecia após a primeira resposta do sujeito depois de transcorridos 10 segundos (FI10"). Após um intervalo de atraso de 3,5 segundos, durante o qual o quadrado branco permanecia na tela, outro estímulo (S2) era apresentado. Se este fosse um estímulo planejado para ser relacionado ao $\mathrm{S} 1$ (ou seja, se fosse o $\mathrm{S}+$ ), então uma resposta após 10 segundos ocasionaria a retirada do estímulo, a liberação de uma pelota de alimento e o início de um intervalo randômico entre tentativas de 5 a 10 segundos. Se S2 não fosse um estímulo planejado para ser relacionado a S1 (ou seja, se fosse o S-), então ele desapareceria da tela após 10 segundos, independente do responder do pombo, e se seguia o intervalo entre tentativas (IET), durante o qual a tela ficava totalmente preta. Sempre que o sujeito não apresentava um aumento nos índices discriminativos por três sessões consecutivas, o IET que 
seguia as tentativas de combinações negativas (combinações não seguidas de reforçamento) era aumentado em 5 segundos. Esse aumento no IET após as combinações negativas tinha o objetivo de torná-las mais aversivas e, conseqüentemente, reduzir a taxa de respostas diante das mesmas (cf. Frank, 2007). Ao longo do treino, os sujeitos passavam a bicar com maior freqüência o S2 nas combinações positivas (combinações seguidas de reforçamento) e a bicar com baixa freqüência o S2 diante das combinações negativas.

O estudo de Frank e Wasserman (2005) apresentou três experimentos que diferiam quanto ao treino realizado antes do teste de simetria. Todos os experimentos foram realizados com dois pombos (diferentes para cada experimento) e utilizaram os mesmos quatro estímulos de treino e teste (sorteados para cada sujeito). No Experimento 1, os sujeitos passavam por um treino em que as sessões eram compostas por combinações de estímulos positivas e negativas de relações de identidade (AA e $\mathrm{BB}$ ) e arbitrárias (AB) misturadas. Quando era obtido um índice discriminativo de pelo menos 0,80 para os três tipos de relações treinadas em uma mesma sessão, os sujeitos passavam por um teste de simetria (BA), que incluía tentativas de linha de base, com reforço, e as tentativas de teste misturadas na proporção de duas tentativas de cada combinação de linha de base para uma de cada combinação de teste. $\mathrm{O}$ responder nas tentativas de teste não era seguido de reforço. No Experimento 2 foi realizado apenas o treino das relações arbitrárias $\mathrm{AB}$ antes do teste de simetria e no Experimento 3 foram realizados primeiramente o treino das relações arbitrárias e teste de simetria, seguidos por um treino idêntico ao do Experimento 1 e um novo teste de simetria. Cada pombo realizou pelo menos duas sessões de teste de simetria.

Os resultados nos testes foram apresentados em termos da taxa de respostas (bicadas por segundo) média para as combinações positivas e negativas de linha de base (relações AB) e teste (relações BA) das duas primeiras sessões de teste de cada pombo. Os sujeitos do Experimento 1 (treino misto) apresentaram forte evidência de emergência das relações simétricas, evidenciada por taxas de respostas médias semelhantes entre as combinações de linha de base e teste, com taxa mais alta nas combinações positivas do que nas negativas. Um sujeito (35Y) apresentou taxa de 1,02 e 1,08 bicadas por segundo nas combinações positivas de linha de base e de teste, respectivamente, e de 0,30 e 0,27 bicadas por segundo nas combinações negativas. O outro sujeito (67Y) apresentou taxa de 1,57 e 1,44 bicadas por segundo nas combinações positivas de linha de base e de teste, respectivamente, e de 0,21 e 0,40 bicadas por segundo nas combinações negativas.

Os sujeitos do Experimento 2 (treino $\mathrm{AB}$ ) não apresentaram diferença significativa na taxa de respostas diante das combinações positivas e negativas do teste. Os sujeitos do 
Experimento 3 também não apresentaram desempenho indicativo de simetria no primeiro teste (após treino $\mathrm{AB}$ ), mas um dos sujeitos (10R) apresentou indícios de emergência de simetria no teste que se seguiu ao treino misto. Entretanto, a diferença entre as taxas de respostas para as combinações positivas e negativas de teste para este sujeito foi menor que nas combinações de linha de base e, conseqüentemente, o desempenho nos testes foi inferior ao dos sujeitos do Experimento 1. Para os autores, essa diferença de desempenho entre os pombos do Experimento 1 e 3 seria explicada pelo fato de que, no último experimento, o sujeito teria aprendido primeiramente que a localização temporal do estímulo era relevante (treino $\mathrm{AB}$ ) para depois aprender que não era (treino misto), o que implicaria em modificar uma aprendizagem estabelecida. Já no Experimento 1, o sujeito aprenderia desde o início do treino que a localização temporal do estímulo era irrelevante e, por isso, teria melhor desempenho nos testes.

Com base nos dados dos três experimentos, Frank e Wasserman (2005) concluíram que o procedimento de MTS sucessivo utilizado em seu estudo se mostra uma alternativa viável para o estudo de relações emergentes entre estímulos e que o treino misto aparentemente seria essencial para a emergência de relações.

O estudo de Frank e Wasserman (2005) abre novas possibilidades de investigação dos processos envolvidos na obtenção de testes positivos de propriedades de relações de equivalência. Diversos desdobramentos podem ser feitos a partir dos dados obtidos por ele, tais como a possibilidade de obtenção de relações emergentes indicativas da propriedade de transitividade e equivalência, a verificação se o desempenho do sujeito se mantém em uma tarefa de MTS padrão com os mesmos estímulos etc. Além disso, é preciso buscar compreender quais aspectos do procedimento seriam essenciais para a obtenção dos testes positivos de simetria. Em outras palavras, é preciso identificar quais teriam sido as condições necessárias e suficientes para a obtenção do resultado positivo nos testes por Frank e Wasserman (2005).

O trabalho de Frank (2007) preocupou-se com essa última questão. Quatro experimentos foram realizados, buscando identificar aspectos do procedimento de Frank e Wasserman (2005; Experimento 1) que teriam sido essenciais para os resultados positivos nos testes de simetria. Frank (2007) manteve praticamente os mesmos parâmetros do estudo anterior, modificando o tipo de estímulos usados (estímulos 3D no lugar dos bidimensionais utilizados anteriormente) e o intervalo de atraso entre S1 e S2 (que foi reduzido de 3,5 para 0,5 seg.). Além disso, foram realizadas seis sessões de teste para cada sujeito, intercaladas com sessões de linha de base, em vez das duas sessões feitas por Frank e Wasserman (2005). 
Os resultados foram apresentados também utilizando a taxa de respostas média nas combinações negativas e positivas de linha de base e teste. Medidas de significância das diferenças entre as taxas de respostas, tanto entre as combinações de teste quanto entre elas e as combinações de treino, foram tomadas como base para determinar se um desempenho indicava ou não emergência de simetria.

No Experimento 1 (Frank, 2007), foi feito um arranjo de estímulos de modo que todos aparecessem em ambas as localizações temporais sem que fosse necessário um treino de identidade com os mesmos. Para tanto, foram treinadas as relações AC, BA e DB. O teste de simetria consistiu no teste $\mathrm{AB}$, no qual não se obtiveram indícios de simetria. Tal dado indica que os resultados positivos nos testes de Frank e Wasserman (2005; Experimento 1) não se deveram simplesmente ao controle da localização temporal de apresentação dos estímulos, mas sim ao fato desse controle ter ocorrido por meio de um treino de relações de identidade. Dessa forma, o treino de identidade parece ser condição necessária para a emergência de simetria.

No Experimento 2, foi feito um treino misto, porém, os estímulos do treino de identidade eram diferentes dos do treino arbitrário. Para tanto, foram treinadas as relações CC, $\mathrm{DD}$ e $\mathrm{AB}$. O teste de simetria consistiu no teste $\mathrm{BA}$, no qual não se obteve emergência de simetria com nenhum dos sujeitos. Tal dado indica que o treino de identidade nesse procedimento precisa ser feito com os mesmos estímulos do treino arbitrário. Entretanto, a autora levanta a hipótese de que um treino de identidade com mais exemplares poderia resultar em identidade generalizada, o que garantiria, em tese, resultados positivos nos testes de simetria sem a necessidade de um treino de identidade com esses estímulos especificamente.

No Experimento 3, Frank (2007) treinou primeiramente as relações de identidade AA e $\mathrm{BB}$ antes de fazer um treino misto ( $\mathrm{AA}, \mathrm{BB}$ e $\mathrm{AB}$ ). $\mathrm{O}$ objetivo era verificar se o treino de identidade anterior ao treino arbitrário seria um facilitador do aprendizado, já que em tese o sujeito aprenderia que a localização temporal dos estímulos não era importante na tarefa antes de entrar em contato com as relações arbitrárias. Dos quatro pombos que passaram por esse experimento, dois demonstraram evidência moderada de simetria emergente, um deles com taxa de respostas para as combinações positivas e negativas de teste de 0,252 e 0,096 (sujeito $12 \mathrm{~W}$ ), respectivamente, e outro (pombo 57B) com taxas de 1,350 e 0,761, respectivamente. Um pombo (34R) apresentou uma sutil diferença nas taxas de respostas nas combinações positivas e negativas de teste $(0,932$ e 0,748 , respectivamente), o que indicaria indícios de simetria. Outro pombo (83Y) não apresentou qualquer indicativo de emergência dessas 
relações, com taxa de repostas de 0,501 para as combinações positivas e de 0,457 nas combinações negativas de teste. De acordo com Frank (2007), estes dados indicam que o treino de identidade anterior ao treino arbitrário pode ensinar ao sujeito que a localização temporal do estímulo não é importante, o que é incompatível com o desempenho exigido no treino arbitrário e no reste de simetria. Frank (2007) conclui, então, que o treino de identidade deve ser efetuado concomitantemente ao treino arbitrário.

No Experimento 4, foi feito o treino misto incluindo combinações de identidade e arbitrárias com um grupo de estímulos, mais as combinações de treino das relações arbitrárias de outro grupo de estímulos. Sendo assim, o treino misto incluía as relações AA, BB, AB e CD. As relações testadas foram BA e DC. Considerando os resultados dos experimentos anteriores e o resultado de Frank e Wasserman (2005; Experimento 1), era esperado que ocorresse apenas a emergência das relações BA, cujos estímulos teriam passado por treino de identidade. Como resultado, no entanto, ocorreu que um dos pombos (97W) apresentou indícios de simetria emergente das relações DC (taxa de respostas 0,396 e 0,250, respectivamente, para combinações positivas e negativas de teste) e moderada evidência de simetria das relações BA (taxa de respostas de 0,490 e 0,192, respectivamente). Outro sujeito (28B) apresentou evidência moderada de simetria das relações BA (taxa de respostas de 1,492 e 1,102, respectivamente, para as combinações positivas e negativas de testes BA) e o terceiro pombo (85R) não apresentou qualquer evidência de simetria. De acordo com a autora, estes dados indicam que, embora o treino de identidade com os mesmos estímulos do treino arbitrário aparentemente seja condição necessária para a obtenção de simetria emergente, não seria condição suficiente para tanto.

Ao se comparar os Experimentos 3 e 4 do estudo de Frank (2007) com o Experimento 1 de Frank e Wasserman (2005), verifica-se uma clara diferença nos resultados, embora não tenha havido uma grande diferença nos procedimentos de treino. Nos três experimentos foi feito treino misto com o mesmo grupo de estímulos. A diferença foi que, no Experimento 3 de Frank (2007), foi feito um treino prévio de identidade e, no Experimento 4, foi incluído o treino de relações arbitrárias com mais um grupo de estímulos. Frank (2007) levanta duas hipóteses para explicar a não obtenção de fortes evidências de simetria neste estudo. Ela se refere apenas ao Experimento 4, mas tais hipóteses se aplicariam também ao Experimento 3. A primeira hipótese se refere à possibilidade de que o treino de identidade anterior ao treino arbitrário (Experimento 3) ou o treino misto com quatro combinações arbitrárias a mais (Experimento 4) sejam fatores que dificultem o aprendizado adequado dos sujeitos para que possa ocorrer simetria emergente. Frank (2007), no entanto, não apresenta nenhum argumento 
que justifique esta hipótese, além da diferença de resultados entre seu estudo e o Experimento 1 do estudo de Frank e Wasserman (2005).

A segunda hipótese apresentada por Frank (2007) se refere à possibilidade de que as pequenas diferenças entre os parâmetros dos procedimentos do seu estudo e do estudo de Frank e Wasserman (2005) tenham sido fatores relevantes para a obtenção de simetria emergente. Mais especificamente, referiu-se à mudança do tipo de estímulos usados (tridimensional X bidimensional) e do intervalo de atraso entre S1 e S2 (0,5 X 3,5 segundos). Infelizmente, Frank (2007) não fez uma replicação do procedimento utilizado por Frank e Wasserman (2005; Experimento 1), o que poderia checar esta hipótese. Por conta disso, fica difícil saber a que atribuir os resultados obtidos nesse estudo. Talvez fosse relevante fazer uma repetição das manipulações dos experimentos de Frank (2007) utilizando o mesmo tipo de estímulos e os mesmos parâmetros usados em Frank e Wasserman (2005) ou, ainda, buscar replicar os dados de emergência de simetria com os parâmetros de Frank (2007). Apenas assim seria possível uma comparação real dos desempenhos dos sujeitos, com base apenas na manipulação dos procedimentos de treino.

Ao analisar o procedimento utilizado por Frank e Wasserman (2005) e Frank (2007), constatou-se um possível problema relativo às sessões de teste. Como já foi descrito, ambos os estudos utilizaram IETs diferentes entre as combinações positivas e negativas de treino. Entretanto, nenhum deles faz menção a quais seriam os IETs utilizados na sessão de teste e, principalmente, nas tentativas de teste. Como os autores descrevem que cada sessão de teste seguia a primeira sessão de treino com índices discriminativos de 0,80 , pode-se supor tanto que a diferença de IET foi mantida na sessão de teste quanto que todos os intervalos entre tentativas foram igualados nessas sessões. Ambas as alternativas poderiam afetar os resultados nos testes caso os sujeitos tenham aprendido que o tamanho do IET fazia parte da combinação de estímulos (combinação com IET menor é seguida de reforço e combinação com IET maior não). Neste caso, se todos os IETs fossem bruscamente igualados na sessão de teste, poderia ocorrer uma deterioração inicial da linha de base que afetaria o desempenho nas tentativas de teste. Já se a diferença entre os IETs fosse mantida, poderia ocorrer um processo de generalização ao longo da sessão de teste, de modo que o sujeito passaria a responder diante de cada combinação de teste da mesma forma que responderia às combinações de linha de base com o mesmo IET. Neste caso, o efeito sobre as tentativas de teste dependeria de qual IET seguia tais tentativas. Se elas apresentassem a mesma diferença de IET das tentativas de linha de base, o sujeito poderia emitir alta taxa de respostas diante das combinações positivas de teste e baixa taxa diante das combinações negativas. Se todas as tentativas de teste 
apresentassem o IET mais curto, o pombo poderia emitir taxas de respostas maiores nas primeiras sessões de teste para todas as combinações e taxas menores nas sessões seguintes, em decorrência da extinção. Se as tentativas de teste apresentassem o IET mais longo, seria muito provável que os sujeitos emitissem poucas respostas nessas tentativas. Qualquer uma das alternativas descritas aqui permitiria uma diferente análise dos desempenhos nos testes dos dois estudos e ajudaria no planejamento de estudos futuros.

A análise dos resultados dos estudos de Frank e Wasserman (2005) e Frank (2007) suscita algumas questões adicionais acerca do desempenho nos testes. De fato, a forma como os dados são apresentados não permite uma análise detalhada do que ocorreu nos testes e nem uma comparação mais direta dos resultados com outros estudos já realizados na área. Um primeiro problema encontrado na forma como os resultados de ambos os estudos são apresentados seria a medida tomada para avaliar a emergência de simetria. Embora os autores tenham considerado o índice discriminativo a medida adequada para avaliar a aquisição das discriminações condicionais no treino, medida esta amplamente utilizada nos estudos de discriminação simples e condicional descritos na literatura, optaram por usar a taxa de respostas como medida nos testes. Além disso, foram tomadas medidas estatísticas de significância para definir se o desempenho do sujeito era ou não indicativo de simetria emergente. Como os estudos sobre simetria costumam utilizar como medida o índice discriminativo das relações de treino e teste, há aqui uma dificuldade em comparar os dados apresentados nestes dois estudos com outras pesquisas na área.

Outro problema na apresentação dos resultados dos estudos de Frank e Wasserman (2005) e Frank (2007) é que ambos consideram desempenhos médios ao invés de absolutos, o que pode gerar distorção nos dados obtidos. Primeiramente, no treino é calculado o índice discriminativo médio de cada tipo de relação (um índice para as duas relações $\mathrm{AB}$, outro para as duas relações AA etc.), de modo que não é possível saber se ambas as discriminações condicionais estavam bem estabelecidas antes do teste. Um índice discriminativo de 0,80 para as relações $\mathrm{AB}$, por exemplo, tanto poderia representar duas relações (A1B1 e A2B2) com índice de 0,80, quanto uma relação com índice de 0,60 (que está ao nível do acaso) e outra com índice de 1,00 (c.f. Rubio \& Tomanari, 2002). Como o critério utilizado em ambos os estudos para a realização dos testes era de apenas uma sessão com os índices discriminativos médios maiores ou iguais a 0,80 , é pouco provável que todas as discriminações condicionais treinadas tenham alcançado este índice. Além disso, uma única sessão de treino com altos índices não garante que o desempenho apresentado seja estável, o que também pode resultar em pouca confiabilidade do desempenho nos testes. Não é possível afirmar, por exemplo, se 
um mau desempenho no teste se deveu ao procedimento usado no treino ou a uma instabilidade da linha de base. Claro que, se em todas as sessões de teste os índices discriminativos de linha de base fossem mantidos, poder-se-ia dizer que havia estabilidade de linha de base, mas nenhum dos estudos apresenta o índice das tentativas de linha de base em cada sessão de teste.

Os dados dos testes de simetria apresentados nos dois estudos também são apresentados sob a forma de média. Neste caso, a distorção dos dados pode ser ainda maior, pois, além dos autores tomarem como base a taxa média de respostas para combinações positivas e negativas de teste (taxa média de A1B1 e A2B2, taxa média de B1A1 e B2A2 etc.), ainda é calculada a média de todas as sessões de teste para cada sujeito. No caso, o estudo de Frank e Wasserman (2005) apresentou a média de duas sessões de teste, enquanto que o estudo de Frank (2007) apresentou a média de seis sessões de teste. Os autores afirmam que os sujeitos, geralmente, apresentaram desempenho semelhante em todas as sessões de teste, mas os testes do único sujeito que teve quatro sessões apresentadas (pombo 97W Frank, 2007) indicam relativa variabilidade das taxas de respostas entre sessões e entre tentativas de linha de base e teste.

Um bom exemplo da distorção que as medidas tomadas nestes estudos podem gerar é observado nos dados dos sujeitos do Experimento 3 de Frank (2007). A autora afirma, com base em medidas estatísticas de diferenças significativas entre taxa de respostas, que dois dos quatro pombos (12W e 57B) apresentaram evidência moderada de simetria e que um sujeito (34R) apresentou indícios de simetria. Utilizando as taxas de resposta médias apresentadas por esses sujeitos nos testes, pode-se calcular os índices discriminativos médios para as relações testadas (dado não apresentado pela autora). $\mathrm{O}$ resultado obtido foi de 0,72 para o pombo $12 \mathrm{~W}, 0,64$ para o pombo $57 \mathrm{~B}$ e 0,55 para o pombo $34 \mathrm{R}$. No caso do primeiro pombo, seria possível dizer que houve emergência de simetria moderada, mas, no caso do pombo 57B, o que todos os cálculos de significância indicam como sendo evidência moderada de simetria emergente é descrito na literatura como sendo um desempenho pouco acima do nível do acaso. Já o desempenho do pombo 34R indicaria apenas um responder indiferenciado entre as combinações positivas e negativas de teste e não um indício de simetria. É preciso lembrar que as medidas aqui tomadas para calcular os índices discriminativos das relações de teste se referem à média de seis sessões, já que os autores não apresentaram as medidas de cada sessão de teste e de cada relação simétrica separadamente.

Todos os dados aqui apontados seriam relevantes para uma comparação entre o procedimento utilizado nos estudos de Frank e Wasserman (2005) e Frank (2007) e o MTS 
padrão. A análise por relação treinada permite afirmar com maior grau de certeza se um determinado procedimento de treino foi efetivo na obtenção de relações emergentes. Além disso, o uso do índice discriminativo como medida permite uma comparação direta entre a maioria dos estudos na área. Análises baseadas em médias de dados ou em diferença entre taxas de resposta (e não índice discriminativo) provavelmente teriam permitido que alguns estudos afirmassem terem obtido a simetria emergente que os dados individuais não permitiram. Com isso, não se está afirmando que Frank e Wasserman (2005) não tenham dados consistentes com a emergência de simetria, mas sim chamando a atenção para o fato de que não é possível saber o quanto os dados apresentados neste estudo e no estudo de Frank (2007) podem ser representativos do que ocorreu nos testes.

A análise do procedimento de Frank e Wasserman (2005; Experimento 1) e Frank (2007; experimentos 3 e 4), sugere ainda mais um aspecto a ser investigado como de possível relevância para a emergência de simetria, mesmo que moderada. Embora não tenha sido treinada nenhuma relação simétrica de combinações positivas, o treino misto programado pelos experimentadores acabou contendo um treino de combinações negativas simétricas (reversibilidade das combinações negativas). Dentre as tentativas de treino referentes às relações de identidade $\mathrm{AA}$ e $\mathrm{BB}$, havia as tentativas negativas A1A2 e A2A1, B1B2 e B2B1, que seriam combinações negativas simétricas. Deste modo, pode ter ocorrido um treino de reversibilidade para os sujeitos que passaram pelo treino misto de relações de identidade e arbitrárias envolvendo os mesmos estímulos. Nesse caso, os desempenhos positivos nos testes de simetria podem não ser evidência de um repertório emergente sem treino direto de simetria.

Outro estudo que buscou compreender as variáveis responsáveis pelos resultados obtidos com o procedimento de Frank e Wasserman (2005, Experimento 1) foi realizado por Urcuioli (2008). Neste estudo, foram realizados cinco experimentos, com pombos como sujeitos, em uma câmara experimental padrão utilizando chaves de resposta. Os Experimentos 1A, 1B e 2 utilizaram o procedimento de MTS padrão com duas escolhas e com múltiplas localizações dos estímulos modelo e comparações. Os experimentos 3 e 4 utilizaram o procedimento de MTS sucessivo.

No Experimento 1A (Urcuioli, 2008), pombos ingênuos passaram por treino de relações arbitrárias $\mathrm{AB}$ em um procedimento de MTS simultâneo com múltiplas localizações dos estímulos. A mesma taxa de respostas (FR10) foi exigida para modelo e comparações para evitar que as taxas diferentes de respostas se tornassem componentes funcionais dos estímulos, o que prejudicaria o desempenho no teste de simetria. Bicadas ao estímulo 
comparação correto resultavam em reforçamento (acesso a grãos) e um intervalo entre tentativas de 10 segundos. Bicadas ao estímulo comparação incorreto resultavam em um timeout, seguido pelo IET. O teste de simetria foi feito com reforçamento, sendo que para metade dos pombos havia reforçamento programado para as relações consistentes com o treino (B1A1 e B2A2), enquanto que para a outra metade havia reforçamento programado para as relações inconsistentes com o treino (B1A2 e B2A1). Uma maior velocidade de aquisição das relações consistentes indicaria evidência de simetria. Porém, não houve diferença significativa na aquisição dos dois grupos. $\mathrm{O}$ autor conclui que exigir a mesma taxa de respostas ao modelo e às escolhas, nesse procedimento, não seria condição suficiente para obtenção de simetria emergente.

No Experimento 1B, os pombos do experimento anterior, após restabelecimento das relações $\mathrm{AB}$, passaram por treino das relações de identidade $\mathrm{AA}$ e $\mathrm{BB}$, em sessões distintas, utilizando o mesmo procedimento do experimento anterior. Deste modo, os pombos teriam a experiência com todos os estímulos em ambas as localizações temporais (modelo e comparação), evitando um efeito dessa variável nos testes. Os mesmos pombos passaram pelas mesmas condições de teste do experimento anterior. Mais uma vez, não foram observadas diferenças entre as aquisições das relações nos grupos consistente e inconsistente.

No Experimento 2 (Urcuioli, 2008), quatro pombos ingênuos passaram por um treino misto das relações $\mathrm{AA}, \mathrm{BB}$ e $\mathrm{AB}$, com o mesmo procedimento utilizado nos experimentos anteriores. $\mathrm{O}$ teste, entretanto, foi feito de forma diferente. Primeiramente, foram realizadas dez sessões de teste com linha de base cheia, nas quais foi mantido o reforçamento diferencial para as tentativas de linha de base e programado o reforçamento não diferencial (reforçamento para todas as tentativas) para as tentativas de teste. Outra mudança foi que, nas tentativas de teste, o modelo sempre era apresentado na chave central e os comparações nas chaves laterais. O autor não justifica nenhuma das mudanças realizadas neste teste. Na primeira sessão, os três pombos que finalizaram o treino responderam ao nível do acaso nas tentativas de teste, mas um dos pombos teve desempenho acima do acaso (entre 70 e $75 \%$ ) nas seis sessões seguintes e outro pombo teve desempenho entre 60 e $70 \%$ nas quatro sessões seguintes de teste. Nas últimas sessões de teste todos os três pombos respondiam ao acaso nas tentativas de teste. $\mathrm{O}$ autor considerou que não houve evidência de simetria nesse teste. Entretanto, considerando as condições de teste (reforçamento não diferencial), o fato de que dois sujeitos apresentaram desempenho acima do nível do acaso por algumas sessões sugere algo diferente. Talvez, para estes sujeitos, as relações de simetria tenham se estabelecido de forma suficiente para se 
manterem ao longo de algumas sessões apesar do reforçamento não diferencial ao qual estavam submetidas nos testes. Essa possibilidade mereceria maiores investigações.

Dado o desempenho dos sujeitos no primeiro teste do Experimento 2, eles foram submetidos a novas sessões de treino misto até atingirem os critérios de acerto. Os pombos foram, então, submetidos a um segundo teste de simetria, composto por 30 sessões semelhantes às sessões do primeiro teste, exceto pelo fato de que havia sido programado o reforçamento diferencial para as tentativas de teste. Para dois pombos havia sido programado o reforçamento para as tentativas consistentes ao treino, enquanto que para o outro pombo havia sido programado o reforçamento para as tentativas inconsistentes ao treino. De acordo com Urcuioli (2008), também não houve evidência de simetria neste teste. Entretanto, pode-se fazer uma análise diferente dos dados obtidos. Um dos sujeitos do grupo consistente mostrou uma porcentagem de escolhas corretas acima de 70\% na maioria das sessões (superior a $80 \%$ em oito das trinta sessões). Essa porcentagem de acertos foi superior à do pombo que passou pelo reforçamento diferencial das relações inconsistentes, que só apresentou desempenho abaixo de $60 \%$ em 22 das 30 sessões de teste e abaixo de $80 \%$ nas outras oito sessões. Este dado poderia indicar que, para o sujeito do grupo consistente, foram estabelecidas em alguma medida as relações simétricas. É preciso considerar, ainda, que o primeiro teste pode ter tido algum efeito sobre o segundo, já que, no primeiro teste, os sujeitos aprenderam que todas as relações eram indiscriminadas (todas as tentativas de teste eram reforçadas) e, no segundo teste, as mesmas relações eram discriminadas. Portanto, os dados do segundo teste do Experimento 2 de Urcuioli (2008), assim como os do primeiro teste, indicam a necessidade de maiores investigações sobre este procedimento.

No Experimento 3 (Urcuioli, 2008), é tentada uma replicação do Experimento 1 de Frank e Wasserman (2005). Oito pombos ingênuos foram submetidos ao treino misto das relações $\mathrm{AA}, \mathrm{BB}$ e $\mathrm{AB}$ em um procedimento de MTS sucessivo. Foi exigido um responder sob esquema de FI5". Bicadas ao modelo nesse esquema produziam, após 0,5 s de intervalo, o segundo estímulo (de escolha). Se este fosse o estímulo "correto", bicadas em FI5" produziam reforçamento e um IET de $15 \mathrm{~s}$. Caso o estímulo fosse "incorreto", desaparecia após $5 \mathrm{~s}$, independente do responder do pombo, sendo seguido pelo mesmo IET. Após atingirem o critério de aquisição (índices de acerto iguais ou superiores a 80\%, em pelo menos cinco dentre seis sessões), os sujeitos passavam por dez sessões de supertreino antes de se iniciarem os testes. Sete pombos passaram para a fase de teste. Foram realizadas oito sessões de teste, com linha de base cheia, sendo que a cada duas sessões eram feitas ao menos cinco sessões de treino, até novo alcance do critério de acerto. Havia reforçamento programado para as 
tentativas de linha de base, enquanto que as tentativas de teste foram feitas em extinção. $\mathrm{O}$ estímulo de escolha desaparecia após cinco segundos em todas as tentativas de teste, independente do responder. Cinco dos sujeitos responderam, em média, mais nas combinações simétricas àquelas treinadas, mas apenas quatro sujeitos apresentaram diferença significativa entre as taxas de resposta das combinações positivas e negativas do teste (três apresentaram uma diferença mais evidente). Nenhum dos sujeitos, entretanto, apresentou uma diferença entre as taxas de resposta tão acentuada quanto a do estudo de Frank e Wasserman (2005, Experimento 1). Urcuioli (2008) atribui essa diferença de resultados a diferenças de procedimento: os pombos do estudo de Frank e Wasserman (2005) apresentavam menor taxa de respostas; os estímulos tinham maior tempo de apresentação (FI10”); o procedimento utilizava um IET variável; eles utilizavam estímulos complexos; e o aparato de registro de respostas era diferente (tela sensível ao toque).

A replicação do procedimento de Frank e Wasserman (2005) realizada por Urcuioli (2008) controlou algumas das variáveis apontadas aqui como sendo um possível problema. Seu estudo não usa IETs distintos para as combinações positivas e negativas de treino, o que permitiu o uso de um IET fixo nas sessões de teste. Além disso, era exigido um responder discriminado estável antes da realização dos testes. Urcuioli (2008) também descreve claramente a sessão de teste, o que permite uma análise mais objetiva dos dados apresentados.

Apesar dessas alterações positivas no procedimento usado por Urcuioli (2008) no Experimento 3, alguns problemas ainda permanecem. O autor fez uso das mesmas medidas que Frank e Wasserman (2005) e Frank (2007) para avaliar a emergência de simetria, ou seja, taxas de resposta médias de quatro sessões e cálculos de significância das diferenças entre as taxas, o que implica nas mesmas questões já levantadas aqui. Como Urcuioli (2008) não apresenta as taxas em uma tabela, não é possível calcular índices discriminativos médios das combinações de teste, como foi feito aqui com o Experimento 3 de Frank (2007). É possível, entretanto, inferir índices discriminativos inferiores a 0,70 para a maioria dos pombos do estudo de Urcuioli (2008) a partir da comparação dos gráficos por ele apresentados com àqueles descritos por Frank (2007) como sendo indicativos de simetria moderada e de indícios de simetria.

Baseado nos resultados dos primeiro quatro experimentos, Urcuioli (2008) apresenta uma teoria que explicaria porque foram obtidos resultados positivos nos testes de Frank e Wasserman (2005) e de seu Experimento 3. De acordo com ele, o fato do procedimento de MTS sucessivo garantir a exposição tanto à condição de reforçamento quanto à condição de extinção seria, provavelmente, fator essencial para tais resultados. Entretanto, as relações 
estabelecidas pelos pombos seriam diferentes das relações planejadas pelos experimentadores. Urcuioli (2008) afirma que cada estímulo seria na verdade um estímulo composto pelo estímulo nominal e sua localização temporal (se modelo ou comparação), de modo que um mesmo estímulo nominal seria um estímulo diferente como modelo e comparação. O autor utiliza letras maiúsculas e minúsculas para nomear estes estímulos compostos (por exemplo, "A1" seria o nome do estímulo quando apresentados como modelo e "al" seria o nome do mesmo estímulo quando apresentado como comparação). Seguindo essa lógica (de que o pombo responderia ao estímulo como um composto), o treino de MTS sucessivo levaria o pombo a formar classes entre cada par de estímulos (modelo e comparação) relacionados ao reforçamento. No caso do treino aqui descrito, seriam formadas seis classes: A1a1, A2a2, $\mathrm{B} 1 \mathrm{~b} 1, \mathrm{~B} 2 \mathrm{~b} 2, \mathrm{~A} 1 \mathrm{~b} 1$ e A2b2. Se estas classes realmente forem formadas, o treino misto de relações de identidade e arbitrárias permitiria elementos em comum entre determinadas classes, o que levaria ao desempenho positivo no teste de simetria. Tomemos como exemplo as três classes A1a1, B1b1 e A1b1, em que são observados dois elementos em comum, A1 e b1. Estes elementos seriam os responsáveis pela formação de uma classe de quatro estímulos (A1, B1, a1 e b1) que incluiria os estímulos testados (no caso a relação de simetria B1a1).

O Experimento 4 foi realizado por Urcuioli (2008) para testar sua teoria. Caso estivesse correta, uma pequena modificação do treino alteraria as classes de estímulos formadas e levaria o pombo a apresentar o desempenho oposto ao esperado nos testes, que foi chamado por ele de "anti-simetria" (escolha oposta à simetria). Pela lógica, se ao invés de treinar as relações de identidade de todos os estímulos fosse realizado um treino de singularidade (a escolha correta seria o estímulo diferente e a incorreta o estímulo idêntico ao modelo) com dois deles, a anti-simetria seria observada. Um treino misto desse tipo produziria, por exemplo, as seis relações modelo-comparação A1a2, A2a1, B1b1, B2b2, A1b1 e A2b2. Ao tomarmos as classes A1a2, A1b1 e B1b1, por exemplo, observamos os elementos em comum A1 e b1, que seriam responsáveis pela formação de uma classe de quatro elementos (A1, B1, a2 e b1). Dados os elementos desta classe, seria esperado que o pombo respondesse mais para a combinação B1a2 durante os testes. Esta foi a exata manipulação experimental feita por Urcuioli (2008) com oito pombos ingênuos. Quatro dos cinco pombos que concluíram o treino apresentaram desempenho nos testes condizente com a anti-simetria e o quinto pombo apresentou responder não diferencial nos testes. Todos os parâmetros do treino e testes foram semelhantes aos do Experimento 3, de modo que a diferença entre os desempenhos dos sujeitos nos dois experimentos não poderia ser atribuídas à mudanças no procedimento outras que não a manipulação experimental realizada. É 
interessante notar que, embora os sujeitos tenham levado um maior número de sessões até o critério nesse experimento, eles apresentaram diferenças mais acentuadas entre as taxas de resposta das combinações simétricas e "anti-simétricas" do que os sujeitos do Experimento 3.

Dados os resultados apresentados por Urcuioli (2008), pode-se questionar se o desempenho positivo dos pombos nos testes de simetria seria ou não demonstração de simetria emergente. O próprio autor levanta esta questão, sem se comprometer em respondêla. Enfatiza, entretanto, que o dado relevante seria que claramente se observou um desempenho emergente com animais não humanos nos testes, o que já seria por si só um importante avanço para a área de equivalência de estímulos.

A teoria apresentada por Urcuioli (2008), embora interessante, ainda precisa ser devidamente estudada e testada. É possível, entretanto, fazer alguns questionamentos a partir dos resultados apresentados neste estudo e no estudo de Frank (2007) nos testes de simetria. Uma primeira questão, já apresentada aqui, seria sobre a medida utilizada para indicar simetria e anti-simetria nestes estudo. Os dados de Urcuioli (2008) nos Experimentos 3 e 4 indicam diferenças pequenas entre as taxas de respostas na combinações positivas e negativas de testes, em comparação com as taxas das combinações de linha de base. Fica a questão, portanto, da possibilidade de considerar tais dados como demonstração de simetria ou antisimetria. No entanto, é preciso assumir o fato de que houve uma clara diferença entre as taxas de respostas nas combinações de teste dos dois experimentos, e essa diferença precisa ser replicada e explicada.

Uma segunda questão sobre a teoria apresentada por Urcuioli (2008) se apóia nos dados do Experimento 3 de Frank (2007). Neste estudo, foram treinadas as relações AA, BB, $\mathrm{AB}$ e $\mathrm{CD}$, conjuntamente, e testadas as relações BA e DC. Um dos pombos teria apresentado indícios de simetria DC, mesmo sem ter passado por treino de identidade com estes estímulos. Esse dado não se encaixaria na teoria de Urcuioli (2008), que atribui a emergência de simetria ao treino misto das relações de identidade e arbitrárias. Replicações do Experimento 3 de Frank (2007) poderiam esclarecer essa questão.

A terceira e última questão se refere ao procedimento utilizado por Urcuioli (2008) no seu último experimento. Para testar sua teoria o autor submeteu os pombos a um treino misto de relações arbitrárias e de singularidade. É importante lembrar, entretanto, que o treino de singularidade estabelece um desempenho oposto ao que seria esperado para uma das propriedades definidoras das classes de equivalência e que também seria pré-requisito para a emergência de simetria, a reflexividade. Para que um sujeito possa responder de acordo com a propriedade de simetria, é preciso que ele reconheça que um estímulo é igual a ele mesmo, a 
despeito do fato dele ser apresentado como modelo ou comparação. Se a propriedade de reflexividade não estiver presente, a relação simétrica da relação treinada será uma relação completamente nova para este sujeito, que provavelmente apresentará um desempenho ao nível do acaso no teste. Por essa lógica, é possível pensar que o procedimento de treino utilizado por Urcuioli (2008) no Experimento 4 estabeleceu um responder incompatível com a emergência de simetria, dado que a relação treinada foi de singularidade e não de igualdade.

Embora a teoria de Urcuioli (2008) ainda precise ser submetida a testes, ela precisa ser considerada na análise de resultados dos estudos que utilizem o mesmo procedimento de treino utilizado por este autor, por Frank e Wasserman (2005) e por Frank (2007). É o caso do presente estudo, que teve o objetivo de ampliar a investigação das condições necessárias e suficientes para a emergência de simetria em animais não humanos a partir do procedimento apresentado por Frank e Wasserman (2005). Para tanto, dois experimentos foram realizados. O Experimento I teve o objetivo de replicar o experimento de Frank e Wasserman (2005, Experimento 1). O Experimento II teve o objetivo de verificar se o treino de reversibilidade das combinações negativas de estímulos pode ter sido um fator determinante na eventual obtenção dos resultados positivos em teste de simetria no experimento anterior. 


\section{EXPERIMENTO I}

\section{MÉTODO}

\section{$\underline{\text { Sujeitos }}$}

Participaram desse experimento três pombos (Columba livia) adultos, alojados individualmente em gaiolas-viveiro (44 X 50,5 X $46 \mathrm{~cm})$ e mantidos no biotério do Departamento de Psicologia Experimental da USP sob um ciclo claro/escuro de 12 horas. Os sujeitos tinham livre acesso à água e grit e recebiam suplemento vitamínico duas vezes por semana, ficando sob regime de restrição de alimento de modo a manterem $80 \%$ do seu respectivo peso ad libitum ${ }^{4}$. Dois sujeitos (P12 e P13) eram experimentalmente ingênuos, enquanto que o outro sujeito (P03) possuía uma história de treino de relações arbitrárias em procedimento de MTS simultâneo com duas escolhas, realizado com equipamento e estímulos da Med Associates (formas geométricas simples e cores).

\section{Ambiente Experimental e Equipamentos}

A coleta de dados foi realizada em uma sala do Laboratório F. S. Keller de Estudos do Comportamento Operante, no Instituto de Psicologia da USP. As sessões foram realizadas em uma caixa de condicionamento operante para pombos de fabricação Med Associates modelo Env-008 (25,5 X 33 X $32 \mathrm{~cm})$. Na parede do fundo da caixa, $9 \mathrm{~cm}$ acima do piso, havia uma abertura de $10 \mathrm{~cm}$ de largura e $17 \mathrm{~cm}$ de altura, à qual foi acoplado um monitor de tela sensível ao toque de 15 polegadas (Elo TouchSystems modelo 1515L), com tecnologia APR (Acoustic Pulse Recognition), no qual eram apresentados os estímulos. O reforço (acesso a grãos de alimento ${ }^{5}$ ) era administrado por meio de um comedouro, localizado na parede direita, próximo ao piso da caixa. A caixa de condicionamento operante estava alocada dentro de uma

\footnotetext{
${ }^{4}$ Esta pesquisa teve seu projeto aprovado pelo Comitê de Ética em Pesquisa Animal do Instituto de Psicologia da Universidade de São Paulo (Projeto de Pesquisa n ${ }^{\circ}$ 009.2009).

${ }^{5}$ A composição da mistura de grãos utilizada foi de: $25 \%$ de milho partido, $20 \%$ de arroz com casca, $20 \%$ de ervilha ou lentilha partida, $20 \%$ de grãos e aveia e $15 \%$ de sementes de girassol.
} 
caixa de isolamento acústico $(63 \times 73$ X $73 \mathrm{~cm})$, contendo um mini ventilador que permanecia ligado durante toda a sessão.

O funcionamento do equipamento foi controlado por um computador IBM-PC (AMD Sempron $\left.^{\mathrm{TM}}, 1.58 \mathrm{GHz}\right)$, localizado do lado de fora da caixa de isolamento acústico. As sessões foram programadas na linguagem Visual Basic 6.0. O comedouro era acionado por meio de uma interface (placa de controle KPORT - central de automação). O andamento da sessão era acompanhado pelo experimentador na sala adjacente à sala de coleta. Nesta sala, havia um segundo monitor, ligado ao computador por um cabo Y, que mostrava os estímulos e um mostrador, no canto inferior esquerdo da tela, indicando o número da tentativa em vigor, o estímulo apresentado (S1 ou S2) e o tempo, em segundos, sem ocorrência de respostas.

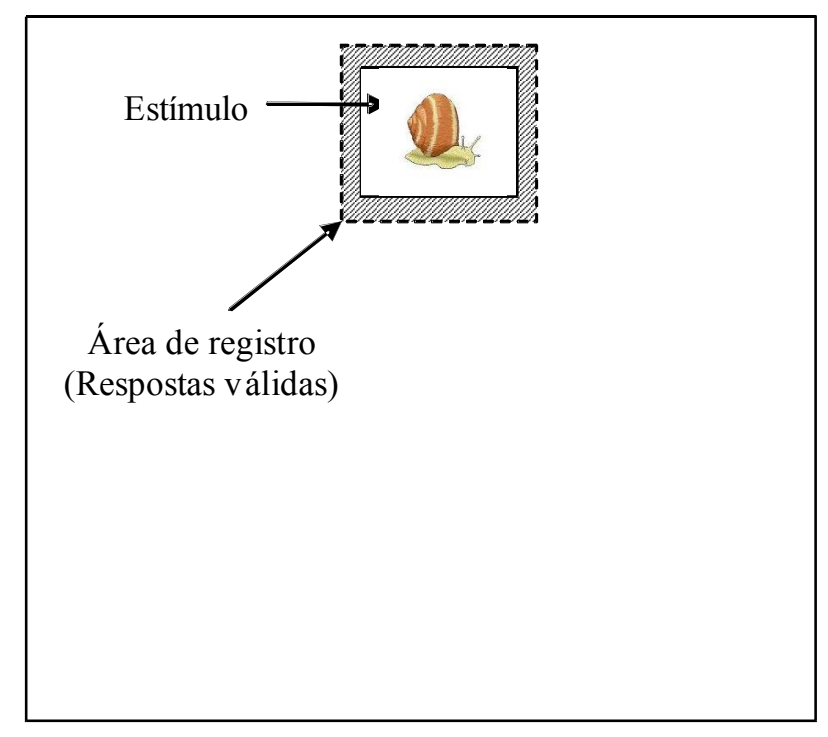

Figura 1 - Esquematização da tela do computador na sessão e da área na qual eram registradas as respostas válidas dos pombos. A área hachurada era da mesma cor do fundo da tela, não possuindo qualquer marcação que a diferenciasse do mesmo.

A área de ativação da tela sensível ao toque (área dentro da qual as bicadas eram registradas e consideradas válidas) equivaleu a um quadrado de $5 \mathrm{~cm}$ de lado (ver Figura 1), constituído pelo quadrado branco de $4 \mathrm{~cm}$ no qual o estímulo era apresentado e uma margem de $0,5 \mathrm{~cm}$ de cada lado (correspondente ao fundo preto da tela). Esta área ficava localizada a aproximadamente $21 \mathrm{~cm}$ do piso da caixa de condicionamento, centralizada horizontalmente na tela. As respostas na margem de $0,5 \mathrm{~cm}$ foram consideradas com base na observação e registro do comportamento de dois sujeitos (P03 e P13), que bicavam majoritariamente na beirada do quadrado branco, ocasionando muitas bicadas não efetivas. Cada resposta dentro da área de ativação produzia um feedback sonoro: um bip curto, de aproximadamente $700 \mathrm{~Hz}$ e $70 \mathrm{~dB}$. Respostas em qualquer outra parte da tela não produziam o bip. 
O software utilizado na coleta de dados registrava as latências de resposta para todos os estímulos, bem como a freqüência de respostas a cada segundo de apresentação dos estímulos a cada tentativa. Além do total de bicadas por tentativa na área de ativação, foram registradas, separadamente, as bicadas que ocorreram apenas na margem de $0,5 \mathrm{~cm}$ ao redor do estímulo.

\section{Estímulos}

Este estudo utilizou seis estímulos, apresentados na Figura 2. O Experimento I utilizou os estímulos X1, X2, X3 e X4, sendo que, para cada sujeito, houve um sorteio para determinar qual dos estímulos seria denominado de A1, A2, B1 ou B2. Por exemplo, para um sujeito o estímulo X1 poderia pertencer ao conjunto A (A1, por exemplo), enquanto que, para outro, ele seria um dos estímulos do conjunto B (por exemplo, B1). Buscou-se evitar, assim, que os resultados do experimento pudessem ser atribuídos a propriedades específicas dos estímulos utilizados no treino. A designação dos estímulos para cada sujeito é apresentada na Tabela 1 .

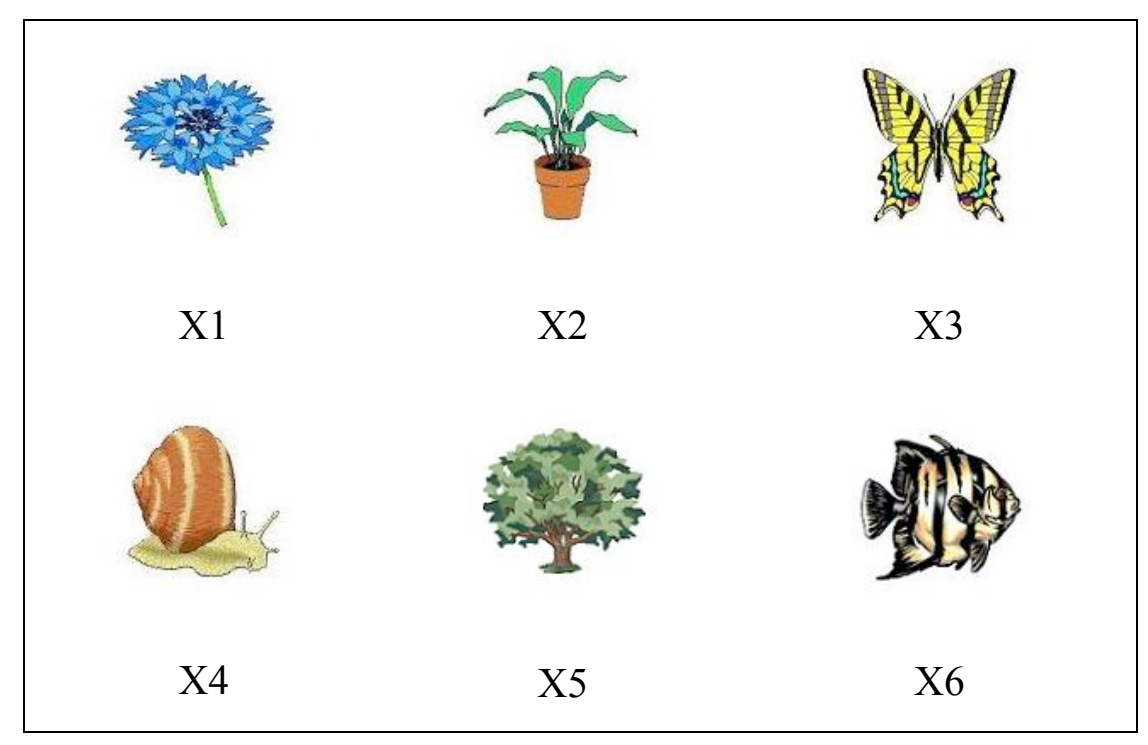

Figura 2 - Estímulos utilizados nos Experimentos I e II.

Os estímulos eram imagens em formato JPEG, bidimensionais e coloridas, como ocorreu no estudo de Frank e Wasserman (2005). Os estímulos foram apresentados no centro de um quadrado branco de 4 X $4 \mathrm{~cm}$ e tinham tamanho aproximado de 2,5 X 2,5 cm. 
Tabela 1 - Estímulos treinados para cada sujeito do Experimento I.

\begin{tabular}{ccccc}
\hline & \multicolumn{4}{c}{ Estímulos } \\
\cline { 2 - 5 } Pombo & A1 & A2 & B1 & B2 \\
\hline P03 & X1 & X2 & X3 & X4 \\
P12 & X1 & X4 & X2 & X3 \\
P13 & X2 & X3 & X4 & X1 \\
\hline
\end{tabular}

\section{Procedimento}

Este experimento contou com uma fase inicial de preparação dos sujeitos para o procedimento de treino, uma fase de treino, uma fase de preparação dos sujeitos para o teste e uma fase de teste de simetria. Cada fase experimental será descrita a seguir.

\section{PRÉ-TREINO:}

Esta fase teve o objetivo de preparar os sujeitos para as sessões experimentais. Optouse por realizar um procedimento de pré-treino semelhante ao utilizado por Frank (2007), adaptando-se apenas o tamanho do estímulo, por se tratar de um procedimento simples, que requer poucas sessões e que se mostrou suficiente para preparar os sujeitos para a fase de treino. Sendo assim, cada sujeito foi treinado a bicar um quadrado de 4 X $4 \mathrm{~cm}$, localizado no centro da tela, a aproximadamente $21 \mathrm{~cm}$ do piso da caixa, iluminado com uma dentre quatro cores (verde, amarelo, vermelho ou azul). Inicialmente, uma bicada sobre o estímulo resultava em acesso ao comedouro por 3 segundos. A cada sessão era exigido um número de bicadas cada vez maior por tentativa para a liberação do reforço, até o estabelecimento do responder sob esquema de razão fixa 20 (FR20). O aumento na razão de respostas exigidas por tentativa se deu da seguinte forma: FR2, FR4, FR7, FR10, FR12, FR15, FR17 e FR20.

Cada sessão contou com 150 tentativas e os estímulos foram apresentados de forma semi-aleatória, de modo que um mesmo estímulo não aparecia em mais do que duas tentativas consecutivas. Durante o período de apresentação do comedouro a tela ficava totalmente preta. Após completar uma sessão sob esquema de reforçamento de FR20, o sujeito passava para a fase de treino. 


\section{TREINO:}

Esta fase consistiu no treino misto de relações de identidade (AA e BB) e arbitrárias (AB) com procedimento de MTS sucessivo. O procedimento descrito por Frank e Wasserman (2005) foi adaptado ${ }^{6}$, utilizando um menor número de tentativas por sessão e um menor intervalo entre S1 e S2, de modo a reduzir o tempo de sessão e facilitar que os sujeitos concluíssem todas as tentativas das sessões.

Os estímulos eram apresentados sempre na mesma localização e a ordem de apresentação das combinações de estímulos era semi-aleatória, evitando-se: 1) que uma mesma combinação fosse repetida consecutivamente dentro de um bloco; 2) que ocorressem mais de três tentativas corretas ou incorretas consecutivamente. As sessões se encerravam após a conclusão das tentativas requeridas ou quando o sujeito deixava de bicar o estímulo por mais de 15 minutos, transcorrido um tempo mínino de uma hora e meia de sessão.

Cada tentativa de treino foi composta por três estímulos (ver Figura 3). O primeiro era um estímulo de orientação, que indicava o início de uma tentativa (uma cruz preta sobre um quadrado de fundo branco) e desaparecia mediante a primeira resposta do sujeito, proporcionando a apresentação imediata do segundo estímulo (S1). A primeira resposta de bicar o estímulo após 10 segundos (FI10”) ocasionava a remoção deste e, após um intervalo de 0,5 segundos (mantendo o quadrado branco na tela), a apresentação do terceiro estímulo $(\mathrm{S} 2)$.

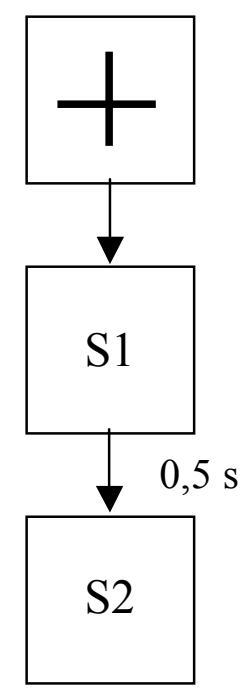

Figura 3 - Configuração de uma tentativa.

\footnotetext{
${ }^{6}$ Inicialmente buscou-se fazer uma replicação sistemática do Experimento 1 de Frank e Wasserman (2005), porém, o desempenho dos sujeitos submetidos a tal procedimento requereu modificações de alguns parâmetros, até que se alcançasse o procedimento aqui descrito. Os dados desses sujeitos serão apresentados na sessão de resultados.
} 
Se S2 fosse um estímulo programado pelo experimentador para ser relacionado a S1 (combinação positiva), então a primeira resposta a S2 depois de transcorridos 10 segundos produziria reforço (acesso a grãos de alimento) e um intervalo entre tentativas (IET) randômico de 5 a 10 segundos, durante o qual a tela ficava preta. Se S2 fosse um estímulo não relacionado a S1 (combinação negativa), seria removido após um tempo fixo de 10 segundos, seguindo-se, então, o IET. O tempo de acionamento do comedouro era adequado à manutenção do peso do pombo, podendo variar entre sujeitos e sessões. No presente estudo o tempo de comedouro variou entre 2,0 e 10 segundos ${ }^{7}$.

O treino realizado neste experimento consistiu no arranjo de 8 combinações referentes ao treino das relações de identidade e 4 combinações referentes ao treino de relações arbitrárias (Tabela 2), com os estímulos dos Conjuntos A e B, em sessões constituídas por 7 blocos de 24 tentativas, totalizando 168 tentativas (quatorze de cada combinação).

Tabela 2 - Combinações de estímulos usadas nas sessões do Experimento I.

\begin{tabular}{|c|c|c|c|}
\hline & S1 & $\mathbf{S 2}$ & Conseqüiência \\
\hline \multirow{8}{*}{ 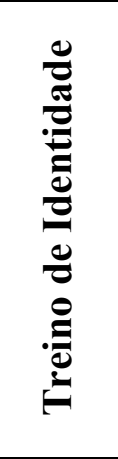 } & $\mathrm{A} 1$ & $\mathrm{~A} 1$ & + \\
\hline & $\mathrm{A} 1$ & $\mathrm{~A} 2$ & - \\
\hline & $\mathrm{A} 2$ & $\mathrm{~A} 1$ & - \\
\hline & $\mathrm{A} 2$ & A2 & + \\
\hline & $\mathrm{B} 1$ & $\mathrm{~B} 1$ & + \\
\hline & $\mathrm{B} 1$ & B2 & - \\
\hline & B2 & $\mathrm{B} 1$ & - \\
\hline & $\mathrm{B} 2$ & $\mathrm{~B} 2$ & + \\
\hline \multirow{4}{*}{ 急 } & A1 & B1 & + \\
\hline & $\mathrm{A} 1$ & B2 & - \\
\hline & $\mathrm{A} 2$ & B1 & - \\
\hline & $\mathrm{A} 2$ & $\mathrm{~B} 2$ & + \\
\hline \multirow{4}{*}{ 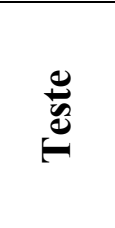 } & $\mathrm{B} 1$ & $\mathrm{~A} 1$ & + \\
\hline & B1 & $\mathrm{A} 2$ & - \\
\hline & B2 & $\mathrm{A} 1$ & - \\
\hline & $\mathrm{B} 2$ & $\mathrm{~A} 2$ & + \\
\hline
\end{tabular}

Um índice discriminativo (ID) foi calculado para todas as combinações positivas a cada sessão. Quando o sujeito alcançasse ID de 0,80 , por três sessões consecutivas, para todas

\footnotetext{
${ }^{7}$ Inicialmente o tempo de acionamento do comedouro foi de 3 segundos, sendo ajustado, ao longo das sessões, ao consumo necessário para que o sujeito se mantivesse a $80 \%$ de seu peso livre.
} 
as seis relações, passava para a fase de preparação para o procedimento de teste (Pré-teste). O índice discriminativo neste procedimento foi calculado pelo número de respostas ao $\mathrm{S} 2 \mathrm{em}$ cada combinação positiva de estímulos, dividido pelo total de respostas ao mesmo S2 (combinações positivas e negativas de estímulos). Deste modo, o ID para a relação alb1, por exemplo, seria calculado pela fórmula: [a1b1 / (a1b1 + a2b1)]. Uma sessão de treino misto de relações de identidade e arbitrárias, portanto, contou com o cálculo de seis índices discriminativos, dois para cada tipo de combinação de estímulos (AA, BB e AB). A Tabela 3 apresenta as combinações positivas e negativas correspondentes a cada relação de treino e de teste.

Tabela 3 - Combinações positivas e negativas de todas as relações do Experimento I.

\begin{tabular}{ccc}
\hline $\begin{array}{c}\text { Relação entre } \\
\text { Estímulos }\end{array}$ & $\begin{array}{c}\text { Combinação } \\
\text { Positiva }\end{array}$ & $\begin{array}{c}\text { Combinação } \\
\text { Negativa }\end{array}$ \\
\hline $\mathrm{a} 1 \mathrm{a} 1$ & $\mathrm{a} 1 \mathrm{a} 1$ & $\mathrm{a} 2 \mathrm{a} 1$ \\
$\mathrm{a} 2 \mathrm{a} 2$ & $\mathrm{a} 2 \mathrm{a} 2$ & $\mathrm{a} 1 \mathrm{a} 2$ \\
$\mathrm{~b} 1 \mathrm{~b} 1$ & $\mathrm{~b} 1 \mathrm{~b} 1$ & $\mathrm{~b} 2 \mathrm{~b} 1$ \\
$\mathrm{~b} 2 \mathrm{~b} 2$ & $\mathrm{~b} 2 \mathrm{~b} 2$ & $\mathrm{~b} 1 \mathrm{~b} 2$ \\
$\mathrm{a} 1 \mathrm{~b} 1$ & $\mathrm{a} 1 \mathrm{~b} 1$ & $\mathrm{a} 2 \mathrm{~b} 1$ \\
$\mathrm{a} 2 \mathrm{~b} 2$ & $\mathrm{a} 2 \mathrm{~b} 2$ & $\mathrm{a} 1 \mathrm{~b} 2$ \\
$\mathrm{~b} 1 \mathrm{a} 1$ & $\mathrm{~b} 1 \mathrm{a} 1$ & $\mathrm{~b} 2 \mathrm{a} 1$ \\
$\mathrm{~b} 2 \mathrm{a} 2$ & $\mathrm{~b} 2 \mathrm{a} 2$ & $\mathrm{~b} 1 \mathrm{a} 2$ \\
\hline
\end{tabular}

Caso o desempenho do sujeito se estabilizasse por três sessões abaixo do critério de 0,80 de índice, o IET posterior a todas as tentativas de combinação negativa era aumentado em 5 segundos nas sessões subseqüentes. Este procedimento era repetido sempre que o índice se estabilizava abaixo do critério.

\section{PRÉ-TESTE:}

Após o alcance do critério na fase de treino, eram realizadas sessões adicionais de treino com todos os IETs (combinações positivas e negativas) idênticos. Este procedimento começava com um IET inferior ao utilizado na frase de treino para as combinações negativas. O IET era, então, aumentado gradativamente até nova obtenção de índices discriminativos de 
no mínimo 0,80 para todas as relações por duas sessões consecutivas. Esse procedimento visava preparar os pombos para a sessão de teste, na qual todos os IETs seriam iguais.

\section{TESTE:}

A sessão de teste era formada por tentativas com todas as combinações de estímulos já treinadas (linha de base) mais as combinações apresentadas na porção identificada pela palavra "Teste" na Tabela 2. Havia reforçamento programado para as tentativas de treino. As tentativas de teste não eram seguidas de reforço, sendo que o S2 desaparecia da tela após 10 segundos, não dependendo da emissão de respostas pelo sujeito. Foi utilizado o mesmo IET para todas as tentativas da sessão de teste, cujo valor era o mesmo da última sessão da fase de Pré-teste. Optou-se por utilizar o mesmo IET para evitar um possível efeito do uso de IETs diferentes sobre o resultado dos testes. Caso a sessão de teste utilizasse IETs diferentes para tentativas diferentes (combinações positivas e negativas) os sujeitos poderiam passar a responder nas tentativas de teste de acordo com o seu IET (curto ou longo).

Uma sessão de teste consistia de 140 tentativas, distribuídas da seguinte forma: um bloco inicial de 12 tentativas (uma de cada combinação treinada); quatro blocos de 28 tentativas (duas tentativas de cada combinação de treino, mais uma tentativa de cada combinação de teste); um bloco final de 16 tentativas (uma tentativa de cada tipo de combinação de treino e teste). As tentativas foram distribuídas desta forma para evitar que tentativas de teste aparecessem antes que as tentativas de treino e para minimizar os efeitos da extinção sobre o desempenho no teste.

Caso não ocorresse deterioração do desempenho nas tentativas de linha de base na sessão de teste, outra sessão de teste era realizada na seqüência. Caso contrário, o treino era retomado até nova obtenção de uma sessão com índice discriminativo de no mínimo 0,80 para todas as relações. Então, uma nova sessão de teste era realizada. Este procedimento foi repetido até completar quatro sessões de teste.

Para cada sessão de teste foram calculados oito índices discriminativos: os seis índices referentes às relações de linha de base, mais os dois índices das relações de teste (relações BA). 


\section{RESULTADOS E DISCUSSÃO}

Para alcançar o objetivo deste experimento, primeiramente seria necessário estabelecer um procedimento efetivo de treino, que garantisse a aquisição das discriminações condicionais treinadas. A Tabela 4 apresenta o total de sessões realizadas por cada pombo e o número de sessões que não foram concluídas. Pode-se verificar o elevado número de sessões realizadas por cada sujeito. No caso do sujeito P03, ocorreu também um elevado número de sessões incompletas. É preciso lembrar que, neste procedimento, as sessões são longas, já que tentativas corretas e incorretas são apresentadas separadamente, o que explica, em parte, a ocorrência de sessões incompletas. O tempo de sessão variou entre uma hora e meia e quatro horas neste experimento e P03 apresentava as maiores latências de resposta nas sessões.

Tabela 4 - Número de sessões de treino realizadas e sessões não finalizadas para cada sujeito na fase de aquisição das discriminações condicionais do Experimento I.

\begin{tabular}{ccc}
\hline & \multicolumn{2}{c}{ Sessões de Treino } \\
\cline { 2 - 3 } Sujeito & Total de Sessões & Sessões Incompletas \\
\hline P03 & 220 & 40 \\
P12 & 115 & 09 \\
P13 & 151 & 05 \\
\hline
\end{tabular}

A Figura 4 apresenta os índices discriminativos de cada sujeito na fase de treino. Nesta figura são apresentados apenas os dados das sessões que foram concluídas, pois as sessões não finalizadas geralmente apresentavam índices muito diferentes dos obtidos nas finalizadas. O que se observa na Figura 4 é que apenas um sujeito (P13 - porção inferior da figura) apresentou uma clara curva de aquisição das relações treinadas, concluindo o treino após 151 sessões. Após o início do processo de aquisição das discriminações (sessão 71), este pombo apresentou alguma instabilidade nos índices discriminativos, com aumento seguido de queda dos índices. Por exemplo, entre as sessões 77 e 80 houve um gradual aumento nos índices discriminativos de cinco relações treinadas (B2B2 foi uma exceção neste caso, mantendo os mesmos índices). A partir da sessão 81 , até a sessão 85 , houve uma queda de todos os índices ao nível do acaso, havendo novo aumento a partir da sessão 82. Por conta dessa instabilidade no desempenho de P13, o IET das tentativas incorretas foi gradativamente aumentado visando 
atingir o critério de três sessões consecutivas com índices discriminativos mínimos de 0,80 . Quando o IET das tentativas incorretas variou entre 15 e 20 segundos (sessões de 96 a 100), o desempenho de P13 apresentou melhora, mas permaneceu instável. O aumento subseqüente do IET (entre 20 e 25 segundos) ocasionou uma queda nos índices discriminativos e um aumento na variabilidade de desempenho do sujeito. Após cerca de dez sessões, entretanto, P13 apresentou um aumento gradual nos índices discriminativos.

P13 atingiu o critério de treino (três sessões consecutivas com todos os seis índices acima de 0,80 ) apenas na sessão 121 , com IET nas tentativas incorretas variando entre 20 e 25 segundos. As trinta sessões seguintes (122 a 151) foram de igualação do IET (pré-teste) de todas as tentativas, começando com o IET randômico mais baixo (entre 5 e 10 segundos) e terminando com o IET de 10 a 15 segundos para todas as tentativas, que foi, posteriormente, o IET usado nas tentativas de teste. Nota-se que, no período de igualação dos IETs, P13 voltou a apresentar o mesmo padrão instável da fase de aquisição, requerendo 30 sessões de pré-teste para voltar a alcançar o critério para o teste.

Diferentemente de P13, os outros dois pombos não apresentaram uma clara curva de aquisição das relações treinadas. P03 apresentou índices discriminativos um pouco mais altos em várias sessões, mas sem qualquer estabilidade ou progressão, raramente apresentando índices discriminativos acima de 0,70 . Na Figura 4, a curva referente à relação b2b2 desse sujeito ilustra claramente esse ponto. Essa relação geralmente apresentava índice discriminativo superior à maioria das relações treinadas, porém esse índice era muito variável e nunca superior a 0,75 . Dada a fórmula de cálculo dos índices discriminativos utilizada nesse estudo, o aumento no ID da relação b2b2 não pode ser explicado por uma preferência B2. Isto porque este índice é calculado considerando as relações corretas e incorretas que têm B2 como S2 [b2b2 / (b2b2 + b1b2)], de modo que uma preferência por B2 resultaria em um índice próximo ao nível do acaso (número de bicadas semelhante nas combinações positivas e negativas). $\mathrm{O}$ aumento no ID de uma relação neste estudo reflete um responder discriminado, ou seja, maior número de bicadas para um S2 quando antecedido pelo S1 relacionado (no caso, relação b2b2) e menor número de bicadas ao mesmo S2 quando antecedido pelo S1 não relacionado (no caso, b1b2). Para este sujeito o IET após as combinações negativas chegou a ser aumentado até 60 segundos entre as sessões 51 e 94 (ver Figura 5). A partir da sessão 95 o IET retornou ao menor valor (entre 5 e 10 segundos), sendo aumentado gradativamente a partir daí, até alcançar 40 segundos ao final do treino. A razão pela qual o IET foi novamente reduzido na sessão 95 será esclarecida mais adiante. 
P03
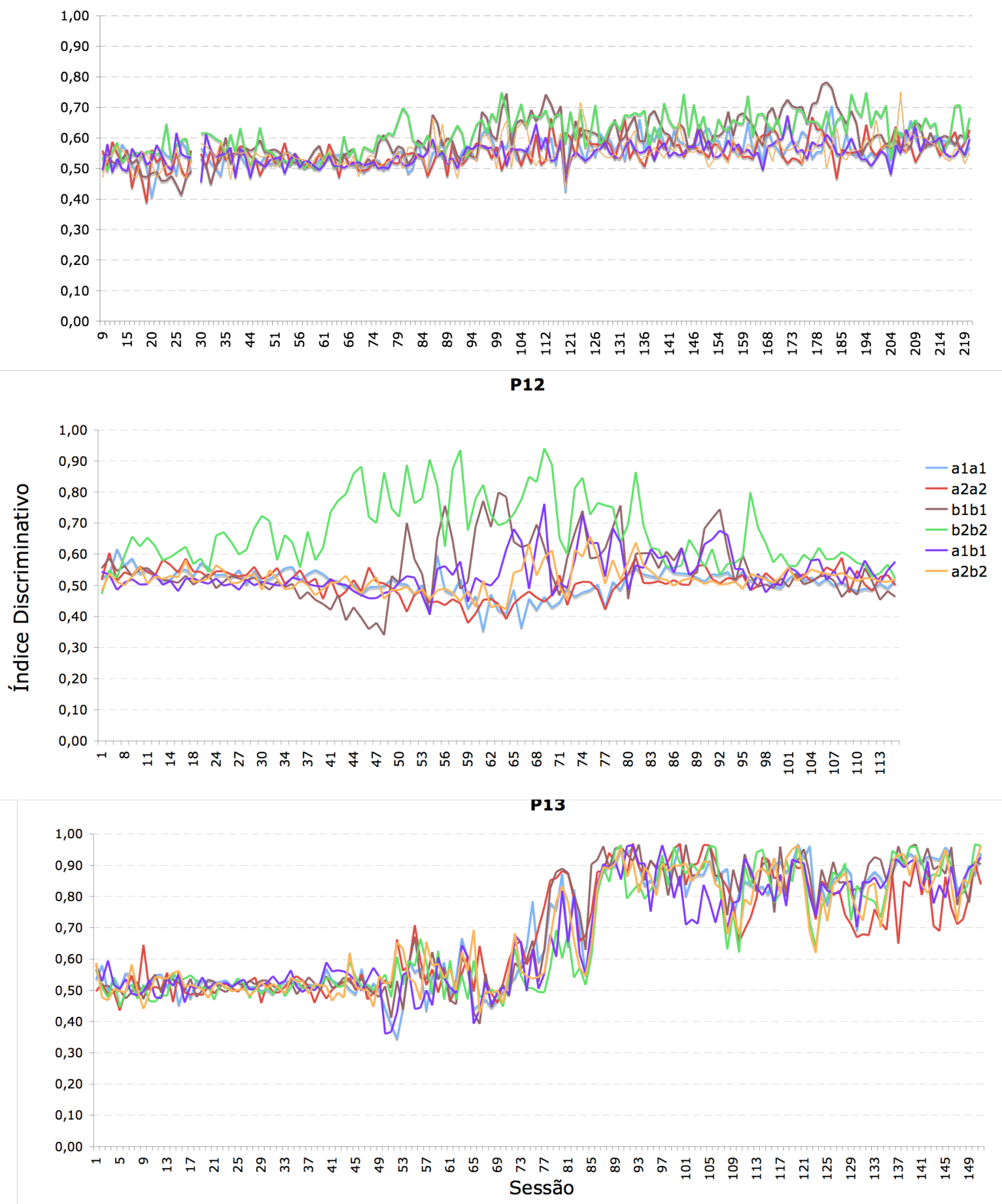

Figura 4 - Índice discriminativo por relação ao longo em cada sessão de treino realizada pelos sujeitos do Experimento I. Os gráficos apresentam apenas os dados das sessões finalizadas.

O sujeito P12 também não apresentou uma curva progressiva de aquisição das relações treinadas. Entretanto, para algumas relações (b1b1, b2b2 e alb1), apresentou aumento significativo do índice discriminativo ao longo de 44 sessões de treino (da sessão 39 à 82). Porém, esse aumento não era estável e os índices discriminativos voltaram ao nível do acaso a 
partir da sessão 83. A relação b2b2 é a que chama maior atenção para este sujeito, já que alcançou os maiores índices discriminativos, mantendo-se entre 0,70 e 0,90 por 31 sessões (da sessão 39 à 69). A partir da sessão 70 teve início uma queda gradual do índice discriminativo para esta relação. O IET foi aumentado até 25 segundos neste período do treino em que houve melhora no desempenho. Quando o IET foi aumentado em mais cinco segundos na sessão 84, variando entre 25 e 30 segundos, o desempenho de P12 praticamente se estabilizou ao nível do acaso. Ao final do treino este sujeito estava com IET variando entre 50 e 55 segundos nas tentativas de combinação negativa, mas ele manteve o desempenho ao nível do acaso.

Não está claro a que se deve a melhora de desempenho de P12 entre as sessões 39 e 82 e nem a razão pela qual os índices discriminativos não se mantiveram altos. A única modificação que ocorreu no procedimento, para este sujeito, foi o aumento do IET das tentativas de combinação negativa sempre que deixava de ocorrer melhora no desempenho por no mínimo três sessões consecutivas. Aparentemente, o IET acima de 25 segundos foi o responsável pela estabilização do responder ao nível do acaso para todas as relações, mas não foi encontrada uma explicação para tal fato nas análises de dados realizadas.

Os dados de P12 também não são explicados por preferência por estímulos, pela mesma razão apresentada para o sujeito P03. Como a fórmula de cálculo do ID só considera o mesmo estímulo como S2, o aumento do ID reflete um aumento na discriminação de estímulos. Diferente dos outros dois sujeitos, entretanto, P12 emitia consistentemente 30\% menos bicadas para A2 e B2 como S2 do que para A1 e B1, independente da combinação, entre as sessões 37 e 49. Esse dado demonstraria preferência por A1 e B1, mas não altera o fato de que P12 respondia diferencialmente diante de B2 como S2. Essa diferença entre as freqüências de resposta foi reduzindo gradativamente a partir da sessão 50 , deixando de existir para este sujeito até o final do treino.

A Figura 5 apresenta as taxas de resposta média para as combinações positivas e negativas de linha de base (relações $\mathrm{AB}$ ) e teste (relações BA) do sujeito P13, nas quatro sessões de teste. Na porção inferior da figura são apresentadas as taxas médias das quatro sessões. Os valores das taxas médias por combinação e os valores de erro padrão são apresentados na Tabela 5. 
Tabela 5 - Taxa de respostas média e erro padrão das combinações de estímulos de linha de base e de teste das sessões de teste do sujeito P13 e da média das quatro sessões.

\begin{tabular}{|c|c|c|c|}
\hline & Combinação de estímulos & Taxa de resposta média & Erro padrão \\
\hline \multirow{4}{*}{ Teste 1} & Positiva de linha de base & 3,08 & 0,18 \\
\hline & Negativa de linha de base & 0,66 & 0,38 \\
\hline & Positiva de teste & 2,47 & 0,55 \\
\hline & Negativa de teste & 2,14 & 1,08 \\
\hline \multirow{4}{*}{ Teste 2} & Positiva de linha de base & 3,11 & 0,16 \\
\hline & Negativa de linha de base & 0,59 & 0,08 \\
\hline & Positiva de teste & 2,63 & 0,35 \\
\hline & Negativa de teste & 1,35 & 0,81 \\
\hline \multirow{4}{*}{ Teste 3} & Positiva de linha de base & 2,80 & 0,06 \\
\hline & Negativa de linha de base & 0,53 & 0,00 \\
\hline & Positiva de teste & 2,33 & 0,27 \\
\hline & Negativa de teste & 1,11 & 0,37 \\
\hline \multirow{4}{*}{ Teste 4} & Positiva de linha de base & 2,81 & 0,00 \\
\hline & Negativa de linha de base & 0,47 & 0,07 \\
\hline & Positiva de teste & 1,73 & 1,27 \\
\hline & Negativa de teste & 0,85 & 0,45 \\
\hline \multirow{4}{*}{$\begin{array}{c}\text { Média } \\
\text { Teste 1-4 }\end{array}$} & Positiva de linha de base & 2,95 & 0,08 \\
\hline & Negativa de linha de base & 0,56 & 0,04 \\
\hline & Positiva de teste & 2,29 & 0,20 \\
\hline & Negativa de teste & 1,36 & 0,28 \\
\hline
\end{tabular}

Pode-se observar que P13 apresentou maior taxa de respostas para as combinações positivas de linha de base e teste, em todas as sessões. Porém, seu desempenho foi variável entre as sessões. A variação entre as taxas de respostas de linha de base das quatro sessões é pequena, sendo a diferença entre a maior e menor taxa de 0,31 respostas por segundo para as combinações positivas e de 0,19 respostas por segundo para as combinações negativas. Já entre as sessões de teste há maior variabilidade, com diferença de 0,90 respostas por segundo para combinações positivas e de 1,29 respostas por segundo para as combinações negativas. 

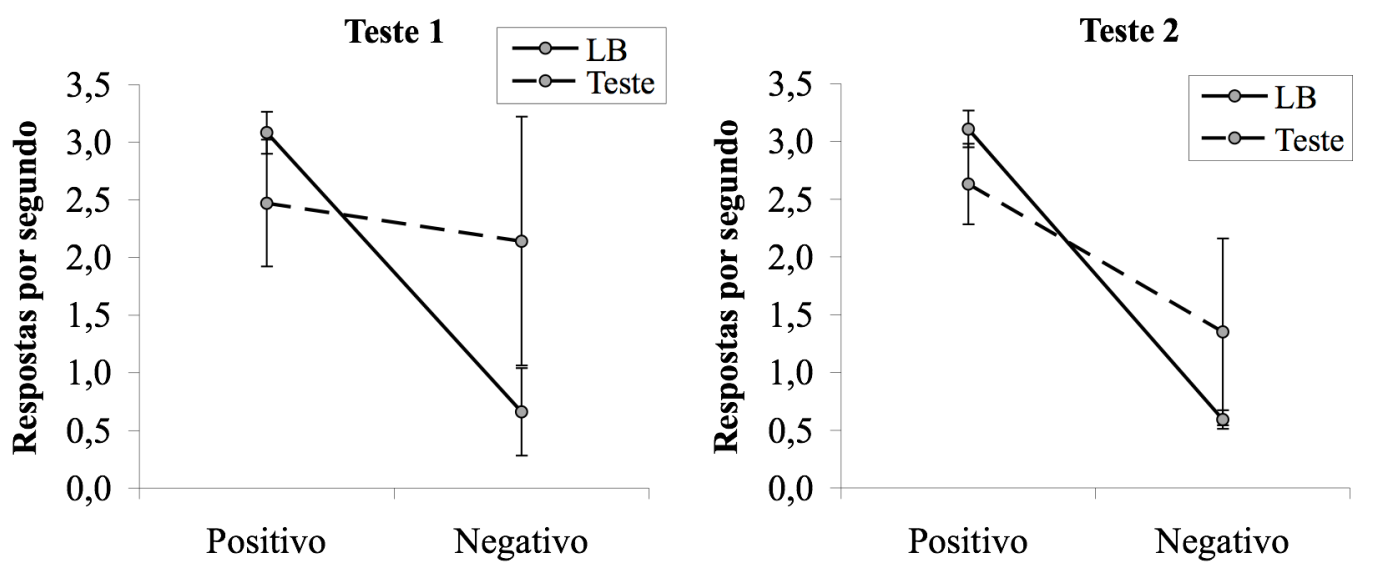

Teste 3
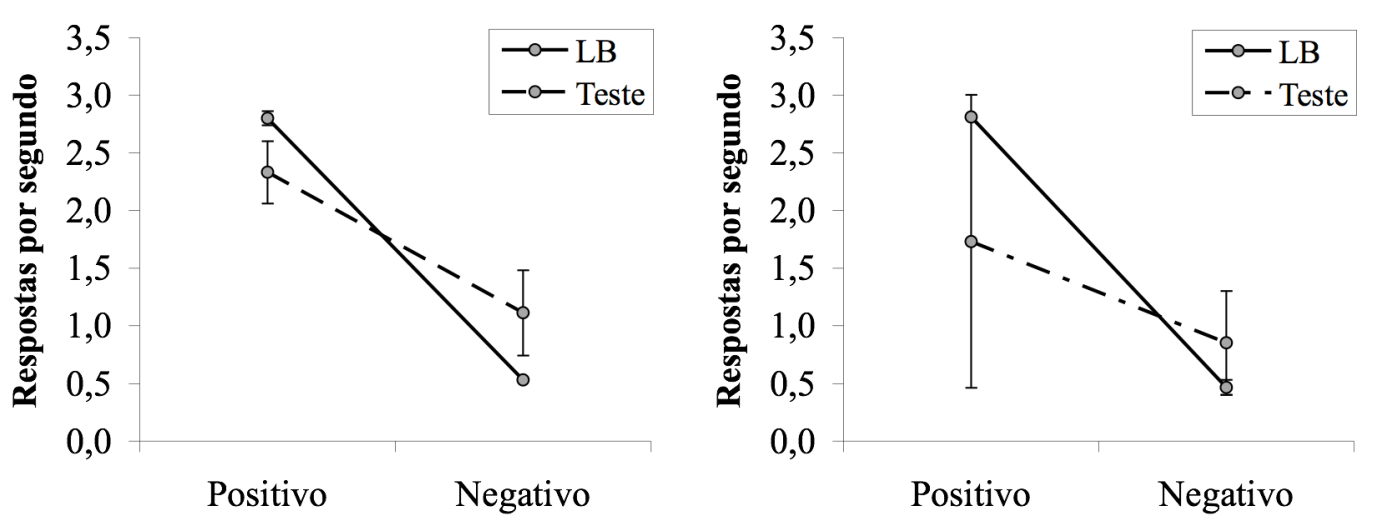

Média Teste 1-4

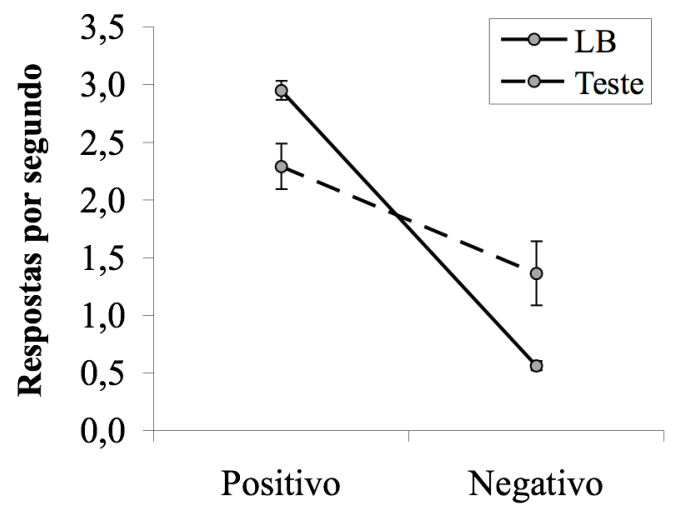

Figura 5 - Taxa de respostas média das combinações positivas e negativas de linha de base $(\mathrm{AB})$ e teste $(\mathrm{BA})$ para as quatro sessões de teste do sujeito P13. O gráfico na porção inferior da figura apresenta a média das taxas das quatro sessões.

A primeira sessão de teste apresentou a menor diferença entre as taxas das combinações positivas e negativas (0,33 respostas por segundo), com taxas mais próximas à taxa da combinação positiva de linha de base, indicando um responder próximo ao nível do acaso para as combinações de teste. Na segunda e terceira sessão de teste, P13 apresenta taxas de respostas próximas entre as tentativas de linha de base e teste. Embora a diferença entre as 
combinações positivas e negativas de linha de base seja maior do que a diferença entre as combinações de teste nestas duas sessões, a diferença apresentada no teste indica emergência de simetria. Na quarta sessão de teste pode-se observar uma diferença entre as taxas de respostas das combinações positivas e negativas de teste menor do que da segunda e terceira sessões, mas consideravelmente maior do que da primeira sessão de teste, o que poderia indicar simetria emergente.

O último gráfico da Figura 5 apresenta a média de todas as sessões de teste. Este gráfico é apresentado para que se possa fazer a comparação dos dados com os dados dos estudos de Frank e Wasserman (2005), Frank (2007) e Urcuioli (2008), que apresentaram os dados médios de todas as sessões de teste. Pode-se notar neste gráfico a diferença entre as taxas de respostas das combinações positivas e negativas de teste. Mesmo sendo uma diferença menor do que das combinações de linha de base, esta diferença poderia ser considerada indicativa de simetria. Pode-se dizer por este gráfico, que os dados de P13 replicam os dados apresentados por Frank e Wasserman (2005), embora com diferenças maiores entre linha de base e teste do que o estudo anterior. A diferença entre as taxas de respostas médias das combinações positivas e negativas de teste de P13 também são maiores do que as observadas no estudo de Urcuioli (2008). Mas a que se devem as diferenças entre os dados do presente estudo e dos dois anteriores?

Em seu estudo, Urcuioli (2008) havia levantado alguns aspectos do procedimento, que poderiam ser responsáveis pela grande diferença entre os dados obtidos por ele e os obtidos por Frank e Wasserman (2005). Valeria a pena avaliar estes fatores, considerando os dados de P13.

Um primeiro ponto era o de que os pombos do estudo de Frank e Wasserman (2005) apresentavam menor taxa de respostas do que os do estudo de Urcuioli (2008), o que poderia favorecer taxas de respostas semelhantes entre linha de base e teste. Isto porque os pombos de seu estudo respondiam nas tentativas de teste com taxas menores do que nas tentativas de linha de base. Os dados de P13 apresentam taxa de respostas intermediárias em comparação com os dois estudos anteriores. Como este sujeito teve desempenho melhor que os pombos de Urcuioli (2008), mas inferior ao dos pombos do estudo de Frank e Wasserman (2005), é possível que a hipótese de Urcuioli (2008) esteja correta. Entretanto, seria preciso replicar a taxa de respostas obtida por Frank e Wasserman (2005) para comprovar este ponto.

Os outros pontos do procedimento que, segundo Urcuioli (2008), seriam responsáveis pelas diferenças entre seu estudo e o de Frank e Wasserman (2005) eram o tempo de apresentação dos estímulos (5 segundos X 10 segundos), o IET utilizado (fixo X variável), o 
tipo de estímulo (simples $\mathrm{X}$ complexo) e o aparato de registro de respostas (chave de respostas $\mathrm{X}$ tela sensível ao toque). $\mathrm{O}$ presente estudo tem todos esses aspectos em comum com o estudo de Frank e Wasserman (2005), utilizando, inclusive, os mesmos estímulos. Apesar disso, os dados de P13 não são tão robustos como os do estudo anterior, indicando que os aspectos apontados por Urcuioli (2008) podem favorecer o desempenho emergente, mas não garantem que este desempenho seja praticamente idêntico à linha de base.

É preciso lembrar que não se tem acesso a todos os detalhes sobre o teste de simetria realizado no estudo de Frank e Wasserman (2005), já que os autores não descreveram como eram os IETs da sessão de teste e nem se o estímulo das tentativas de teste desaparecia sozinho ou dependia de uma resposta do sujeito. É possível, portanto, que diferenças entre as sessões de teste dos estudos sejam, ao menos em parte, responsáveis pelos resultados distintos.

Até este ponto, foram apresentados e discutidos os dados de teste com base nas médias entre as relações de linha de base e teste e entre sessões. Como já foi dito anteriormente, médias de desempenho podem distorcer os dados, e esta foi uma das críticas feitas aos estudos anteriores que utilizaram o mesmo procedimento do presente estudo. A partir de agora, serão analisados os dados de cada relação de linha de base e teste, em cada sessão de teste.

A Figura 6 apresenta a taxa de respostas nas combinações positivas e negativas de linha de base e teste para cada relação, em cada sessão de teste do sujeito P13. As combinações de linha de base mantêm o mesmo padrão nas sessões, com taxa de respostas semelhante entre as combinações positivas e negativas de ambas as relações (a1b1 e a2b2), de tal forma que as retas que representam essas taxas chegam a se sobrepor na terceira e quarta sessão. Já as combinações de teste apresentam grande variabilidade entre as sessões.

$\mathrm{Na}$ primeira sessão de teste, observa-se uma grande diferença entre as taxas de resposta apresentadas por P13 para a relação b1a1 e b2a2, bem como entre essas relações e as de linha de base. A relação bla1 apresenta taxa de respostas das combinações negativas um pouco superior a das combinações positivas, ambas com alta taxa de respostas, indicando responder indiscriminado. A relação b2a2 apresenta uma diferença evidente entre a taxa de respostas das combinações positivas e negativas, o que indica a possível emergência dessa relação.

Na segunda e terceira sessão de teste ambas as relações testadas apresentam diferença visível entre as taxas de respostas das combinações positivas e negativas. Entretanto, é possível notar diferenças entre as taxas de respostas das duas relações testadas. Na segunda sessão (Teste 2) a relação b2a2 apresenta taxas mais próximas das taxas de linha de base e a 
relação bla1 apresenta uma menor diferença entre as taxas das combinações positivas e negativas do que as demais relações (linha de base e teste). Já na terceira sessão (Teste 3), o resultado é o oposto: b1a1 apresenta taxas de respostas praticamente idênticas às das relações de linha de base, enquanto que b2a2 apresenta uma menor diferenças entre suas taxas de respostas nas combinações positivas e negativas.

Teste 1

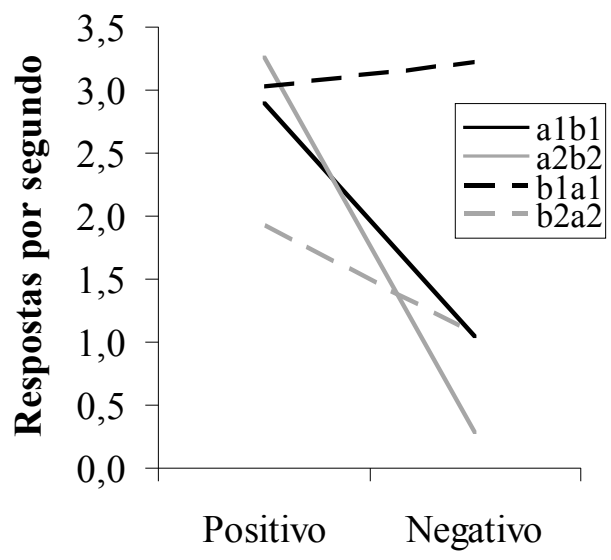

Teste 3

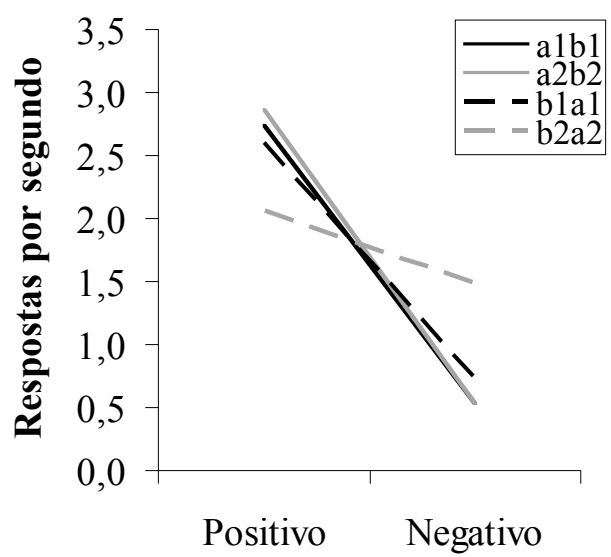

Teste 2

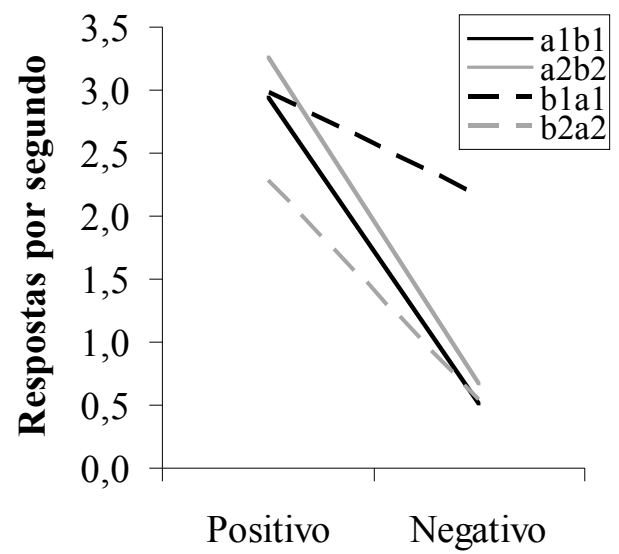

Teste 4

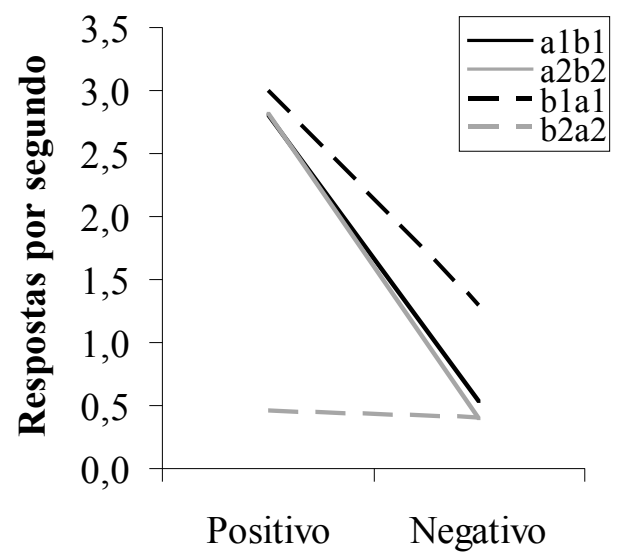

Figura 6 - Taxa de respostas nas combinações positivas e negativas de linha de base (AB) e teste (BA), para cada relação, das quatro sessões de teste do sujeito P13.

$\mathrm{Na}$ quarta sessão de teste $\mathrm{b} 2 \mathrm{a} 2$ continua apresentando taxas mais próximas às das relações de linha de base. Já a relação bla1 praticamente não apresenta diferença entre as taxas das combinações positivas e negativas, com taxas de respostas baixas, semelhantes as taxas das combinações negativas de linha de base.

Os dados apresentados na Figura 6 apontam um desempenho variável entre sessões e entre as relações testadas. Ambas as relações de teste apresentaram um aumento na diferença entre as taxas de resposta das combinações positivas e negativas da primeira para a segunda sessão, mas nas sessões seguintes o responder de P13 diante da relação b2a2 foi se tornando 
indiferenciado, até que, na quarta sessão, este sujeito emitia poucas respostas diante dessa combinação de estímulos. Já diante de bla1, P13 apresentou um aumento no responder diante das combinações positivas e uma redução diante das combinações negativas.

Ao se comparar os dados apresentas na Figura 6 com as médias apresentadas na Figura 5 , nota-se que, para todas as sessões de teste, o desempenho médio distorce o dado. No caso de P13, cada relação BA apresentou um padrão diferente da outra relação a cada sessão. No caso da primeira e da quarta sessão, enquanto uma relação apresentou diferença clara entre as taxas de repostas das combinações positivas e negativas, a outra relação apresentou um responder indiferenciado. Esta diferença entre as relações b1a1 e b2a2 fica oculta quando se considera a taxa de respostas média das duas relações, apresentada na Figura 5. Já no caso da segunda e terceira sessão de teste, seria possível dizer que a taxa de respostas média representa o dado obtido em ambas as relações BA (taxas maiores para as combinações positivas e menores para as negativas), mas não é possível observar com este dado (Figura 5) que ocorre uma inversão de taxas entre as duas relações BA nestas duas sessões, que irá se manter na sessão seguinte.

Até aqui foram apresentados e discutidos dados sob a forma de taxa de respostas. Entretanto, o presente estudo também critica o uso exclusivo dessa medida para avaliar relações emergentes, já que geralmente se utilizada o índice discriminativo na grande maioria dos estudos na área de equivalência.

A Figura 7 apresenta os índices discriminativos das relações de linha de base (AB) e teste (BA) ao longo das sessões do sujeito P13. São apresentados ainda os índices das sessões de treino que antecederam e seguiram as sessões de teste. Nesta figura, é possível observar que a linha de base (representada na Figura 7 pelas linhas preta e cinza) se manteve estável, com ID acima de 0,80 , ao longo das sessões, à exceção de uma pequena queda no ID da relação a1b1, na primeira sessão de teste. Já as relações testadas (representadas pelos círculos preto e cinza) constantemente apresentaram índices inferiores à linha de base. Estes índices variaram, entre 0,81 e 0,48 , sendo que apenas três dos oito índices discriminativos foram superiores a 0,70: relação b2a2 no Teste 2 (ID de 0,81 ); relação b1a1 no Teste 3 (ID de 0,78 ) e no Teste 4 (ID de 0,70). Os demais índices discriminativos foram inferiores à 0,64.

Observa-se, ainda, nesta figura uma diferença quanto à relação de teste com maior e menor ID a cada sessão. Nas primeiras duas sessões de teste, a relação b2a2 apresentou índices maiores que a relação b1a1. Ocorreu o oposto na terceira e quarta sessão de teste. Esta inversão entre os índices discriminativos das relações de teste decorre do fato de que houve uma melhora gradual da discriminação de P13 diante da relação b1a1 desde a primeira sessão, 
enquanto que há uma queda no índice discriminativo da relação b2a2 após a segunda sessão de teste, até o índice de 0,53. Exceto pela quarta sessão de teste, na qual P13 emitiu poucas respostas diante das combinações positivas e negativas da relação b2a2, não foi constatada preferência por estímulos nas sessões de teste.

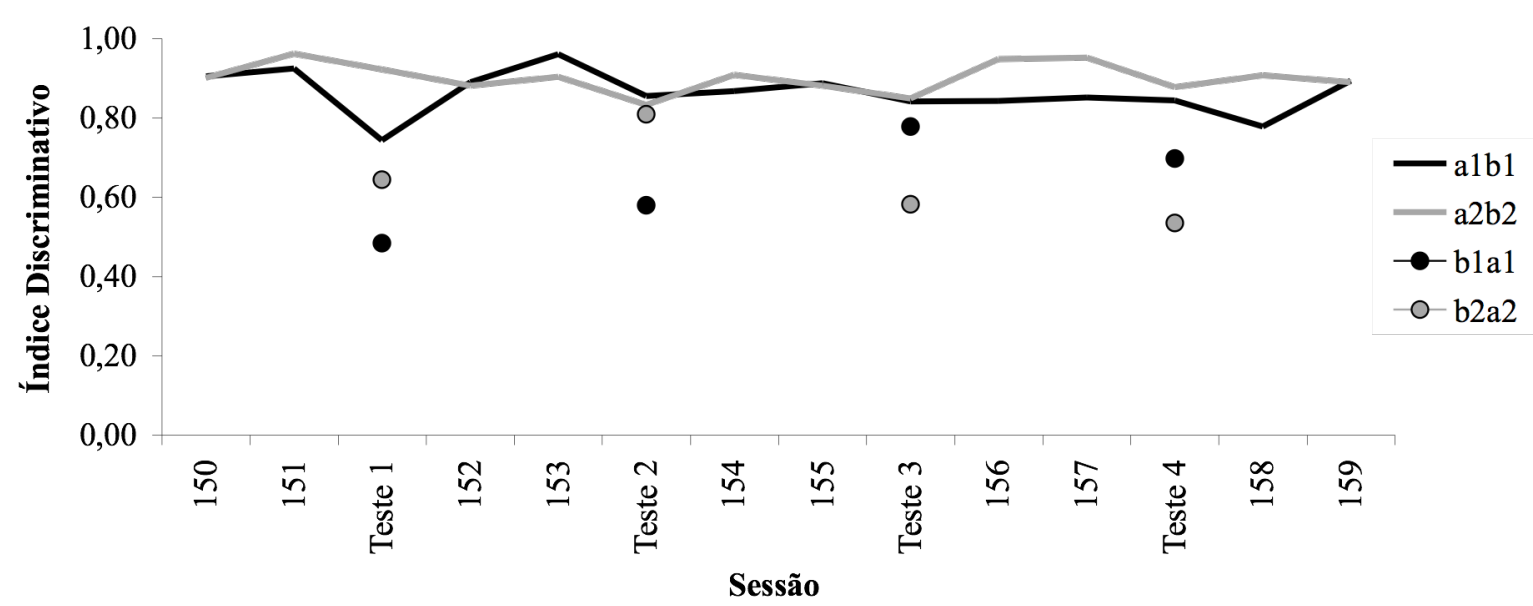

Figura 7 - Índice discriminativo por relação de linha de base e teste nas sessões de teste e nas sessões de treino anteriores e posteriores aos testes do sujeito P13.

Embora tenham ocorrido poucas sessões com ID acima de 0,70 para as relações testadas, é possível avaliar esse desempenho como indicativo de simetria emergente. $\mathrm{O}$ fato de ter havido variabilidade entre as sessões não invalida o dado de que houve responder discriminado para a relação b2a2 na segunda sessão de teste e para a relação b1a1 na terceira e quarta sessão. É preciso, entretanto, buscar compreender os fatores relacionados a esta variabilidade, para que se possa restringi-la em estudos futuros.

O aumento do ID da relação b1a1 a cada sessão, bem como o aumento do ID da relação b2a2 na segunda sessão de teste, pode indicar uma emergência atrasada (Sidman, 1994) destas relações. Já a queda nos índices da relação b2a2 pode decorrer da extinção, já que tentativas de teste nunca eram seguidas de reforço. Entretanto, nenhuma afirmação pode ser feita sobre as quedas e aumentos dos índices discriminativos das relações testadas, já que estamos falando em mudanças que ocorreram durante duas ou três sessões. Talvez a variabilidade nos resultados dos testes seja efeito do procedimento utilizado no treino e no teste. Como apenas um sujeito do Experimento I chegou à fase de teste, também é possível que os resultados obtidos tenham relação com especificidades deste sujeito.

O desempenho instável de P13 nos testes, evidente nas Figuras 5, 6 e 7, levanta algumas questões a respeito do procedimento utilizado neste estudo e dos critérios que devem 
ser usados para afirmar que houve emergência de relações após um dado treino discriminativo.

O problema dos testes realizados em extinção tem sido recorrente na literatura da área de equivalência, tanto em estudos realizados com animais não humanos como nos realizados com pessoas com atraso no desenvolvimento cognitivo (Galvão, Calcagno, \& Sidman, 1992; Schusterman \& Kastak, 1993). Embora procedimentos alternativos de teste venham sendo estudados (reforçamento não diferencial, reforço diferencial de relações consistentes e inconsistentes etc.), cada um delas apresenta seus problemas. $\mathrm{O}$ procedimento de teste empregado no presente estudo, por um lado, minimiza os efeitos da extinção sobre os testes, na medida em que inclui poucas tentativas de teste em meio a muitas tentativas de linha de base na sessão. Entretanto, não é possível descartar o efeito da ausência de reforçamento sobre as relações testadas, sendo este um provável fator relacionado à variabilidade de desempenho observada nos testes de P13. Se uma relação aparece com alto ID neste tipo de teste, é esperado que esse índice caia ao longo dos testes se ele nunca é seguido de reforço. Já o aumento do ID ao longo das sessões, apesar dos testes em extinção, pode dar mais força à afirmação de que houve emergência daquela relação, já que o responder discriminado se manteve ou melhorou mesmo na ausência de reforçamento.

Os dados de teste de P13 foram apresentados de várias formas neste estudo: taxa de respostas média por sessão e das quatro sessões (Figura 5); taxa de respostas por relação e por sessão (Figura 6); índice discriminativo por relação ao longo das sessões (Figura 7). Embora a variabilidade de desempenho estivesse presente em todas as figuras, cada uma delas permitia uma análise diferente do desempenho de P13 nos testes. Os dados da Figura 5 indicavam emergência robusta de simetria em algumas sessões e evidência moderada na média entre as sessões. Os dados da Figura 6 indicavam diferenças entre as relações a cada sessão, com dados robustos de simetria emergente em três sessões (Testes 2, 3 e 4) para pelo menos uma relação testada, dados de simetria moderada para uma relação de teste também em três sessões (Testes 1, 2 e 3) e dados de responder indiferenciado para uma relação em duas sessões (Teste 1 e 4). Já a Figura 7 indicou possível emergência de simetria para uma única relação em três sessões (Testes 2, 3 e 4). Lembrando que, nas Figuras 6 e 7, fica claro que a relação que evidencia simetria emergente muda entre as sessões.

Tantas possibilidades de análise dos resultados dos testes levantam a questão sobre qual seria a melhor medida indicativa de relações emergentes. O que se conclui com base nos dados de P13 é que o índice discriminativo ainda parece ser a melhor medida. A Figura 7 apresentou a mesma variabilidade de dados apresentada pela Figura 6. A diferença principal 
se encontra na forma como os dados podem ser interpretados. O uso de taxas de resposta nas combinações positivas e negativas de teste, como o da Figura 6, além de exigir uma série de medidas estatísticas de significância, induz uma análise favorável à emergência das relações por conta da forma de apresentação dos dados. Uma linha inclinada, com maior taxa na combinação positiva de teste, mesmo que não se sobreponha às linhas das combinações de linha de base, leva o leitor a concluir que há um claro responder discriminado, indicativo de simetria emergente. Frank (2007) denominou este padrão das taxas de "simetria moderada" ou até de "clara evidência de simetria" a depender das medidas estatísticas de significância. Urcuioli (2008), apenas denominou todas as diferenças entre taxas de "simetria" (Experimento 3) ou de "anti-simetria" (Experimento 4), também com uso de medidas estatísticas.

Quando se toma o índice discriminativo como medida não se fazem necessários os cálculos estatísticos, pois o ID já é uma medida relativa, baseada na freqüência de respostas do sujeito nas tentativas corretas e incorretas. Essa medida já indica o tamanho da diferença entre respostas incorretas e corretas ou, no caso deste procedimento, entre respostas nas combinações positivas e negativas de linha de base e teste. O índice discriminativo não conduz o leitor a uma conclusão equivocada do dado. Ou o sujeito apresentou responder discriminado para a relação testada ou não. Um ID de 0,64 não é indicativo de "simetria moderada". Esse valor de ID no máximo indica uma tendência de responder mais diante da combinação positiva de estímulos, mas esta só seria comprovada por um aumento no índice nas sessões seguintes.

Como foi dito anteriormente, talvez os dados variáveis nos testes do sujeito P13 se devam a características do procedimento. Foi colocada a questão do teste realizado em extinção como possível explicação desta variabilidade. Dado que apenas este sujeito chegou à fase de teste, é preciso avaliar também características do procedimento de treino que possam estar relacionadas à aquisição das relações de identidade e arbitrária de linha de base. Caso sejam identificadas variáveis de controle relevantes, será possível refinar o procedimento em estudos futuro, garantindo a aprendizagem de todos os sujeitos experimentais. A partir deste ponto serão descritos e analisados dados obtidos ao longo das sessões de treino dos três sujeitos do Experimento I. Primeiramente serão descritos os dados relativos à definição dos parâmetros do procedimento utilizado neste estudo, para depois serem descritos outros dados do treino que possam contribuir neste sentido.

Os parâmetros do procedimento empregado nesta pesquisa foram estabelecidos com base na coleta de dados realizada com dois pombos do Experimento I: P03 e P13. 
Inicialmente tentou-se fazer uma replicação direta do procedimento de treino descrito por Frank e Wasserman (2005) com estes sujeitos, mas, como não houve aumento nos índices discriminativos, foram realizadas algumas mudanças de parâmetros que resultaram no procedimento descrito no presente estudo, utilizado para todos os demais sujeitos experimentais. Essas alterações serão descritas a seguir.

Como nem todos os parâmetros do estudo de Frank e Wasserman (2005) foram claramente descritos, foi preciso fazer algumas suposições, como, por exemplo, qual seria o tamanho do estímulo apresentado e sua localização na tela. Assim sendo, os pombos P03 e P13 iniciaram o treino com estímulos constituídos por um quadrado branco de $7 \mathrm{X} 7 \mathrm{~cm}$ com um desenho de 5 X $5 \mathrm{~cm}$ no centro. O intervalo entre S1 e S2 também era o mesmo utilizado no referido estudo (3,5 segundos) e o estímulo era apresentado exatamente no centro da tela sensível (a aproximadamente $14 \mathrm{~cm}$ do piso da caixa).

Após 51 sessões, P13 não apresentou qualquer melhora de desempenho, tendo índices discriminativos em torno de 0,50 para todas as seis relações treinadas, mesmo com o aumento do IET para as tentativas incorretas alcançando 60 segundos. P03 apresentou um desempenho semelhante, mas, por ter iniciado o treino mais tarde, realizou apenas 18 sessões com este procedimento, das quais metade foram incompletas (sessões de 1 a 8 e sessão 10).

Com base nestes dados, optou-se por alterar parâmetros do procedimento até que fossem observados aumentos nos índices discriminativos. Cinco alterações foram feitas para isto. Foi realizada uma modificação de cada vez, sendo que a alteração subseqüente ocorria se, após um mínimo de três sessões, não ocorresse melhora no desempenho dos sujeitos. Em ordem, os parâmetros modificados foram: 1) redução no tamanho dos estímulos de 5 X $5 \mathrm{~cm}$ para 2,5 X 2,5 cm, mantendo o quadrado branco com $7 \mathrm{~cm}$ de lado; 2) redução do intervalo entre $\mathrm{S} 1$ e S2 de 3,5 para 0,5 segundos; 3) redução do quadrado branco no qual o estímulo era apresentado para $4 \times 4 \mathrm{~cm}$, mantendo o estímulo bem no centro da tela (a aproximadamente $14 \mathrm{~cm}$ do piso da caixa); 4) acréscimo de um feedback sonoro (um "bip") para cada bicada dentro da área do estímulo; 5) aumento da altura do estímulo na tela, colocando-o a $21 \mathrm{~cm}$ do piso da caixa.

A Figura 8 apresenta os mesmos dados da Figura 4 (índice discriminativo por relação ao longo do treino), mas apresenta cada mudança de parâmetro realizada com P03 e P13, indicando a sessão em que a alteração ocorreu (marcada pela linha tracejada). Para facilitar a visualização das mudanças de desempenho após cada alteração de parâmetro, o gráfico do sujeito P13 tem início na sessão número 39 nesta figura. 


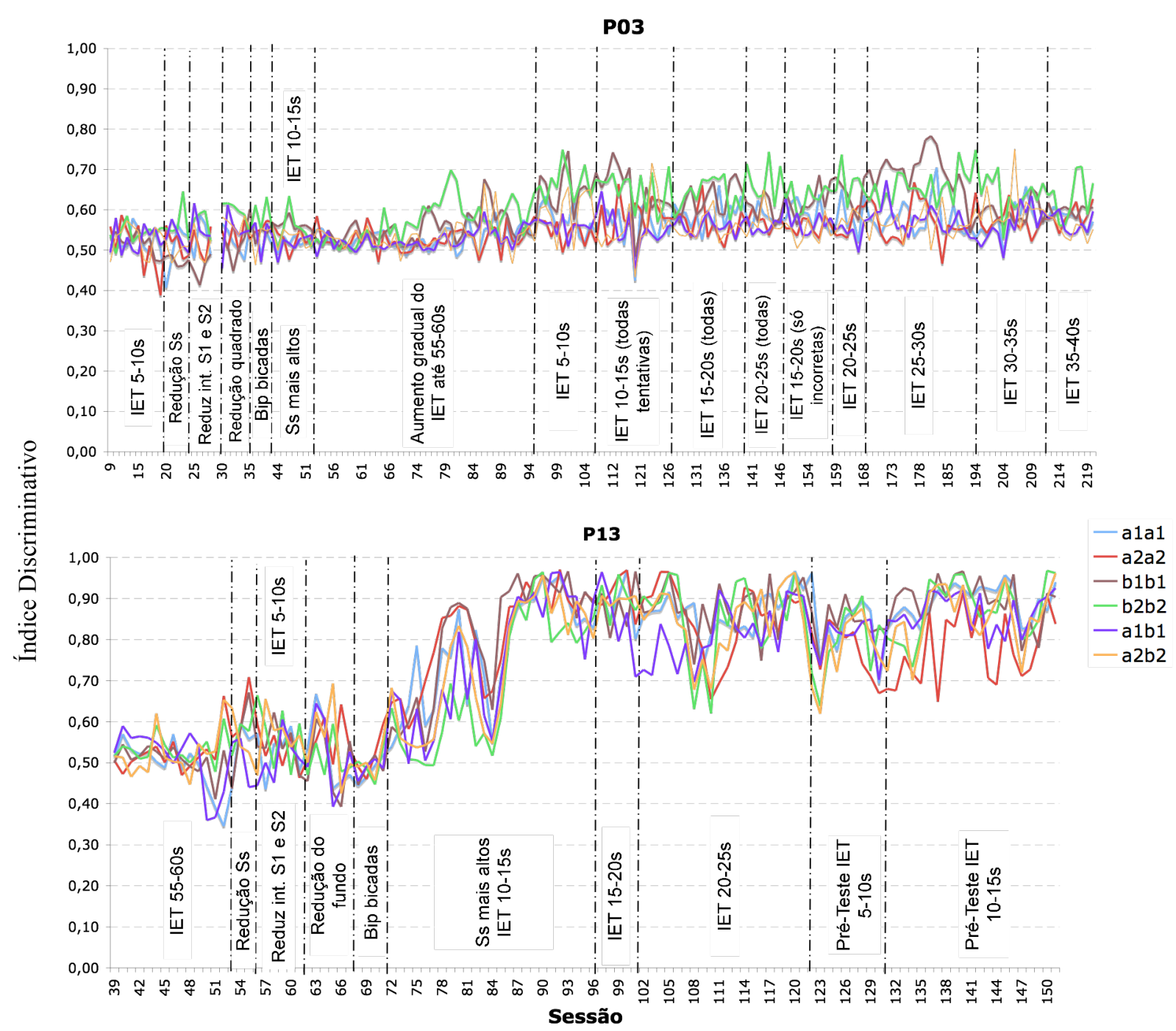

Figura 8 - Índice discriminativo por relação ao longo do treino para os sujeitos P03 e P13. As linhas tracejadas marcam as sessões em que ocorreram mudanças de parâmetros do procedimento. A mudança realizada é descrita logo após cada marca.

Pode-se observar que o sujeito P03 não apresentando melhora no desempenho após as alterações de procedimento (a última alteração foi realizada na sessão 37 para este sujeito). Mesmo com o subseqüente aumento do IET das tentativas incorretas, que chegou a variar entre 55 e 60 segundos, apresentou desempenho praticamente estável, com índices discriminativos em torno de 0,50 para todas as relações em quase todas as sessões. Como o aumento do IET para este sujeito foi ocorrendo em conjunto com as mudanças de parâmetros do procedimento, optou-se por reduzir novamente o IET das combinações negativas ao menor valor (entre 5 e 10 segundos), aumentando-o gradativamente conforme descrito anteriormente.

O pombo P13 apresentou maior variabilidade no responder desde a primeira mudança de parâmetros do procedimento (redução do tamanho do estímulo - sessão 52), mas só foi 
observada uma clara melhora de desempenho após a última modificação (aumento na altura dos estímulos para $21 \mathrm{~cm}$ acima do piso da caixa - sessão 71), quando o IET das tentativas incorretas variava entre 10 e 15 segundos. Apesar da melhora de desempenho ter ocorrido apenas com um dos dois sujeitos, optou-se por utilizar o mesmo procedimento com os outros quatro pombos, que iniciaram a coleta posteriormente.

Como a igualação dos IETs para o sujeito P13 não levou a deterioração do desempenho discriminado previamente adquirido, cogitou-se a possibilidade de utilizar este procedimento (aumento gradual dos IETs tanto para combinações positivas como negativas de estímulos) com o sujeito P03 na fase de aquisição, pois, assim, não seria necessário realizar a fase de igualação dos IETs antes do teste (pré-teste). Este procedimento foi realizado da sessão 94 à 157 (Figura 5) do sujeito P03 até alcançar IET variável entre 20 e 25 segundos para todas as tentativas (corretas e incorretas). Como nenhuma alteração de desempenho foi observada, decidiu-se retomar o IET diferente entre tentativas corretas e incorretas, já que os dados da literatura (Frank, 2007; Frank e Wasserman, 2005) mostravam que este procedimento tinha bons resultados.

Outra mudança de procedimento, não apresentada na Figura 8, foi realizada com base na análise dos dados de P03 e P13. Inicialmente, o software utilizado na coleta de dados só registrava as respostas que ocorressem dentro da área do quadrado branco onde os estímulos eram apresentados. Observações assistemáticas das sessões de treino desses sujeitos, entretanto, indicavam que ambos bicavam majoritariamente na beirada do quadrado, ou seja, na região onde a cor branca do quadrado se contrapunha a cor preta do fundo da tela (área de maior contraste). Mesmo após as modificações de parâmetros já descritas (redução no tamanho dos estímulos, bip para as bicadas etc.) esse padrão de respostas se manteve. Como este poderia ser um fator relacionado ao desempenho instável de P13, passou-se a computar as bicadas ao redor do quadrado branco (que agora tinha $4 \times 4 \mathrm{~cm}$ ), em uma margem de aproximadamente $0,5 \mathrm{~cm}$, para, posteriormente, avaliar se seria relevante considerar tais respostas na análise de dados. Porém, como este registro era meramente exploratório, as bicadas nesta área não foram consideradas respostas válidas, ou seja, não faziam parte da contingência programada (não produziam reforço) e, por conseguinte, não eram consideradas no cálculo dos índices discriminativos. Esse registro das repostas na margem do estímulo ocorreu entre as sessões 49 e 122 para P03 e da sessão 85 em diante para P13.

Foi constatado que P03 bicava entre 7 e 47\% das vezes na margem ao redor do estímulo, em todas as tentativas (corretas ou incorretas). Como a porcentagem de bicadas na margem era semelhante para as combinações positivas e negativas das sessões, os índices 
discriminativos desse sujeito eram os mesmos, considerando ou não as bicadas fora do quadrado branco. Já o sujeito P13 bicava entre 30 e 60\% das vezes na margem do estímulo nas tentativas corretas e entre 10 e $40 \%$ nas incorretas. A diferença entre as porcentagens nas tentativas corretas e incorretas gerou uma diferença significativa entre os índices discriminativos considerando apenas as repostas dentro da área do estímulo e considerando também as respostas na margem de $0,5 \mathrm{~cm}$. Ao se considerar também as repostas ao redor do estímulo, observou-se uma menor variabilidade nas curvas de aquisição de P13, além de índices discriminativos que, em média, eram superiores em 0,10 (variando entre 0,05 e 0,15) aos índices calculados com base apenas nas respostas dentro da área do estímulo. Caso o critério de acertos do treino se baseasse nestes índices, P13 teria alcançado o mesmo já na sessão 88 (33 sessões antes do que ocorreu ao se considerar apenas as bicadas na área do estímulo).

Aparentemente, as respostas ao redor do estímulo ocorrem devido a uma imprecisão das bicadas dos pombos. Ao se considerar apenas as bicadas dentro da área do estímulo como sendo respostas válidas, é possível que se esteja lidando com dados distorcidos, já que o percentual de bicadas ao redor do estímulo é consideravelmente alto (até 60\% para P13 e até $40 \%$ para P03). Com base nestes dados, decidiu-se considerar as bicadas ao redor do estímulo como sendo bicadas válidas, ou seja, como tendo o mesmo efeito que as bicadas dentro da área do estímulo. Isto ocorreu a partir da sessão 123 do sujeito P03 e para todos os demais sujeitos deste estudo desde o início da coleta. Esta mudança não foi feita apenas para P13, já que ele já se encontrava na fase de teste. Para todos os sujeitos foi mantido registro das bicadas na margem do estímulo em separado para análises futuras.

Com todas as mudanças de parâmetros realizadas com P03 e P13 imaginava-se ter chegado a um procedimento que propiciasse a aprendizagem das relações discriminativas para todos os sujeitos. Entretanto, como visto na Figura 4, apenas P13 chegou à fase de teste no Experimento I. Esse fato indica a necessidade de análises mais detalhadas do desempenho dos três sujeitos no treino, com o intuito de compreender semelhanças e diferenças que possam estar associadas à aprendizagem das discriminações condicionais.

Conforme descrito no método, o software utilizado nesta pesquisa registrava alguns dados além da freqüência de respostas para S1 e S2. Eram registradas as latências de respostas para todos os estímulos, a duração de S1 e S2 e freqüência de respostas por segundo para S1 e S2. 

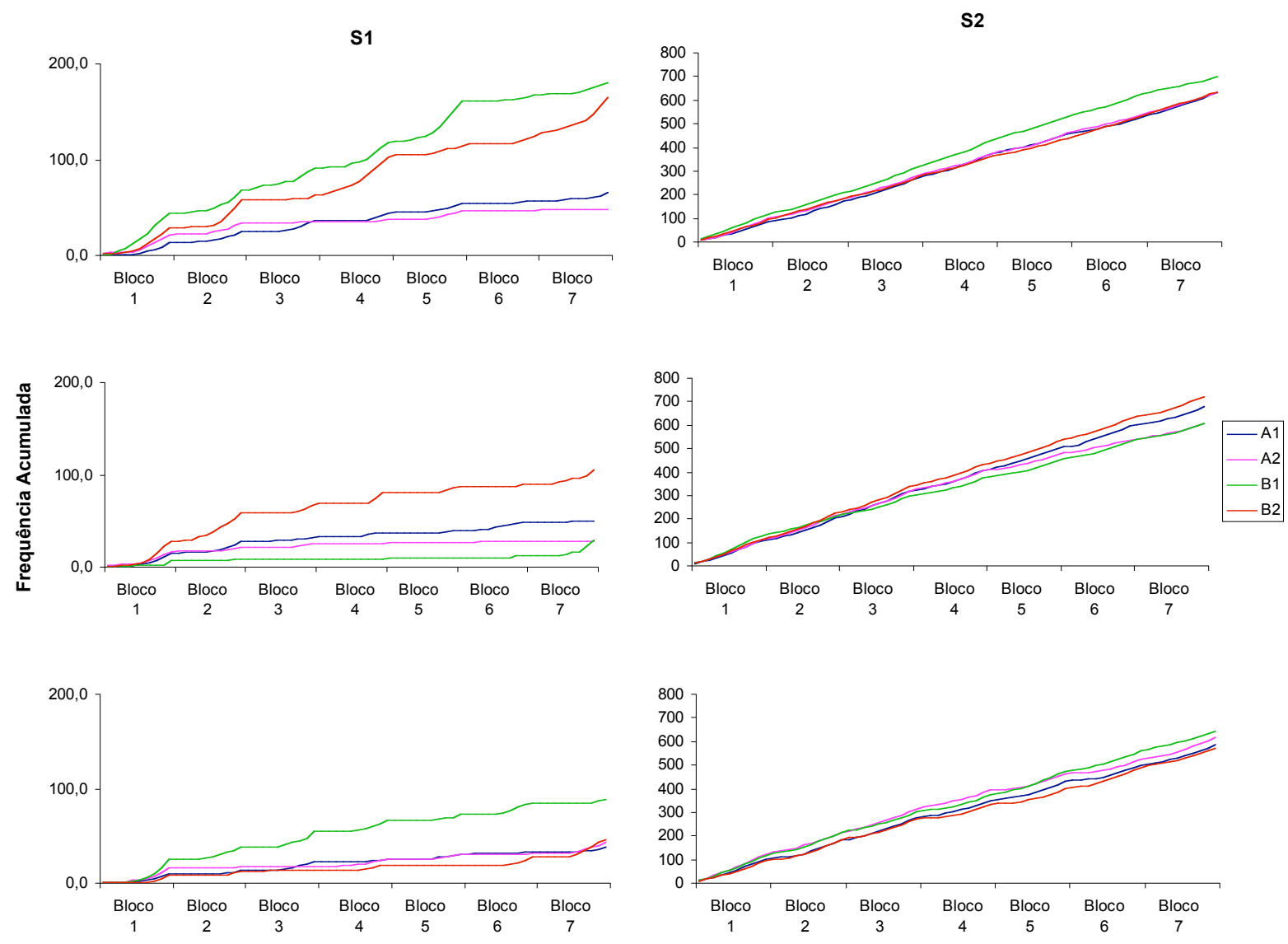

Figura 9 - Freqüência acumulada de respostas para S1 e S2 por bloco de treino nas três últimas sessões do sujeito $\mathrm{P} 03$. À esquerda são apresentados os gráficos referentes à $\mathrm{S} 1$ e à direita os referentes à S2. O eixo dos valores (Y) é diferente entre S1 e S2 para permitir a visualização dos padrões de resposta diante de cada estímulo. Os valores apresentados são proporcionais ao número de apresentações de cada estímulo como S1 ou S2.

Não foram observadas diferenças na latência de respostas para S1 e S2 entre os sujeitos, mas foi observada uma diferença na distribuição de respostas emitidas diante de S1 e S2. As Figuras 9, 10 e 11 apresentam a freqüência acumulada de respostas para S1 (porção esquerda) e S2 (porção direita) por bloco de treino nas três últimas sessões dos sujeitos P03 e P12 e nas últimas três sessões antes do início da aquisição das discriminações para o sujeito P13, respectivamente. Para cada bloco há dez valores de freqüência, correspondendo aos dez segundos de duração do estímulo. Os valores apresentados são proporcionais ao número de apresentações de cada estímulo como S1 ou S2, ou seja, os estímulos que apareciam o dobro de vezes como S1 (estímulos A1 e A2) ou S2 (estímulos B1 e B2) tiveram suas freqüências de resposta divididas por dois.

A Figura 9 mostra uma clara diferença entre as curvas de respostas acumuladas para S1 e S2 nas três últimas sessões de treino realizadas por P03. Este sujeito apresenta um responder marcado por longas pausas diante do $\mathrm{S} 1$ em todas as sessões, característico do 
esquema de intervalo fixo. Por conta destas pausas, P03 apresenta um total de respostas baixo para S1. Diferentemente, P03 apresenta um responder constante para o S2, alcançando um total de respostas muito superior ao do $\mathrm{S} 1$.

O sujeito P12 (Figura 10) também apresenta um padrão de respostas marcado por pausas diante de S1, mas estas pausas são bem mais curtas do que as apresentadas por P03. Justamente por isso, P12 alcança um total de respostas relativamente alto para este estímulo, geralmente inferior ao total de respostas para S2. O responder para S2 também é constante de praticamente sem pausas para este sujeito.
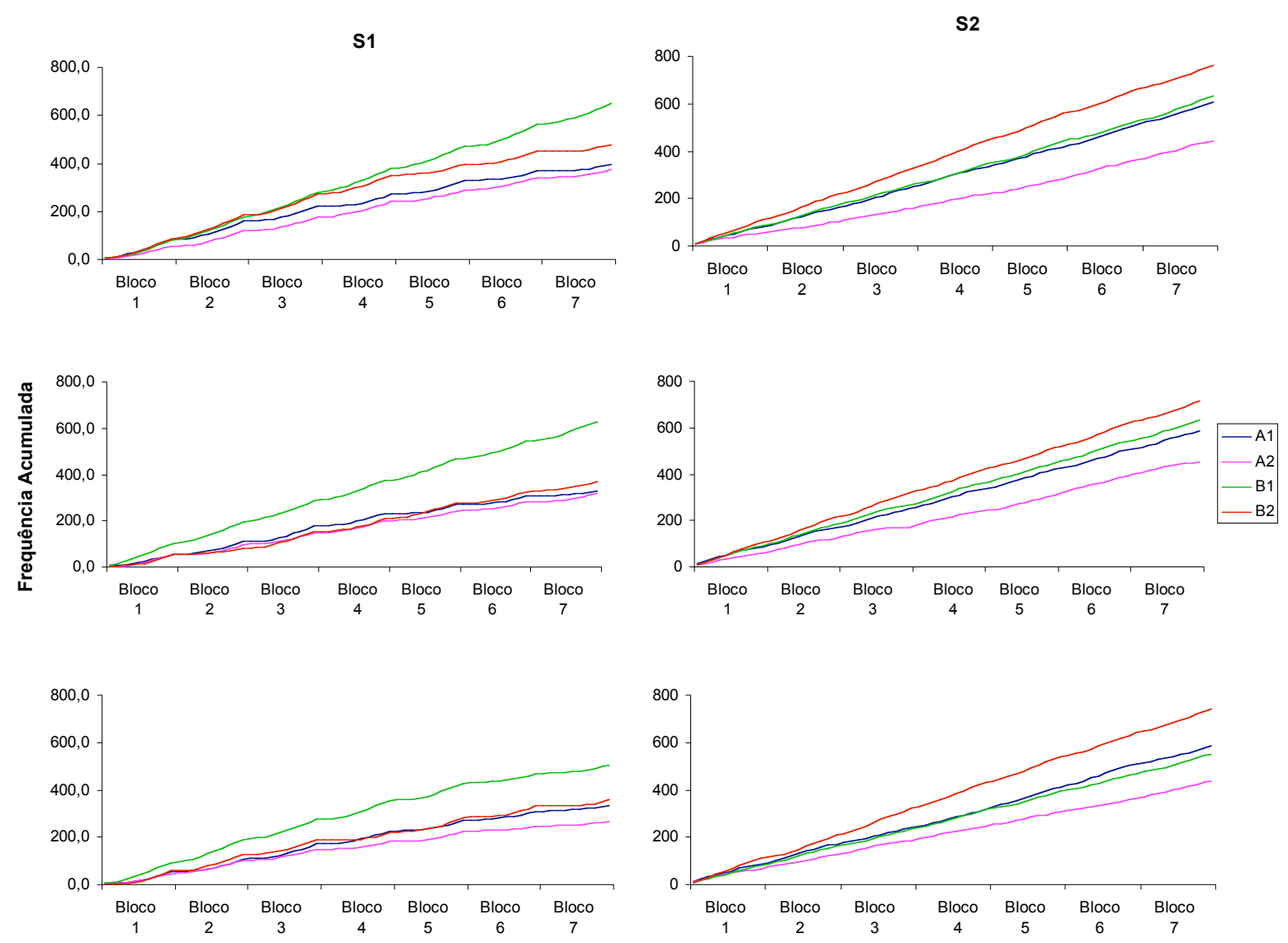

Figura 10 - Freqüência acumulada de respostas para S1 e S2 por bloco de treino nas três últimas sessões do sujeito P12. À esquerda são apresentados os gráficos referentes à $\mathrm{S} 1$ e à direita os referentes à S2. Os valores apresentados são proporcionais ao número de apresentações de cada estímulo como S1 ou S2.

Na Figura 10 é possível observar as curvas de respostas acumuladas para S1 e S2 nas três últimas sessões de treino realizadas por P13 antes do início da curva de aquisição das discriminações. Este sujeito apresenta um responder semelhante diante de S1 e S2, com uma curva de respostas marcada por poucas e curtas pausas. As pausas entre respostas para S2 são 
um pouco maiores do que para $\mathrm{S} 1$, o que talvez explique o fato desse sujeito apresentar um total de respostas maior para S1 do que para S2, diferente do que ocorreu para P03 e P12.

S1
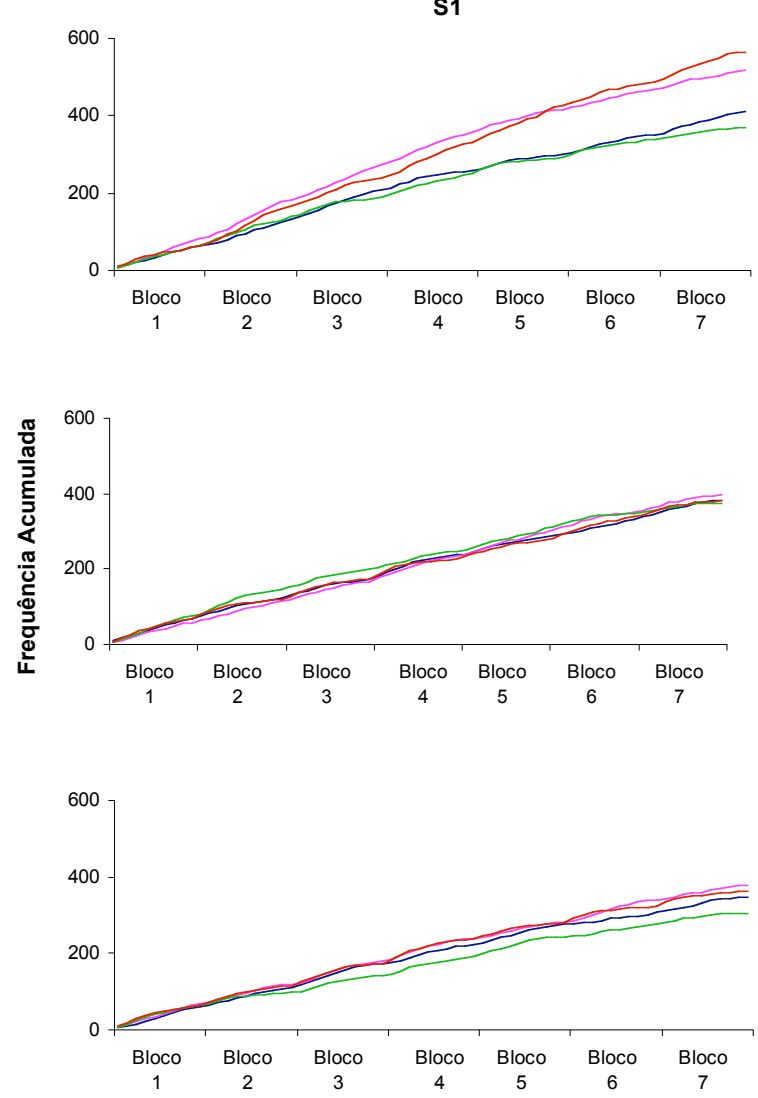

S2
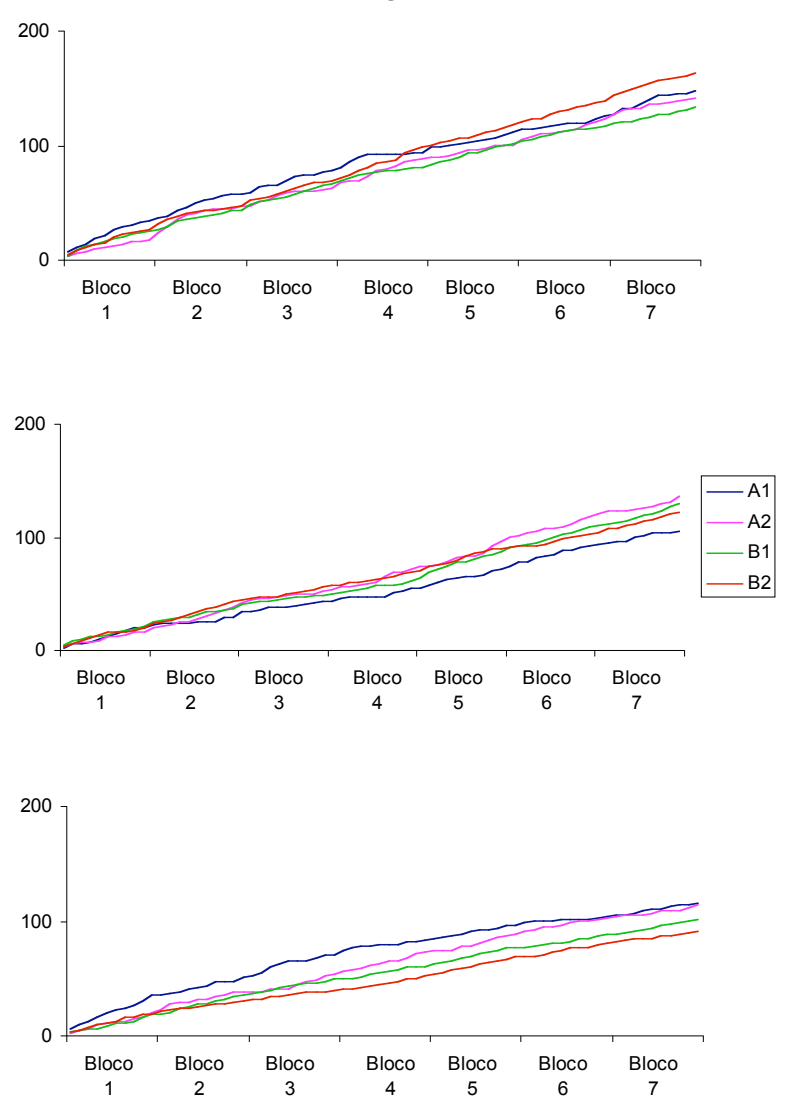

Figura 11 - Freqüência acumulada de respostas para S1 e S2 por bloco de treino nas três últimas sessões do sujeito P13, antes do início da aquisição das discriminações. À esquerda são apresentados os gráficos referentes à $\mathrm{S} 1$ e à direita os referentes à $\mathrm{S} 2$. O eixo dos valores (Y) é diferente entre S1 e S2 para permitir a visualização dos padrões de resposta diante de cada estímulo. Os valores apresentados são proporcionais ao número de apresentações de cada estímulo como $\mathrm{S} 1$ ou S2.

O padrão de respostas dos três sujeitos do Experimento I mostra diferenças que podem indicar uma variável relevante para a obtenção do responder discriminado com o procedimento de treino usado. O único pombo que chegou à fase de testes apresentou um padrão de respostas diferente dos outros dois pombos. P13 apresentou um responder como menos pausas diante de $\mathrm{S} 1$, além de ter emitido mais respostas diante de $\mathrm{S} 1$ do que diante de S2. Este dado indica que a alta freqüência de respostas, com poucas pausas, diante do S1pode ser uma variável importante na aprendizagem com este procedimento. Isto talvez ocorra porque o responder constante ao S1 implique em maior controle exercido por este estímulo sobre o responder no estímulo seguinte (S2). Em outras palavras, a freqüência constante de respostas ao S1 garantiria que o sujeito atentasse para este estímulo. 
Um responder com longas pausas indica que o sujeito responde mais sob controle da passagem do tempo, ao invés de atentar para características relevantes do S1. Urcuioli (2008) relata que os pombos que não aprenderam as relações treinadas em seus Experimentos 3 e 4, geralmente, respondiam mais ao final do intervalo de duração do estímulo (que era de cinco segundos). Aparentemente, isto também ocorreu com P03 e P12. Seria relevante, portanto, que experimentos futuros com este procedimento buscassem trabalhar com um esquema de reforçamento de altas taxas, para verificar se esta hipótese procede.

Embora apenas um sujeito tenha concluído todas as etapas do Experimento I, pode-se dizer que o objetivo proposto foi cumprido, já que os dados deste sujeito replicam os dados apresentados na literatura com o mesmo procedimento. A análise detalhada das sessões de treino e teste também indica variáveis experimentais necessárias para a aprendizagem e emergência das relações de simetria, o que também está em consonância com o objetivo geral deste trabalho. 


\title{
EXPERIMENTO II
}

\author{
MÉTODO
}

\section{$\underline{\text { Sujeitos }}$}

Três pombos adultos (P14, P15 e P20), mantidos no mesmo biotério e sob as mesmas condições dos sujeitos do Experimento I. Dois sujeitos eram experimentalmente ingênuos. O outro sujeito (P20) possuía uma história de treino com procedimento go/no-go com estímulos circulares de metades iguais ou diferentes apresentados em um monitor de tela sensível ao toque.

\section{Ambiente Experimental e Equipamentos}

O ambiente experimental e o equipamento utilizados neste experimento foram os mesmos do Experimento I.

\section{Estímulos}

Foram utilizados neste experimento os seis estímulos apresentados na Tabela 2 (Experimento I): X1, X2, X3, X4, X5 e X6. Para cada sujeito houve um sorteio específico para determinar qual dos estímulos seria denominado de A1, A2, B1, B2, C1 e C2.

Tabela 6 - Estímulos treinados para cada sujeito do Experimento II.

\begin{tabular}{ccccccc}
\hline & \multicolumn{7}{c}{ Estímulos } \\
\cline { 2 - 7 } Pombo & A1 & A2 & B1 & B2 & C1 & C2 \\
\hline P14 & X2 & X4 & X1 & X5 & X3 & X6 \\
P15 & X1 & X4 & X6 & X3 & X5 & X2 \\
P20 & X1 & X3 & X2 & X5 & X6 & X4 \\
\hline
\end{tabular}


O tamanho e a configuração dos estímulos eram os mesmos do Experimento I. A designação dos estímulos para cada sujeito é apresentada na Tabela 6 .

$\underline{\text { Procedimento }}$

Este experimento contou com as mesmas fases do Experimento I, que serão descritas a seguir.

PRÉ-TREINO:

Esta fase foi idêntica ao Experimento I.

\section{TREINO:}

Esta fase consistiu no treino misto de relações de identidade (AA, BB e CC) e arbitrárias $(\mathrm{AB})$ com procedimento de MTS sucessivo. As combinações de estímulos foram diferentes do experimento anterior para evitar o treino de reversão das combinações negativas. A configuração das tentativas era a mesma do Experimento I.

O treino realizado neste experimento consistiu no arranjo de 12 combinações referentes às relações de identidade (com estímulos dos Conjuntos A, B e C) e 4 combinações referentes ao treino de relações arbitrárias (com os estímulos dos Conjuntos A e B) em sessões de 160 tentativas, divididas em cinco blocos de 32 tentativas (duas de cada tipo de combinação). A inserção dos estímulos do Conjunto $\mathrm{C}$ no treino garantia que não fosse treinada a reversibilidade das combinações negativas nas tentativas de pareamento por identidade, ao mesmo tempo em que mantinha o equilíbrio entre o número de combinações positivas e negativas das sessões. As combinações de estímulos são apresentadas na Tabela 7.

Cada sessão de treino contava com o cálculo de oito índices discriminativos: dois as relações $\mathrm{AA}$, dois das relações $\mathrm{BB}$, dois das relações $\mathrm{CC}$ e dois das relações $\mathrm{AB}$. Para calcular o ID foi utilizada a mesma fórmula descrita no Experimento I, considerando respostas a um mesmo S2 nas combinações positivas e negativas. As combinações positivas e negativas de todas as relações entre estímulos do Experimento II são apresentadas na Tabela 8. 
Tabela 7 - Combinações de estímulos usadas nas sessões do Experimento II.

\begin{tabular}{|c|c|c|c|}
\hline & S1 & S2 & Conseqüência \\
\hline \multirow{12}{*}{ 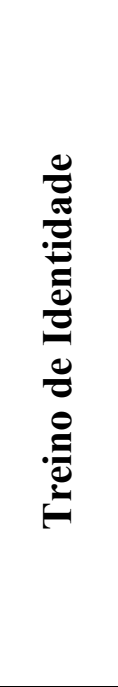 } & A1 & A1 & + \\
\hline & A1 & $\mathrm{A} 2$ & - \\
\hline & $\mathrm{A} 2$ & $\mathrm{C} 1$ & - \\
\hline & A2 & $\mathrm{A} 2$ & + \\
\hline & B1 & B1 & + \\
\hline & B1 & $\mathrm{C} 2$ & - \\
\hline & B2 & B1 & - \\
\hline & B2 & B2 & + \\
\hline & $\mathrm{C} 1$ & $\mathrm{C} 1$ & + \\
\hline & $\mathrm{C} 1$ & B2 & - \\
\hline & $\mathrm{C} 2$ & A1 & - \\
\hline & $\mathrm{C} 2$ & $\mathrm{C} 2$ & + \\
\hline \multirow{4}{*}{ 承 } & A1 & B1 & + \\
\hline & A1 & B2 & - \\
\hline & $\mathrm{A} 2$ & $\mathrm{~B} 1$ & - \\
\hline & A2 & B2 & + \\
\hline \multirow{4}{*}{ 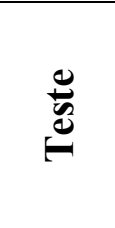 } & $\mathrm{B} 1$ & A1 & + \\
\hline & B1 & $\mathrm{A} 2$ & - \\
\hline & B2 & A1 & - \\
\hline & B2 & $\mathrm{A} 2$ & + \\
\hline
\end{tabular}

O critério para encerramento da fase de treino foi o mesmo do Experimento I (índice discriminativo de 0,80 para todas as relações, por três sessões consecutivas). Caso o desempenho do sujeito se estabilizasse abaixo do critério, o IET das tentativas de combinação negativa era aumentado da mesma forma descrita no Experimento I.

PRÉ-TESTE:

A fase de pré-treino foi conduzida de forma idêntica ao Experimento I.

\section{TESTE:}

A sessão de teste era constituída por todas as tentativas de linha de base mais as quatro combinações de teste de simetria (BA) apresentadas na porção identificada pela palavra "Teste" na Tabela 7. As conseqüências para as tentativas de linha de base e teste foram programadas da mesma forma que ocorreu nos testes do Experimento I. 
Tabela 8 - Combinações positivas e negativas de todas as relações do Experimento II.

\begin{tabular}{ccc}
\hline $\begin{array}{c}\text { Relação entre } \\
\text { Estímulos }\end{array}$ & $\begin{array}{c}\text { Combinação } \\
\text { Positiva }\end{array}$ & $\begin{array}{c}\text { Combinação } \\
\text { Negativa }\end{array}$ \\
\hline $\mathrm{a} 1 \mathrm{a} 1$ & $\mathrm{a} 1 \mathrm{a} 1$ & $\mathrm{c} 2 \mathrm{a} 1$ \\
$\mathrm{a} 2 \mathrm{a} 2$ & $\mathrm{a} 2 \mathrm{a} 2$ & $\mathrm{a} 1 \mathrm{a} 2$ \\
$\mathrm{~b} 1 \mathrm{~b} 1$ & $\mathrm{~b} 1 \mathrm{~b} 1$ & $\mathrm{~b} 2 \mathrm{~b} 1$ \\
$\mathrm{~b} 2 \mathrm{~b} 2$ & $\mathrm{~b} 2 \mathrm{~b} 2$ & $\mathrm{c} 1 \mathrm{~b} 2$ \\
$\mathrm{c} 1 \mathrm{c} 1$ & $\mathrm{c} 1 \mathrm{c} 1$ & $\mathrm{a} 2 \mathrm{c} 1$ \\
$\mathrm{c} 2 \mathrm{c} 2$ & $\mathrm{c} 2 \mathrm{c} 2$ & $\mathrm{~b} 1 \mathrm{c} 2$ \\
$\mathrm{a} 1 \mathrm{~b} 1$ & $\mathrm{a} 1 \mathrm{~b} 1$ & $\mathrm{a} 2 \mathrm{~b} 1$ \\
$\mathrm{a} 2 \mathrm{~b} 2$ & $\mathrm{a} 2 \mathrm{~b} 2$ & $\mathrm{a} 1 \mathrm{~b} 2$ \\
$\mathrm{~b} 1 \mathrm{a} 1$ & $\mathrm{~b} 1 \mathrm{a} 1$ & $\mathrm{~b} 2 \mathrm{a} 1$ \\
$\mathrm{~b} 2 \mathrm{a} 2$ & $\mathrm{~b} 2 \mathrm{a} 2$ & $\mathrm{~b} 1 \mathrm{a} 2$ \\
\hline
\end{tabular}

A sessão de teste consistiu de 180 tentativas, distribuídas da seguinte forma: um bloco inicial de 16 tentativas (uma de cada combinação de treino); quatro blocos de 36 tentativas (duas de cada combinação de treino e uma de cada combinação de teste); um bloco final de 20 tentativas (uma de cada combinação de treino e teste). Deste modo o número de tentativas de teste por sessão foi o mesmo do Experimento I.

Todas as tentativas da sessão de teste tiveram IET igual ao da última sessão de préteste. Para cada sessão de teste foram calculados dez índices discriminativos: os oito índices referentes às relações de linha de base, mais os dois índices das relações de teste (relações BA).

Caso não ocorresse deterioração do desempenho nas tentativas de linha de base na sessão de teste, outra sessão de teste era realizada na seqüência. Caso contrário, o treino era retomado até nova obtenção de uma sessão com índice discriminativo de no mínimo 0,80 para todas as relações. Então, uma nova sessão de teste era realizada. Este procedimento foi repetido até completar quatro sessões de teste. 


\section{RESULTADOS E DISCUSSÃO}

Primeiramente serão apresentados os dados do treino dos três sujeitos que participaram deste experimento. A Tabela 9 apresenta o total de sessões realizadas por cada pombo, bem como quantas dessas sessões não foram concluídas. Pode-se verificar que dois sujeitos (P14 e P15) realizaram mais de 90 sessões. P20 realizou 66 sessões. O sujeito P14 deixou de completar apenas uma sessão, enquanto que P15 e P20 não completaram 16 e 10 sessões, respectivamente. O tempo de sessão variou entre uma hora e meia e três horas neste experimento e P15 apresentava as maiores latências de resposta nas sessões.

Tabela 9 - Número de sessões de treino realizadas e sessões não finalizadas para cada sujeito na fase de aquisição das discriminações condicionais do Experimento II.

\begin{tabular}{ccc}
\hline & \multicolumn{2}{c}{ Sessões de Treino } \\
\cline { 2 - 3 } Sujeito & Total de Sessões & Sessões Incompletas \\
\hline P14 & 98 & 01 \\
P15 & 91 & 16 \\
P20 & 66 & 10 \\
\hline
\end{tabular}

A Figura 12 apresenta os índices discriminativos de cada sujeito na fase de treino. Nesta figura são apresentados apenas os dados das sessões que foram concluídas, já que as sessões não finalizadas geralmente apresentavam índices muito diferentes dos obtidos nas sessões finalizadas.

O que se observa na Figura 12 é que apenas um sujeito (P14 - porção superior da figura) apresentou uma clara curva de aquisição das relações treinadas, concluindo o treino após 98 sessões. Após o início do processo de aquisição das discriminações (sessão 18), este pombo apresentou grande variabilidade no desempenho, com aumentos seguidos de queda nos índices discriminativos para todas as relações. Por exemplo, entre as sessões 26 e 35 houve um gradual aumento nos índices discriminativos da relação ala1, seguido por uma queda que se manteve até a sessão 65, quando o ID voltou a apresentar aumento gradual. 

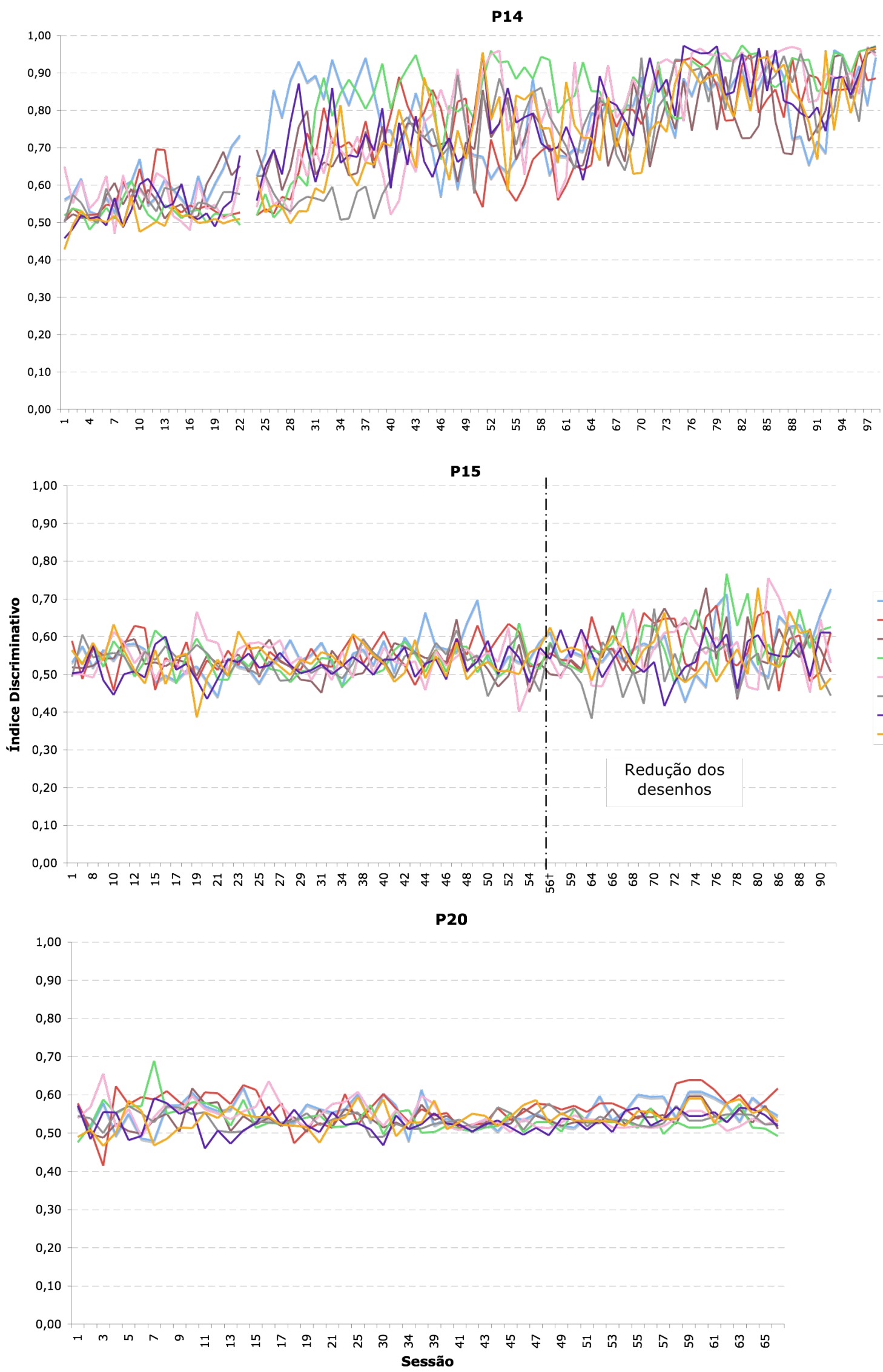

Figura 12 - Índice discriminativo por relação ao longo em cada sessão de treino realizada pelos sujeitos do Experimento II. Os gráficos apresentam apenas os dados das sessões finalizadas. 
Em decorrência da instabilidade no desempenho de P14 desde o início da aquisição das discriminações o IET das tentativas incorretas (combinações negativas de estímulos) foi gradativamente aumentado, visando atingir o critério de três sessões consecutivas com índices discriminativos mínimos de 0,80 . Foi observada uma gradativa redução na variabilidade dos índices discriminativos a cada aumento de IET. Quando o IET das combinações negativas variou entre 35 e 40 segundos (sessões 88 a 95) P14 atingiu o critério de encerramento do treino, com responder estável para todas as relações. Teve início, então, a fase de igualação dos IETs para todas as tentativas de treino (pré-teste), começando com um intervalo intermediário ao IET das combinações positivas e negativas de treino, que variava entre 15 e 20 segundos. Como P14 manteve a estabilidade no desempenho nas três sessões com mesmo IET (da sessão 95 a 98), passou para a fase de teste.

Diferentemente de P14, os outros dois pombos não apresentaram uma clara curva de aquisição das relações treinadas. P15 apresentou um pequeno aumento nos índices discriminativos das últimas sessões de treino (da sessão 66 à sessão 87), mas sem qualquer estabilidade ou progressão, raramente apresentando índices superiores a 0,70. Para este sujeito o IET das combinações negativas chegou a variar entre 35 e 40 segundos. Não foi encontrado um padrão de responder que indicasse preferência por estímulos para este sujeito.

Pode ser observado na Figura 12 que ocorreu uma alteração de procedimento no treino de P15 a partir da sessão 56. Como este sujeito não apresentou melhora de desempenho após 55 sessões, o tamanho dos estímulos foi reduzido em 0,5 centímetros para este sujeito, passando a medir aproximadamente $2,0 \times 2,0 \mathrm{~cm}$. O tamanho do quadrado no qual os estímulos eram apresentados não foi alterado. Após esta alteração de procedimento observouse um aumento na variabilidade dos índices discriminativos para este sujeito, sem haver clara melhora de desempenho. O aumento dos índices discriminativos citado anteriormente só foi observado após o aumento do IET das combinações negativas de treino em mais 10 segundos.

O sujeito P20 não apresentou qualquer indício de aprendizagem ao longo do treino. Foram raras as vezes em que um ID esteve acima de 0,60 , como no caso da relação ala1 nas sessões 58, 59 e 60. O IET após das combinações negativas de estímulos chegou a variar entre 45 e 50 segundos para este sujeito.

A Figura 13 apresenta as taxas de resposta média para as combinações positivas e negativas de linha de base (relações $\mathrm{AB}$ ) e teste (relações BA) do sujeito P14, nas quatro sessões de teste. Na porção inferior da figura são apresentadas as taxas médias das quatro sessões. Os valores das taxas médias por combinação e os valores de erro padrão são apresentados na Tabela 10 . 
Tabela 10 - Taxa de respostas média e erro padrão das combinações de estímulos de linha de base e de teste das sessões de teste do sujeito P14 e da média das quatro sessões.

\begin{tabular}{|c|c|c|c|}
\hline & Combinação de estímulos & Taxa de resposta média & Erro padrão \\
\hline \multirow{4}{*}{ Teste 1} & Positiva de linha de base & 3,28 & 0,01 \\
\hline & Negativa de linha de base & 0,35 & 0,15 \\
\hline & Positiva de teste & 2,47 & 0,57 \\
\hline & Negativa de teste & 0,88 & 0,58 \\
\hline \multirow{4}{*}{ Teste 2} & Positiva de linha de base & 3,17 & 0,10 \\
\hline & Negativa de linha de base & 0,65 & 0,03 \\
\hline & Positiva de teste & 1,83 & 1,09 \\
\hline & Negativa de teste & 0,65 & 0,03 \\
\hline \multirow{4}{*}{ Teste 3} & Positiva de linha de base & 2,82 & 0,43 \\
\hline & Negativa de linha de base & 0,39 & 0,27 \\
\hline & Positiva de teste & 1,29 & 0,97 \\
\hline & Negativa de teste & 1,04 & 0,24 \\
\hline \multirow{4}{*}{ Teste 4} & Positiva de linha de base & 2,95 & 0,35 \\
\hline & Negativa de linha de base & 0,40 & 0,23 \\
\hline & Positiva de teste & 1,40 & 1,22 \\
\hline & Negativa de teste & 0,50 & 0,28 \\
\hline \multirow{4}{*}{$\begin{array}{c}\text { Média } \\
\text { Teste 1-4 }\end{array}$} & Positiva de linha de base & 3,06 & 0,10 \\
\hline & Negativa de linha de base & 0,44 & 0,07 \\
\hline & Positiva de teste & 1,75 & 0,27 \\
\hline & Negativa de teste & 0,77 & 0,12 \\
\hline
\end{tabular}

Pode-se observar que P14 apresentou maior taxa de respostas para as combinações positivas, tanto de linha de base como de teste, em todas as sessões. Porém, seu desempenho foi variável entre as sessões. A variação entre as taxas de respostas de linha de base é pequena entre as sessões, sendo a diferença entre a maior e menor taxa de 0,46 respostas por segundo para as combinações positivas e de 0,30 respostas por segundo para as combinações negativas. Já entre as sessões de teste há maior variabilidade entre as taxas das combinações positivas das quatro sessões, com diferença de 1,18 respostas por segundo, e uma diferença menor entre as taxas das combinações negativas, 0,54 respostas por segundo.

A primeira sessão de teste apresentou a maior diferença entre as taxas das combinações positivas e negativas de teste (1,59 respostas por segundo), com taxas mais próximas às taxas das combinações positivas e negativas de linha de base, indicando emergência de simetria. Na segunda e quarta sessão de teste, P14 apresentou taxas de respostas semelhantes, com menor diferença entre as combinações positivas e negativas de 
teste (1,18 respostas por segundo no Teste 2 e 0,90 no Teste 4). Nessas sessões, P14 apresentou taxa de respostas semelhante entre as combinações negativas de treino e teste, mas apresentou grande diferença entre as taxas de respostas nas combinações positivas (diferença de 1,34 respostas por segundo no Teste 2 e 1,55 no Teste 4). Apesar dessa maior diferença entre as combinações de treino e teste na segunda e quarta sessão de teste, a diferença entre a taxa de respostas das combinações positivas e negativas de teste pode indicar emergência de simetria. Na terceira sessão de teste a diferença entre as taxas das combinações positivas e negativas de teste é muito pequena $(0,25$ respostas por segundo), indicando a ausência de simetria.

O último gráfico da Figura 13 apresenta a média de todas as sessões de teste. Como foi dito no experimento anterior (Experimento I), este gráfico é apresentado para que se possa fazer a comparação dos dados com os dados dos estudos de Frank e Wasserman (2005), Frank (2007) e Urcuioli (2008). Pode-se notar neste gráfico a diferença entre as taxas de respostas das combinações positivas e negativas de teste. Mesmo sendo uma diferença menor do que das combinações de linha de base, esta diferença poderia ser considerada indicativa de simetria. Pode-se dizer por este gráfico, que os dados de P14 replicam os dados apresentados por Frank e Wasserman (2005), embora com diferenças maiores entre linha de base e teste do que o estudo anterior. A diferença entre as taxas de respostas médias das combinações positivas e negativas de teste de P14 também são maiores do que as observadas no estudo de Urcuioli (2008).

Como o desempenho de P14 foi semelhante ao desempenho do sujeito P13 no Experimento I do presente estudo, é possível aplicar neste caso as mesmas análises sobre as diferenças encontradas entre os dados de P14 e os dados dos estudos de Frank e Wasserman (2005) e Urcuioli (2008). Ou seja, a diferença entre os dados de P14 e os dados de Frank e Wasserman (2005) não podem ser atribuídas a parâmetros do procedimento ou ao equipamento de coleta de dados, já que o presente estudo não diferiu do anterior quanto a estes fatores. Já a hipótese de que a diferença de desempenho entre os sujeitos se deveria a diferenças entre as taxas de respostas apresentadas pelos sujeitos em cada estudo (Urcuioli, 2008) pode estar correta.

Até este ponto, foram apresentados e discutidos os dados de teste com base nas médias entre as relações de linha de base e teste e entre sessões. A partir de agora, serão analisados os dados de cada relação de linha de base e teste, em cada sessão de teste. 
Teste 1

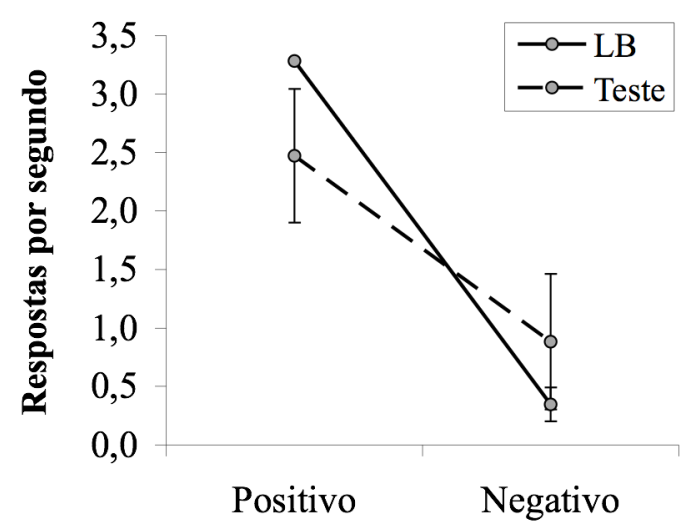

Teste 3

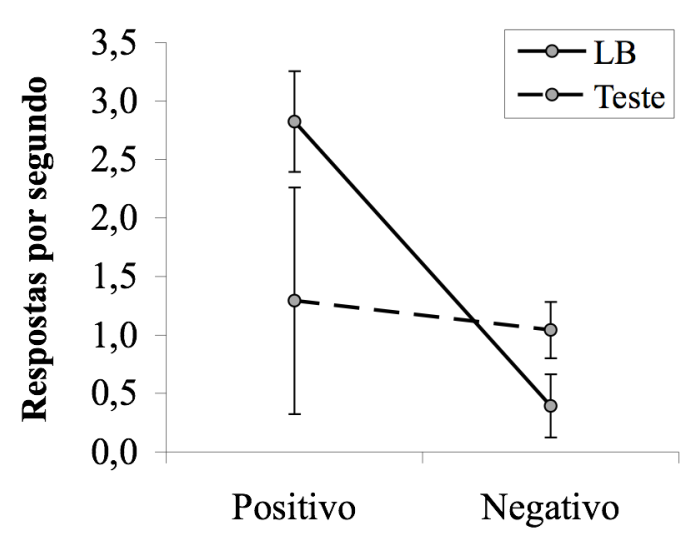

Teste 2

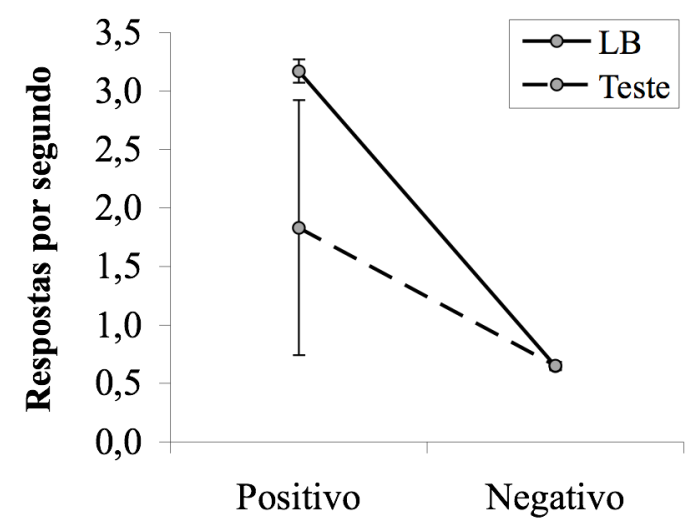

Teste 4

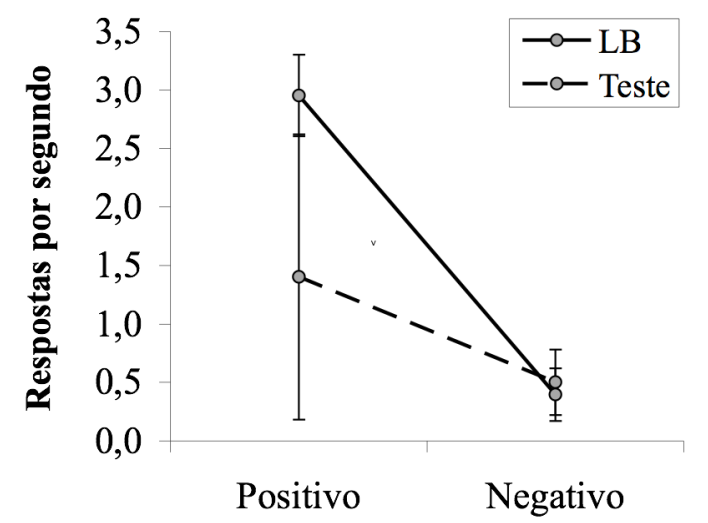

Média Teste 1-4

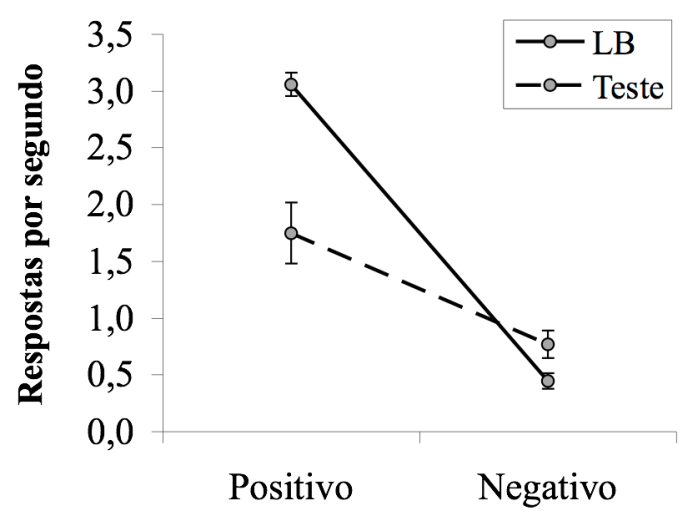

Figura 13 - Taxa de respostas média das combinações positivas e negativas de linha de base $(\mathrm{AB})$ e teste (BA) para as quatro sessões de teste do sujeito $\mathrm{P} 14$. O gráfico na porção inferior da figura apresenta a média das taxas das quatro sessões.

A Figura 14 apresenta a taxa de respostas nas combinações positivas e negativas de linha de base e teste para cada relação, em cada sessão de teste do sujeito P14 As combinações de linha de base mantêm o mesmo padrão entre a primeira e segunda sessão de teste, com taxa de respostas semelhante entre as combinações positivas e negativas de ambas as relações (a1b1 e a2b2). Ocorre, porém, uma modificação neste padrão na terceira sessão de 
teste, com redução na taxa de respostas diante das combinações positivas e aumento na taxa das combinações negativas da relação a2b2, que se mantém na última sessão de teste. Apesar dessa redução na diferença entre as taxas de respostas das combinações positivas e negativas da relação a2b2 (Testes 3 e 4), P14 ainda apresentou desempenho típico de um responder discriminado para esta relação.

Já as combinações de teste apresentam grande variabilidade entre as sessões. Na primeira sessão de teste, as relações b1a1 e b2a2 apresentam diferença semelhante entre a taxa de respostas diante da combinação positiva e negativa (diferença de 1,58 respostas por segundo para b1a1 e de 1,60 para b2a2), embora P14 tenha respondido diante das combinações de b2a2 com taxas inferiores às apresentadas diante de b1a1. Estes dados indicam emergência de simetria para ambas as relações.

$\mathrm{Na}$ segunda sessão de teste, P14 responde diante das combinações positivas e negativas da relação bla1 de forma praticamente idêntica à apresentada diante das combinações de linha de base. Já o responder diante das combinações da relação b2a2 se mostra indiferenciado, com taxas de resposta de 0,74 respostas por segundo para as combinações positivas e 0,62 para as combinações negativas. Os dados da segunda sessão de teste indicam emergência de simetria apenas para a relação b1a1.

Na terceira sessão de teste, P14 continua apresentando um responder discriminado para a relação b1a1, mas apresenta uma queda na diferença entre as taxas de respostas diante das combinações positivas e negativas em relação à sessão anterior. Já para a relação b2a2 é observada uma maior taxa de respostas diante das combinações negativas $(0,80$ respostas por segundo) do que diante das combinações positivas (0,32 respostas por segundo) nesta sessão. Os dados desta sessão indicam possível simetria apenas para a relação bla1.

$\mathrm{Na}$ quarta sessão de teste, P14 continuou emitindo poucas respostas diante das combinações positivas e negativas da relação b2a2, apresentando taxas de resposta semelhantes entre as combinações $(0,18$ e 0,22 respostas por segundo, respectivamente). Já para a relação b1a1 houve aumento na diferença entre as taxas em relação a terceira sessão de teste, apresentando taxas semelhantes às de uma das relações de linha de base (a2b2) nesta sessão. Os dados desta sessão também indicam simetria apenas para a relação bla1.

Os dados apresentados na Figura 14 apontam um desempenho variável entre sessões e entre as relações testadas. A relação bla1 apresentou diferença entre as combinações positivas e negativas em todas as sessões, com maior ou menor diferença a depender da sessão. Já a relação b2a2 apresentou maior taxa de respostas diante das combinações positivas, em 
comparação com as negativas, apenas na primeira sessão, apresentando responder indiferenciado nas sessões seguintes.

Teste 1

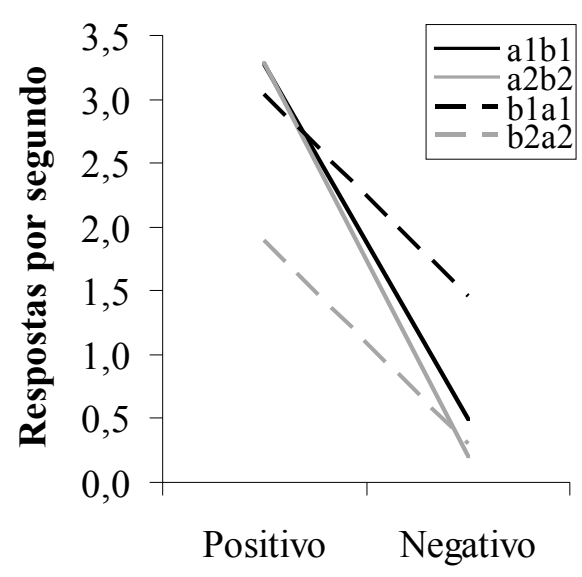

Teste 3

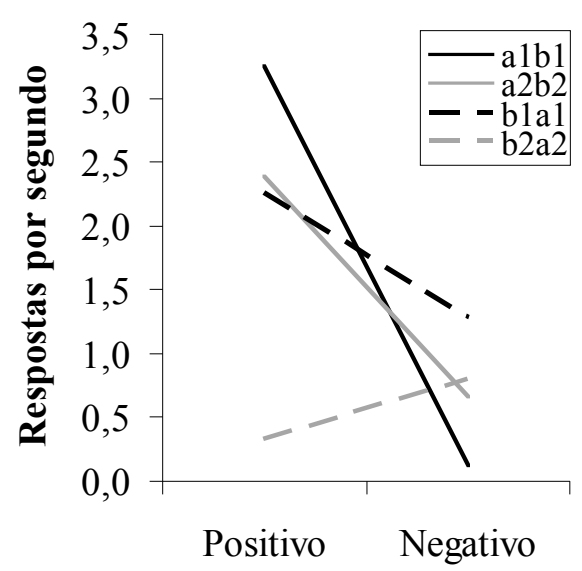

Teste 2

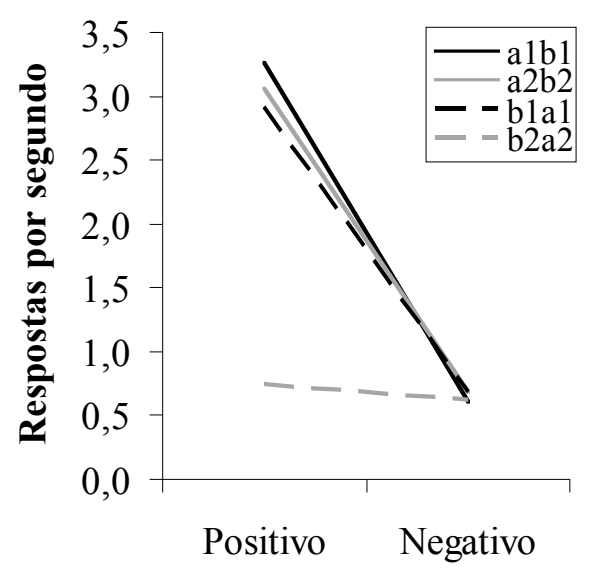

Teste 4

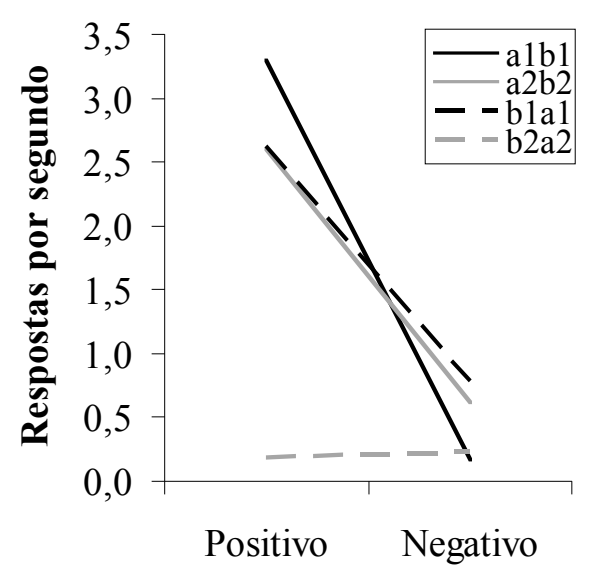

Figura 14 - Taxa de respostas nas combinações positivas e negativas de linha de base (AB) e teste (BA), para cada relação, das quatro sessões de teste do sujeito P14.

Ao se comparar os dados apresentas na Figura 14 com as médias apresentadas na Figura 13, nota-se que, para quase todas as sessões de teste (o Teste 1 é uma exceção), o desempenho médio distorce o dado. Cada relação BA apresentou um padrão diferente na segunda, terceira e quarta sessão. Esta diferença entre as relações b1a1 e b2a2 fica oculta quando se considera a taxa de respostas média das duas relações, apresentada na Figura 13.

A Figura 15 apresenta os índices discriminativos das relações de linha de base (AB) e teste (BA) ao longo das sessões do sujeito P14. São apresentados ainda os índices das sessões de treino que antecederam as sessões de teste. Nesta figura, é possível observar que a linha de base (representada pelas linhas preta e cinza) se manteve praticamente estável, sempre com ID acima de 0,80 , ao longo das sessões. Já as relações testadas (representadas pelos círculos preto e cinza) apresentaram maior variação entre as sessões, com índices discriminativos 
quase sempre inferiores aos da linha de base. Estes índices variaram, entre 0,86 e 0,29, sendo que apenas três dos oito índices discriminativos foram superiores a 0,70 : relação b2a2 no Teste 1 (ID de 0,86); relação bla1 no Teste 2 (ID de 0,81) e no Teste 4 (ID de 0,77). Na primeira sessão de teste o ID da relação b1a1 foi próximo a 0,70 (ID de 0,68). Os demais índices discriminativos foram inferiores à 0,64 .

Observa-se, ainda, nesta figura uma diferença quanto à relação de teste com maior e menor ID a cada sessão. Na primeira sessão de teste, a relação b2a2 apresentou maior índice discriminativo do que a relação bla1. Ocorreu o oposto nas sessões seguintes de teste, isto porque houve uma queda no índice discriminativo da relação b2a2 na segunda e terceira sessões, enquanto os índices da relação bla1 apresentaram menor variação entre as sessões, oscilando entre 0,64 e 0,86. Exceto pela quarta sessão de teste, na qual P14 emitiu poucas respostas diante das combinações positivas e negativas da relação b2a2, não foi constatada preferência por estímulos nas sessões de teste.

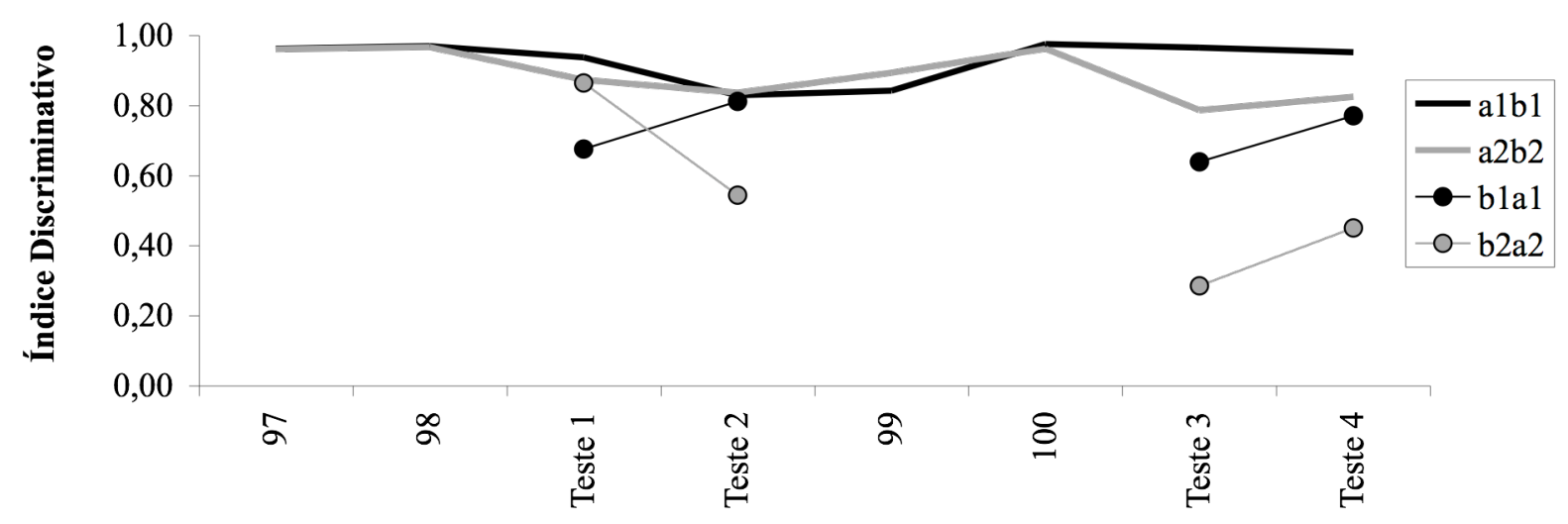

Sessão

Figura 15 - Índice discriminativo por relação de linha de base e teste nas sessões de teste e nas sessões de treino anteriores e posteriores aos testes do sujeito P14.

Embora tenham ocorrido poucas sessões com ID acima de 0,70 para as relações testadas, é possível avaliar esse desempenho como indicativo de simetria emergente. Assim como foi argumentado sobre o desempenho do sujeito P13 no Experimento I, o fato de ter havido variabilidade entre as sessões não invalida o dado de que houve responder discriminado para a relação b2a2 na primeira sessão de teste e para a relação b1a1 na segunda e quarta sessão. Dada a semelhança entre o desempenho de P13 (Experimento I) e P14 (Experimento II) nos testes as análises feitas sobre a variabilidade do desempenho de P13 nos 
testes também se aplicam ao desempenho de P14, embora este sujeito tenha apresentado uma variabilidade menor para uma das relações (b1a1) entre as sessões.

$\mathrm{O}$ fato de apenas um sujeito do Experimento II ter chegado à fase de teste indica a necessidade de análises mais detalhadas do desempenho dos três sujeitos no treino. A partir deste ponto será feira uma análise dos padrões de respostas de P14, P15 e P20 nas últimas sessões de treino.
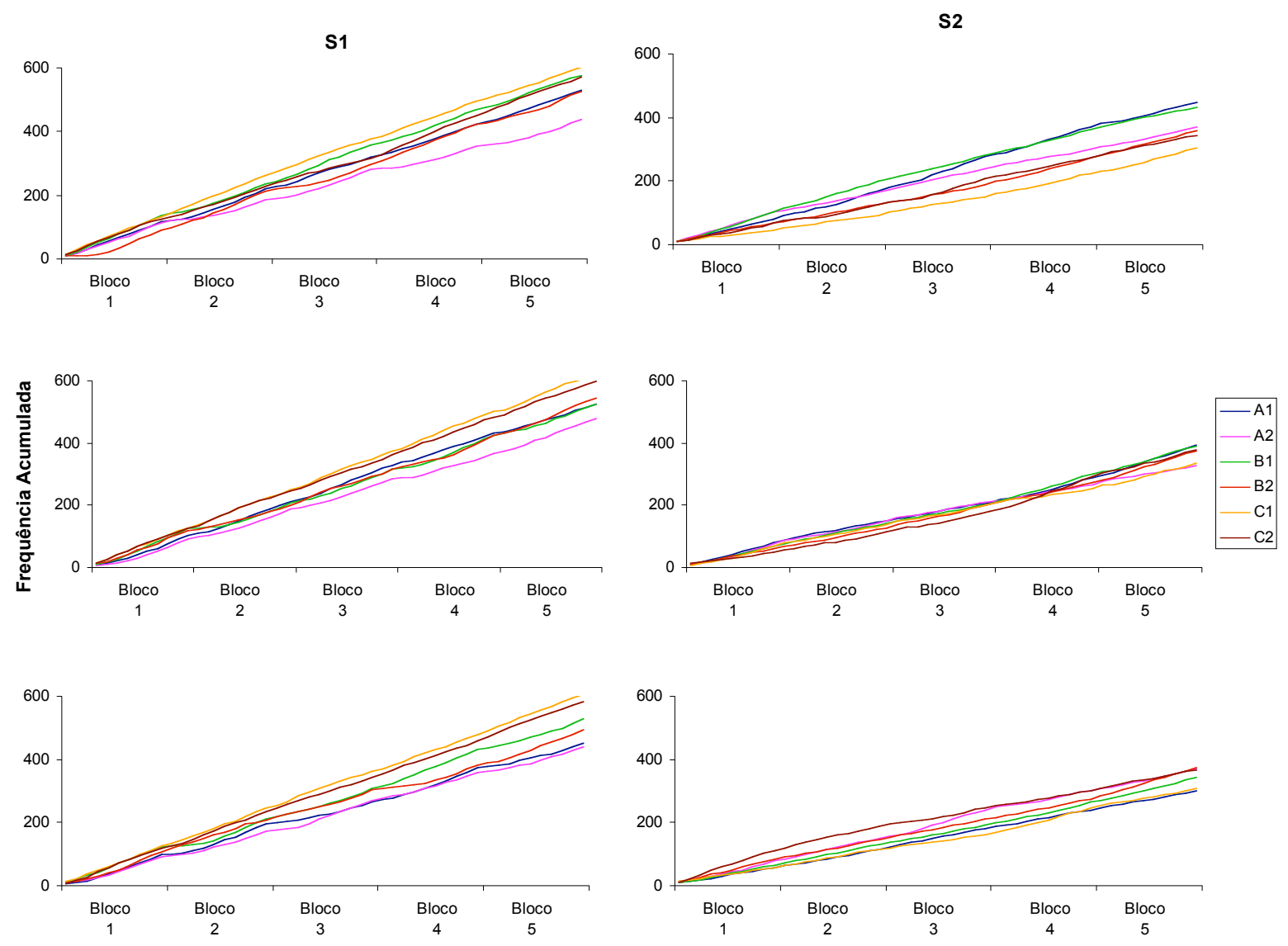

Figura 16 - Freqüência acumulada de respostas para S1 e S2 por bloco de treino nas três últimas sessões do sujeito P14, antes do início da aquisição das discriminações. À esquerda são apresentados os gráficos referentes à $\mathrm{S} 1$ e à direita os referentes à S2. Os valores apresentados são proporcionais ao número de apresentações de cada estímulo como S1 ou S2.

Não foram observadas diferenças na latência de respostas para S1 e S2 entre os sujeitos deste experimento, mas foi observada uma diferença na distribuição de respostas emitidas diante de S1 e S2. As Figuras 16, 17 e 18 apresentam a freqüência acumulada de respostas para S1 (porção esquerda) e S2 (porção direita) por bloco de treino nas três últimas sessões antes do início da aquisição das discriminações do sujeito P14 e nas últimas três sessões de treino dos sujeitos P15 e P20, respectivamente. Para cada bloco há dez valores de freqüência, correspondendo aos dez segundos de duração do estímulo. Os valores 
apresentados são proporcionais ao número de apresentações de cada estímulo como S1 ou S2, ou seja, os estímulos que apareciam o dobro de vezes como S1 (estímulos A1 e A2) ou S2 (estímulos B1 e B2) tiveram suas freqüências de resposta divididas por dois.

A Figura 16 mostra curvas de respostas acumuladas de P14 nas sessões anteriores ao início da aquisição das discriminações. É possível observar semelhanças entre as curvas de respostas diante de S1 e S2. Este sujeito apresentou um responder constante, com poucas pausas para os dois estímulos. É possível notar ainda que a freqüência de respostas emitidas diante de S1 era um pouco superior à freqüência de respostas diante de S2 para este pombo.
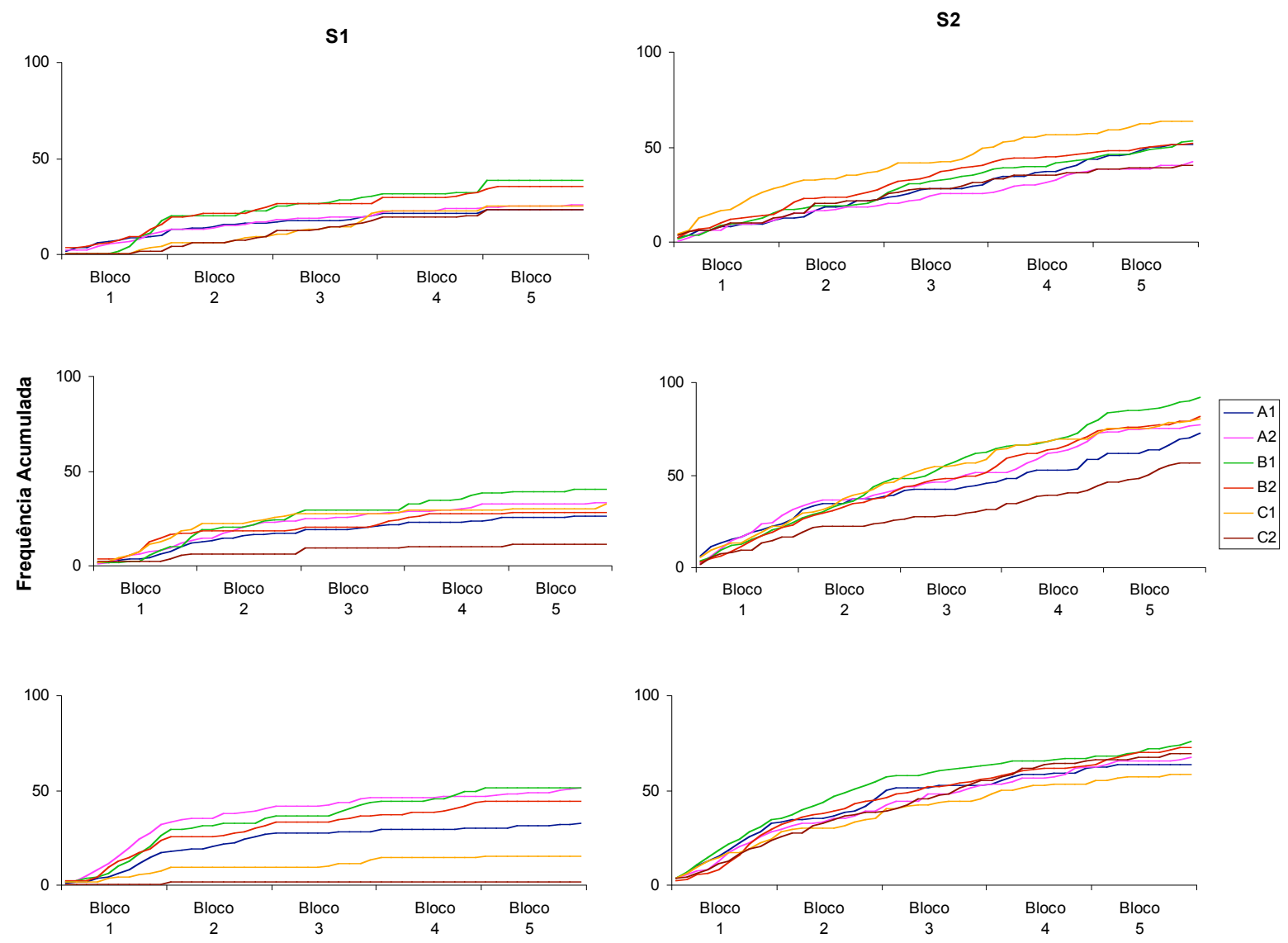

Figura 17 - Freqüência acumulada de respostas para S1 e S2 por bloco de treino nas três últimas sessões do sujeito $\mathrm{P} 15$. À esquerda são apresentados os gráficos referentes à $\mathrm{S} 1$ e à direita os referentes à $\mathrm{S} 2$. Os valores apresentados são proporcionais ao número de apresentações de cada estímulo como S1 ou S2.

O sujeito P15 (Figura 17) apresentou um padrão de respostas marcado por longas pausas tanto para S1 quanto para S2. Nas três sessões é possível observar uma freqüência total de respostas um pouco maior diante de S2 do que diante de S1, provavelmente em decorrência das pausas entre respostas serem mais longas para este último. 
A Figura 18 apresenta o padrão de respostas de P20 diante de S1 e S2. Este sujeito apresentou uma curva acumulada de respostas para S1 marcada por longas pausas seguidas de aumento gradual do responder no final do intervalo de duração do estímulo, ou seja, apresentou um padrão de respostas típico do esquema de intervalo fixo diante de S1. Já diante de S2, P20 apresentou uma freqüência constante de respostas, com poucas pausas. Em decorrência dessa diferença no responder diante de S1 e S2, a freqüência total de respostas para S1 é aproximadamente metade da freqüência para S2 para este sujeito.
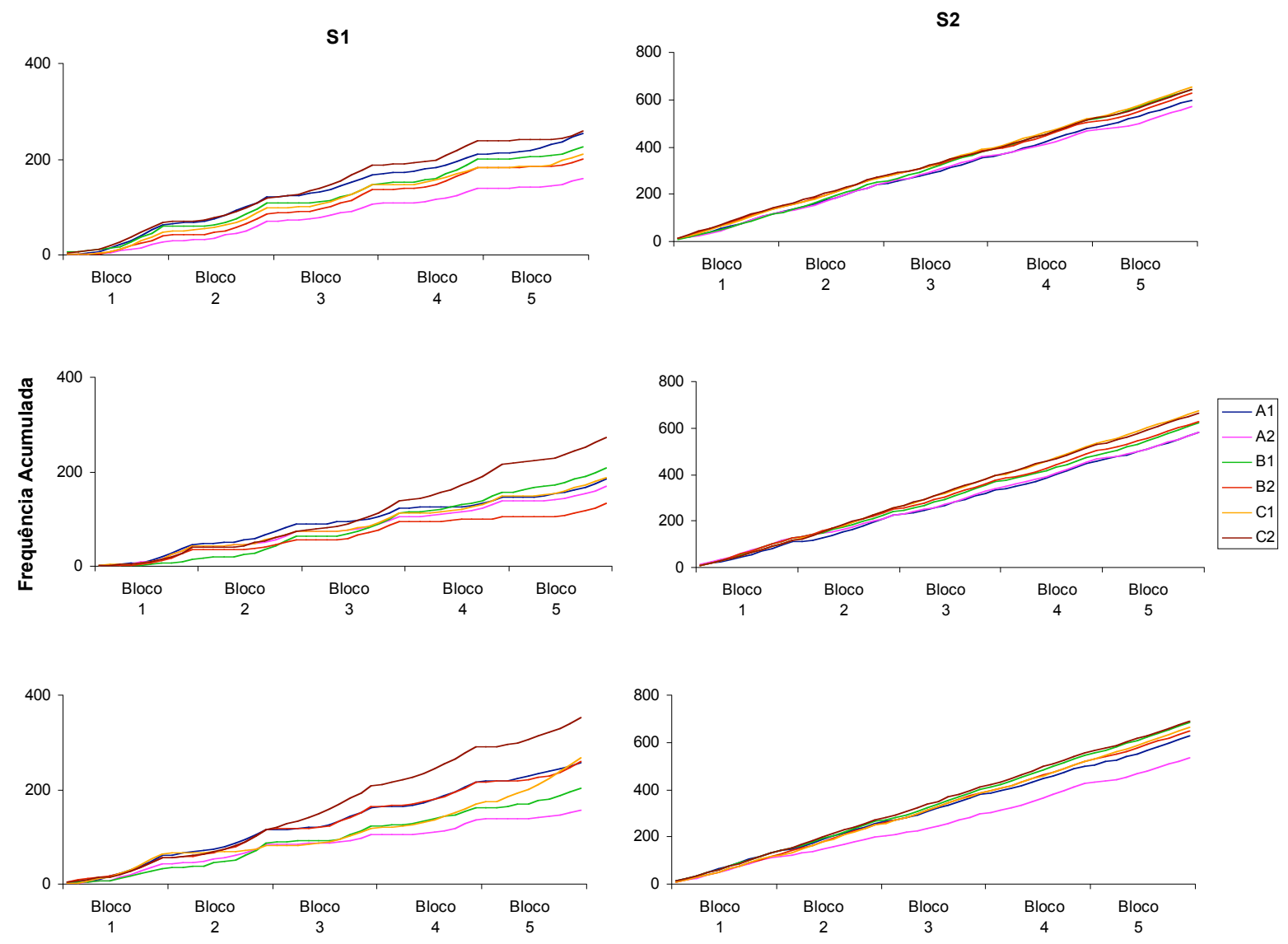

Figura 18 - Freqüência acumulada de respostas para S1 e S2 por bloco de treino nas três últimas sessões do sujeito P20. À esquerda são apresentados os gráficos referentes à S1 e à direita os referentes à S2. O eixo dos valores (Y) é diferente entre S1 e S2 para permitir a visualização dos padrões de resposta diante de cada estímulo. Os valores apresentados são proporcionais ao número de apresentações de cada estímulo como S1 ou S2.

O padrão de respostas dos três sujeitos deste experimento mostra diferenças significativas. O único sujeito que chegou à fase de testes (P14) apresentou um padrão de respostas diferente dos outros dois pombos. P14 apresentou um responder como menos pausas diante de S1, além de ter emitido mais respostas diante de S1 do que diante de S2. Este dado indica que a alta freqüência de respostas, com poucas pausas, diante do S1 pode ser uma variável importante para a aprendizagem com este procedimento. Estudos futuros deveriam, 
portanto, utilizar esquemas de reforçamento que produzam esse padrão de respostas ao modelo.

Embora apenas um sujeito tenha concluído todas as etapas do Experimento II, pode-se dizer que o objetivo proposto foi cumprido. O desempenho de P14 nos testes foi semelhante ao apresentado por P13 no Experimento I, indicando emergência de simetria. Pode-se concluir, portanto, que o treino de reversão das combinações negativas de estímulos não é uma variável necessária para a obtenção de simetria com o procedimento empregado no presente estudo. Isto indica que este procedimento produz um controle do responder discriminado pelas tentativas de combinação positiva.

A análise detalhada das sessões de treino e teste também indicou uma variável aparentemente necessária para a aprendizagem das relações condicionais e emergência das relações de simetria: a exigência de um responder constante de alta freqüência para o estímulo S1. Este dado também está em consonância com o objetivo geral deste trabalho. 


\section{DISCUSSÃO GERAL}

O presente estudo buscava ampliar a investigação das condições necessárias e suficientes para a emergência de simetria em animais não humanos a partir do procedimento apresentado por Frank e Wasserman (2005), por este apresentar dados robustos de simetria em pombos sem a necessidade de treino de simetria com múltiplos exemplares. Para tanto, dois experimentos foram realizados com o objetivo de replicar os dados obtidos no Experimento 1 do estudo de Frank e Wasserman (2005) e investigar se o treino de reversibilidade de combinações negativas poderia ser um fator importante para a obtenção de resultados positivos em teste de simetria.

Os dados obtidos indicam o objetivo deste trabalho foi alcançado. Embora os dados dos testes não tenham sido tão robustos quanto os obtidos por Frank e Wasserman (2005), cujas taxas de respostas nas combinações de teste eram quase idênticas às taxas nas combinações de linha de base, eles indicaram simetria emergente para pelo menos uma relação na maioria das sessões de teste dos dois experimentos. Além disso, os dados dos testes de P14 (Experimento II), que apresentou simetria, indicam que a reversibilidade das combinações negativas de treino não é condição necessária para a obtenção de simetria emergente.

Além dos dados dos testes, a análise dos desempenhos apresentados pelos pombos na fase de treino permitiu a identificação de padrões de resposta aparentemente importantes para a aquisição do responder discriminado. Os pombos que chegaram à fase de teste apresentaram mais respostas diante de $\mathrm{S} 1$ do que diante de $\mathrm{S} 2$, além de responderem com freqüência constante para os dois estímulos. Os quatro pombos que não aprenderam as relações durante o treino apresentavam menor freqüência de respostas diante de S1 do que diante de S2, tendo um responder marcado por pausas entre respostas. Com base nessas análises é possível indicar mudanças no procedimento que produzam padrões de resposta semelhantes ao de P13 e P14, que chegaram à fase de teste. Sugere-se que estudos futuros utilizem esquemas de reforçamento que produzam um responder constante e de altas taxas tanto para S1 quanto para S2, como o esquema de FR30 ou um esquema de VR20, por exemplo.

Outro dado relevante do presente estudo se refere às medidas utilizadas para avaliar a emergência de relações nos estudos na área de equivalência de estímulos. Os dados de P13 e P14 nos testes foram apresentados sob três formas distintas: taxa de respostas média das relações de linha de base e teste por sessão e do total de sessões; taxa de respostas por relação 
de linha de base e teste a cada sessão; e índice discriminativo das relações de linha de base e teste nas sessões de teste. A análise realizada indicou que o uso da taxa de respostas nas combinações positivas e negativas de linha de base e teste pode levar à uma falsa constatação da existência de simetria emergente, enquanto que o uso do índice discriminativo não deixa dúvidas quanto à emergência de relações.

As descrições de procedimento apresentadas nos estudos de Frank e Wasserman (2005) e Frank (2007) não foram suficientes para a replicação dos resultados. Nesses dois estudos a maioria dos sujeitos aprendeu as relações treinadas, mesmo quando o treino envolvia oito relações condicionais (como no caso do Experimento II do presente estudo). No presente estudo, entretanto, a maioria dos sujeitos não aprendeu nenhuma das relações, apesar de alcançarem IETs relativamente altos nas tentativas de combinações negativas. Essa dificuldade em replicar os dados dos estudos anteriores, bem como o fato de que o estudo de Urcuioli (2008) conseguiu apenas uma simetria moderada com metade dos sujeitos experimentais, pode indicar que o procedimento apresentado por Frank e Wasserman (2005), apesar de aparentemente resolver alguns problemas existentes no procedimento de matchingto-sample padrão (no caso, o problema da localização espacial e temporal dos estímulos), possui outros problemas, que serão analisados a seguir.

Um primeiro problema observado, que talvez seja o mais importante, se refere à contingência de treino. Embora o sujeito seja sempre exposto tanto às tentativas corretas quanto às incorretas, o que, em tese, facilitaria o processo de discriminação das relações treinadas, a contingência de treino na verdade não exige que o sujeito pare de responder nas tentativas incorretas. Se o sujeito responder em todas as tentativas ele consome a mesma quantidade de reforços do que se ele responder apenas às tentativas corretas. Tendo em vista que a resposta de bicar é de baixo custo para o pombo, não é de se estranhar que ele responda a qualquer estímulo, indiscriminadamente.

Pode-se argumentar que o fato do reforço seguir algumas combinações de estímulos e não outras deveria ser suficiente no estabelecimento de um responder discriminado neste procedimento. Isto certamente é verdade quando falamos de um treino envolvendo discriminação simples, no qual um estímulo é sempre correlacionado ao reforçamento, enquanto outro estímulo é sempre correlacionado à extinção. Entretanto, em um treino de discriminação condicional, todos os estímulos são apresentados tanto em contingências de reforçamento quanto de extinção, o que aumenta a complexidade da tarefa e, conseqüentemente, exige maior controle experimental. No MTS padrão, quanto mais o sujeito escolhe os estímulos corretos, maior a densidade de reforço na sessão. No MTS sucessivo de 
comparação única utilizado no presente estudo, a densidade de reforço é a mesma independente do padrão de respostas do sujeito.

Uma forma de contornar essa fragilidade, por assim dizer, da contingência seria aumentar o custo da resposta para as tentativas incorretas (de combinação negativa). $\mathrm{O}$ aumento do IET após as tentativas incorretas, utilizado neste estudo e nos estudos de Frank e Wasserman (2005) e Frank (2007), aparentemente cumpre essa função. Porém, tal procedimento gera outros problemas. Em primeiro lugar, o aumento do IET não é contingente ao responder do sujeito na tentativa incorreta. Se o fosse, talvez facilitasse a aquisição das discriminações condicionais treinadas, mas, da forma como esse aumento de IET ocorreu nestes estudos, é possível que o pombo tenha aprendido que há combinações de estímulos que são seguidas por alimento e outras que são seguidas por um longo período de escuridão, que, de acordo com a própria Frank (2007), funciona como conseqüência aversiva para os pombos. Essa diferente entre os IETs das tentativas corretas e incorretas pode gerar problemas nas sessões de teste, nas quais os IETs das sondas devem ser igualados para evitar que os sujeitos diferenciem as combinações positivas e negativas de teste pela diferença de IET.

Embora o presente estudo tenha usado do aumento do IET das tentativas incorretas como forma de favorecer a discriminação, tomou-se o cuidado de igualar os IETs das tentativas de treino antes de realizar os testes de simetria. Embora ambos os sujeitos (P13 e P14) já apresentassem um responder discriminado estável, houve certa dificuldade em obter nova estabilidade nessa fase de igualação dos IETs para um deles. Essa dificuldade favorece a hipótese de que o IET diferenciado entre as combinações positivas e negativas pode se tornar parte importante da contingência na aquisição das discriminações. Porém, o novo alcance da estabilidade do responder indica que, após a aquisição, a diferença entre os IETs das tentativas corretas e incorretas pode ser eliminada sem maiores problemas.

Os estudos de Frank e Wasserman (2005) e Frank (2007) não descrevem qualquer procedimento de igualação dos IETs antes das sessões de teste, o que sugere que tal procedimento não foi adotado. Caso isso seja verdadeiro, resta ainda a dúvida sobre como foram apresentadas as tentativas de teste nesses estudos: Os IETs eram iguais em todas as tentativas de teste ou diferentes para combinações positivas e negativas? Se eram iguais, o IET usado era o mesmo das tentativas de treino corretas ou incorretas? Qualquer uma das alternativas afetaria o resultado dos testes de uma maneira específica.

Outro problema do aumento do IET que segue as tentativas incorretas ser a forma usada para favorecer a aquisição das discriminações é que este é um procedimento extremamente impreciso. Até quanto tempo deve-se aumentar o IET antes de se constatar que 
o procedimento não está sendo efetivo para ensinar as relações entre estímulos pretendidas? Não há uma resposta certa para esta pergunta e este foi justamente o problema enfrentado no presente estudo. Era mesmo necessário modificar todos os parâmetros alterados ao longo da coleta de dados ou o IET das tentativas incorretas ainda era curto demais para a aquisição das discriminações?

As primeiras alterações de procedimento realizadas com o sujeito P13 só ocorreram após ele alcançar 60 segundos de IET nas tentativas incorretas. Outras alterações, entretanto, ocorreram em sessões com IETs mais curtos. Se para cada mudança de parâmetro nova fosse necessário alcançar IETs de aproximadamente 60 segundos, talvez P13 ainda não tivesse alcançado a fase de testes. Como a aquisição das discriminações para este sujeito ocorreu rapidamente após as mudanças de parâmetros, podemos supor que o fator preponderante não foi a longa duração do IET (já que a curva de aquisição foi iniciada com IET variando entre 10 e 15 segundos). A rápida aquisição das relações de outro sujeito, $\mathrm{P} 14$, também indica que a mudança de parâmetros foi necessária. Porém há outros quatro pombos que não apresentaram uma curva de aquisição, indicando que outros controles experimentais são necessários neste procedimento.

Em seu estudo, Urcuioli (2008) usou um IET fixo de 15 segundos para todas as tentativas (corretas e incorretas) e a maioria dos sujeitos aprendeu as discriminações condicionais. No presente estudo um sujeito (P03) passou por sessões de treino em que o mesmo IET randômico seguia todas as tentativas, sendo este aumentado após algumas sessões sem melhora de desempenho. Mesmo com IETs acima de 40 segundos não foi observada uma curva de aprendizagem para este sujeito. O estudo de Urcuioli (2008) tinha muitos outros parâmetros diferentes do estudo de Frank e Wasserman (2005), de modo que é possível supor que o IET usado não tenha sido a variável preponderante para a aquisição das discriminações em seu estudo. Talvez o menor tempo de duração dos estímulos tenha sido a variável mais importante no estudo de Urcuioli (2008), reduzindo consideravelmente o tempo da tentativa. O problema é que, de acordo com o próprio autor, o menor tempo de duração dos estímulos e o uso do IET fixo podem ter sido em parte responsáveis pelo desempenho inferior de seus pombos nos testes, em comparação com os pombos do estudo de Frank e Wasserman (2005).

Outro problema observado no procedimento aqui usado se refere à sensibilidade deste procedimento a mudanças de parâmetros. Os dados obtidos no presente estudo indicam o procedimento é afetado tanto quanto o MTS padrão por mudanças de diferentes parâmetros, como o intervalo entre estímulos, tamanho do IET, altura, tamanho e duração do estímulo etc. Este fator, aliado à fragilidade da contingência de treino em controlar o responder dos sujeitos 
e à longa duração de cada sessão, acaba pondo em dúvida a aparente vantagem que ele poderia ter sobre o MTS padrão.

Apesar de todos os problemas aqui levantados, é preciso considerar o fato de que o MTS sucessivo de comparação única, misturando tentativas de treino de relações de identidade e arbitrárias, pode produzir um dado robusto de simetria a partir de um treino com poucos estímulos. Embora o procedimento ainda careça de maior controle experimental, o fato de ser possível obter simetria emergente a partir de um treino com quatro estímulos em menos de 100 sessões (como no caso de P14), exige que maiores esforços sejam dedicados ao seu estudo. Dessa forma, será possível identificar os aspectos do procedimento relevantes para a aprendizagem e a emergência de relações e, a partir daí, refinar este procedimento de treino, tornando-o mais eficiente. A identificação desses aspectos pode sugerir também modificações importantes em outros procedimentos de treino, como o próprio MTS padrão. 


\section{REFERÊNCIAS}

Berryman, R., Cumming, W. W., Cohen, L.R., \& Johnson (1965). Acquisition and transfer of simultaneous oddity. Psychological Report, 17, 767-775.

Carr, D., Wilkinson, K. M., Blackman, D. \& McIlvane, W. J. (2000). Equivalence classes in individuals with minimal verbal repertoires. Journal of the Experimental Analysis of Behavior, 74(1), 101-114.

Carter, D. E., \& Eckerman, D. A. (1975). Symbolic matching by pigeons: Rate of learning complex discrimination predicted from sample discrimination. Science, 187, 662-664.

Cruz, I. R. N., Kataoka, K. B., Costa, A. C. O., Fernandes, M. G., Galvão, O. F., \& Barros, R. S. (2009). Modelagem do estímulo-modelo para estabelecer relações condicionais arbitrárias em macacos-prego (Cebus apella). Arquivos Brasileiros de Psicologia, $\underline{61}, 128$ 139.

Cumming, W. W., \& Berryman, R. (1965). The complex discriminated operant: Studies of matching to sample and related problems. In D. I. Mostofski (Ed.). Stimulus generalization (pp. 284-329). Stanford, CA: Stanford University Press.

Dube, W. V., Mcllvane, W. J., Callahan, T. D., \& Stoddard, L. T. (1993). The search for stimulus equivalence in nonverbal organisms. The Psychological Record, $\underline{43}, 761-778$.

Frank, A. J. (2007). An examination of the temporal and spatial stimulus control in emergent symmetry in pigeons. Unpublished doctoral dissertation, The University of Iowa.

Frank, A. J. \& Wasserman, E. A. (2005). Associative symmetry in the pigeon after sucessive matching-to-sample training. Journal of the Experimental Analysis of Behavior, 84(2), 147-165.

Galvão, O. F., Barros, R. S., Santos, J. R., Brino, A. L. F., Brandão, S., Lavratti, C. M., Dube, W. V. \& Mcllvane, W. J. (2005). Extent and limits of the matching concept in Cebus apella: A matter of experimental control. The Psychological Record, 55, 219-232.

Galvão, O. F., Calcagno, S., \& Sidman, M. (1992). Testing for emergent performance in extinction. Experimental Analysis of Human Behavior Bulletin 10(2), 18-20. 
Hayes, S. C. (1989). Nonhumans have not yet shown stimulus equivalence. Journal of the Experimental Analysis of Behavior, 51, 385-392.

Hayes, S. C. (1991). A relational control theory of stimulus equivalence. In L. J. Hayes \& P. N. Chase (Eds.), Dialogues on verbal behavior (pp. 19-41). Reno, NV: Contex Press.

Horne, P. J. \& Lowe, C. F. (1996). On the origens of naming and other symbolic behavior. Journal of the Experimental Analysis of Behavior, $\underline{65}, 185-241$.

Iversen, I. H. (1993). Acquisition of matching-to-sample performance in rats using visual stimuli on nose keys. Journal of the Experimental Analysis of Behavior, 59, 471-482.

Iversen, I. H. (1997). Matching-to-sample performance in rats: A case of mistaken identity? Journal of the Experimental Analysis of Behavior, 68, 27-45.

Kastak, C. R., Schusterman, R. J., \& Kastak, D. (2001). Equivalence classification by california sea lions using class-specific reinforcers. Journal of the Experimental Analysis of Behavior, 76, 131-158.

Lionello-DeNolf, K. M. (2009). The search for symmetry: 25 years in review. Learning \& Behavior, $37(2), 188-203$.

Lionello-DeNolf, K. M., \& Urcuioli, P. J. (2000). Transfer of pigeons' matching to sample to novel sample locations. Journal of the Experimental Analysis of Behavior, $\underline{73}, 141-161$.

Lionello-DeNolf, K. M. \& Urcuioli, P. J. (2002). Stimulus control topographies anda test of simmetry in pigeons. Journal of the Experimental Analysis of Behavior, $\underline{78}$, 467-495.

McIlvane, W. J. \& Cataldo, M. F. (1996). On the clinical relevance of animal models for the study of human mental retardation. Mental Retardation and Developmental Disabilities Research Reviews, 2, 188-196.

Rubio A. R., \& Tomanari, G. Y. (2002). Análises moleculares do desempenho de participantes humanos no treino de relações condicionais entre estímulos. Arquivos Brasileiros de Psicologia, 54(3), 221-239.

Santos, J. R. (2003). Cognição animal: identidade generalizada e simetria. Dissertação de Mestrado, Programa de Pós-Graduação em Teoria e Pesquisa do Comportamento, Universidade Federal do Pará, Belém. 
Santos, J. R., Barros, R. S., \& Galvão, O. (2003, May). Symmetry in Cebus apella. Paper presented at the 29th Annual Meeting of the Association for Behavior Analysis, San Francisco.

Schusterman, R. J., \& Kastak, D. (1993). A California sea lion (Zalophus californianus) is capable of forming equivalence relations. The Psychological Record, $\underline{43}, 823-839$.

Sidman, M. (1971). Reading and auditory-visual equivalence. Journal of Speech and Hearing Research, 14, 5-13.

Sidman, M. (1994). Equivalence relations and behavior: A research story. Boston, MA: Authors Cooperative, Inc., Publishers.

Sidman, M. (2000). Equivalence relations and the reinforcement contingency. Journal of the Experimental Analysis of Behavior, 74, 127-146.

Sidman, M., \& Cresson, O. (1973). Reading and crosmodal transfer or stimulus equivalence in severe mental retardation. American Journal of Mental deficiency, 77, 515-523.

Sidman, M. \& Tailby, W. (1982). Conditional discrimination vs. matching-to-sample: An expansion of testing paradigm. Journal of the Experimental Analysis of Behavior, $\underline{37}$, 522.

Tomanaga, M., Matsuzawa, T., Fujita, K. \& Yamamoto, J. (1991). Emergence of simmetry in a visual conditional discrimination by chimpanzees (Pan Troglodytes). Psychological $\underline{\text { Reports, }} \underline{68}, 51-60$.

Urcuioli, P. J. (2008). Associative symmetry, antisymmetry, and a theory of pigeons' equivalence-class formation. Journal of the Experimental Analysis of Behavior, 90 , 257282.

Vaughan, W. (1988). Formation of equivalence sets in pigeons. Journal of Experimental Psychology: Animal Behavior Processes, 14, 36-42.

Velasco, S. M. (2009). Simetria e transitividade em discriminações condicionais de humanos e pombos (Columba livia) avaliadas sob condições de reforçamento diferencial. Tese de Doutorado, Instituto de Psicologia, Universidade de São Paulo, São Paulo. 
Yamamoto, J., \& Asano, T. (1995). Stimulus equivalence in a chimpanzee (Pan troglodytes). The Psychological Record, 45, 3-21. 